\title{
Experimental and theoretical assessment of the mechanism and site requirements for ketonization of carboxylic acids on oxides
}

\section{Shuai Wang and Enrique Iglesia*}

Department of Chemical and Biomolecular Engineering, University of California at Berkeley, Berkeley, CA 94720 USA

*Corresponding author: iglesia@berkeley.edu 


\section{ABSTRACT:}

Ketonization of carboxylic acids removes O-atoms and forms new C-C bonds, thus providing routes from sustainable carbon feedstocks to fuels and chemicals. The elementary steps involved and their kinetic relevance, as well as the number and nature of the active sites on active $\mathrm{TiO}_{2}$ and $\mathrm{ZrO}_{2}$ catalysts, remain matters of active discourse. Here, site titrations demonstrate the requirement for coordinatively-unsaturated $\mathrm{M}-\mathrm{O}-\mathrm{M}$ sites $(\mathrm{M}=\mathrm{Ti}, \mathrm{Zr})$ with specific geometry and intermediate acid-base strength. The measured site densities allow rigorous reactivity comparisons among catalysts based on turnover rates and activation free energies, as well as the benchmarking of mechanistic proposals against theoretical assessments. Kinetic, isotopic, spectroscopic, and theoretical methods show that $\mathrm{C}_{2}-\mathrm{C}_{4}$ acids react on anatase $\mathrm{TiO}_{2}$ via kinetically-relevant $\mathrm{C}-\mathrm{C}$ coupling between 1-hydroxy enolate species and coadsorbed acids bound at vicinal acidbase pairs saturated with active monodentate carboxylates. Smaller Ti-Ti distances on rutile $\mathrm{TiO}_{2}$ lead to the prevalence of unreactive bidentate carboxylates and lead to its much lower ketonization reactivity than anatase. The prevalent dense monolayers of chemisorbed acid reactants reflect their strong binding at acid-base pairs and their stabilization by $\mathrm{H}$-bonding interactions with surface $\mathrm{OH}$ groups derived from the dissociation of the carboxylic acids or the formation of 1-hydroxy enolates; these interactions also stabilize $\mathrm{C}-\mathrm{C}$ coupling transition states preferentially over their carboxylate precursors; high coverages favor sequential dehydration routes of the $\alpha$ hydroxy- $\gamma$-carboxy-alkoxide C-C coupling products over previously unrecognized concerted six-membered-ring transition states. Infrared spectra show that ubiquitous deactivation, which has precluded broader deployment of ketonization in practice and unequivocal mechanistic inquiries, reflects the gradual formation of inactive bidentate carboxylates. Their dehydration to ketene-like gaseous species is faster on anatase $\mathrm{TiO}_{2}$ than on $\mathrm{ZrO}_{2}$ and allows the effective scavenging of bidentate carboxylates via ketene hydrogenation to alkanals/alkanols on a $\mathrm{Cu}$ function present within diffusion distances. These strategies make anatase $\mathrm{TiO}_{2}$, a more effective catalyst than $\mathrm{ZrO}_{2}$, in spite of its slightly lower initial turnover rates. This study provides details about the mechanism of ketonization of $\mathrm{C}_{2}-\mathrm{C}_{4}$ carboxylic acids on $\mathrm{TiO}_{2}$ and a rigorous analysis of the sites required and of active and inactive bound species on $\mathrm{TiO}_{2}$ and $\mathrm{ZrO}_{2}$. The preference for specific distances and for intermediate acid-base strength in $\mathrm{M}-\mathrm{O}-\mathrm{M}$ species is consistent with the structure and energy of the proposed transition states and intermediates; their relative stabilities illustrate how densely-covered surfaces, prevalent during ketonization catalysis, represent an essential requirement for the achievement of practical turnover rates.

Keyword: $\mathrm{TiO}_{2} ; \mathrm{ZrO}_{2}$; Ketonization; Carboxylic acids; Acid-base pairs; Density functional theory; Infrared spectroscopy. 


\section{Introduction}

Carboxylic acids form new $\mathrm{C}-\mathrm{C}$ bonds via bimolecular ketonization reactions to give alkanones, $\mathrm{CO}_{2}$, and $\mathrm{H}_{2} \mathrm{O}[1]$ :

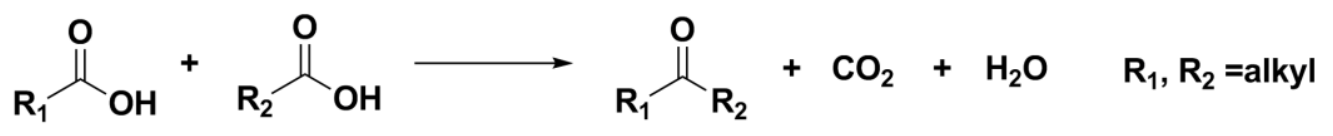

Such reactions remove three $\mathrm{O}$-atoms and form a new $\mathrm{C}-\mathrm{C}$ bond from two acid molecules, thus providing an attractive route for oxygen removal using the $\mathrm{C}$-atoms within reactants, instead of added $\mathrm{H}_{2}$, in upgrading biomass-derived feedstocks into fuels and chemicals [2-6]. The alkanone products can be used in subsequent aldol condensation reactions to increase their chain length and remove additional O-atoms $[7,8]$.

Ketonization is catalyzed by metal oxides (e.g. $\mathrm{MgO}, \mathrm{BaO}, \mathrm{MnO}_{2}, \mathrm{CeO}_{2}, \mathrm{ZrO}_{2}$, and $\mathrm{TiO}_{2}$ ) [6-22], with $\mathrm{ZrO}_{2}$ and $\mathrm{TiO}_{2}$ among the most effective oxides [2,3]. Ketonization elementary steps and their kinetic relevance on oxides remain controversial subjects of inquiry, because of a dearth of detailed kinetic, isotopic, and spectroscopic data at conditions of strict kinetic control and also because of limited theoretical confirmation for the diverse types of pathways proposed $[2,3,9,17,19]$.

Ketonization requires the presence of a $\mathrm{H}$-atom at an $\alpha$-position with respect to the $\mathrm{COOH}$ group in one of the acid reactants [2]. For instance, pivalic acid $\left(\mathrm{C}\left(\mathrm{CH}_{3}\right)_{3} \mathrm{COOH}\right)$, which lacks an $\alpha$-H-atom, reacts with valeric acid $\left(\mathrm{CH}_{3}\left(\mathrm{CH}_{2}\right)_{3} \mathrm{COOH}\right.$, two $\alpha$-H-atoms $)$ to form 2,2-dimethyl heptan-3-one in cross-ketonization, but cannot undergo selfketonization to form 2,2,4,4-tetramethyl pentan-3-one [19]. Similarly, aldol condensation reactions of carbonyl compounds require two $\alpha$-H-atoms in one of the reactants, because such reactions involve enolate species formed by cleavage of $\alpha-\mathrm{C}-\mathrm{H}$ bonds and subsequent dehydration of aldols formed to $\alpha, \beta$-unsaturated carbonyl compounds [23,24]. 
These $\mathrm{C}-\mathrm{H}$ bonds exhibit lower heterolytic dissociation energies than those at other locations within the molecules; their cleavage is mediated by acid-base pairs of intermediate strength, which stabilize the transition states required for enolate formation $[5,7,24]$. The enolates formed from the carbonyl reactants then couple with another carbonyl species to form unstable aldols with a new $\mathrm{C}-\mathrm{C}$ bond, which subsequently dehydrate to $\alpha, \beta$-unsaturated carbonyl aldol condensation products (Scheme 1).

(a) Aldol condensation

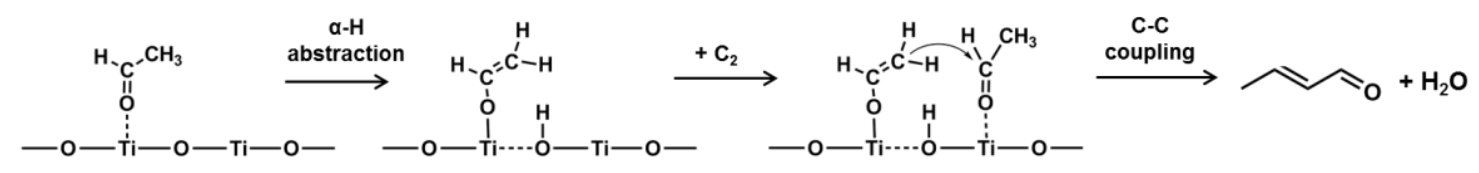

(b) Ketonization

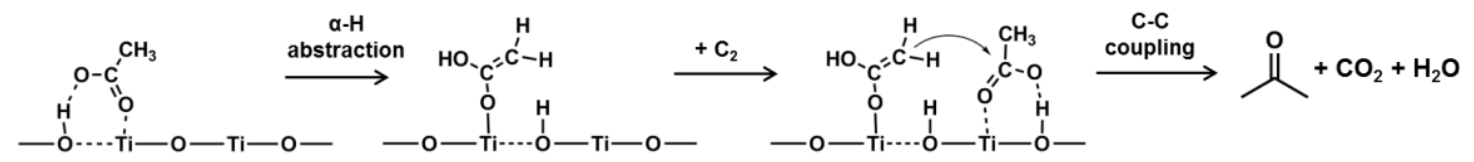

Scheme 1. Analogous elementary steps involved in ethanal condensation and ethanoic acid ketonization on acid-base pairs (shown for $\mathrm{TiO}_{2}$ catalysts as an illustrative example).

It seems plausible that the ketonization of carboxylic acids is also mediated by enolate-like species, in this case, in the form of 1-hydroxy enolates. The species formed from $\mathrm{C}-\mathrm{C}$ bond formation via reactions of 1-hydroxy enolates with another acid reactant ultimately decompose via $\mathrm{CO}_{2}$ and $\mathrm{H}_{2} \mathrm{O}$ elimination, instead of the $\mathrm{H}_{2} \mathrm{O}$ elimination route in condensation reactions, because neither dehydration nor decarboxylation steps alone can form stable products (Scheme 1). ${ }^{13} \mathrm{C}$ tracer studies show that the $\mathrm{CO}_{2}$ molecule forms from the carboxyl group in the acid reactant that undergoes $\alpha-\mathrm{C}-\mathrm{H}$ bond cleavage and then nucleophilically attacks a coadsorbed acid reactant [10,25]; this is consistent with 1-hydroxy enolates as reaction intermediates, but excludes ketene-mediated routes, which would form $\mathrm{CO}_{2}$ from the carboxyl group in the coadsorbed acid instead of that in the acid that undergoes $\alpha-\mathrm{C}-\mathrm{H}$ bond cleavage $[2,9]$. 
Here, we report turnover rates and selectivities for ketonization of $\mathrm{C}_{2}-\mathrm{C}_{4}$ carboxylic acids on anatase and rutile $\mathrm{TiO}_{2}\left(\mathrm{TiO}_{2}(\mathrm{a}), \mathrm{TiO}_{2}(\mathrm{r})\right)$ and on monoclinic and tetragonal $\mathrm{ZrO}_{2}\left(\mathrm{ZrO}_{2}(\mathrm{~m}), \mathrm{ZrO}_{2}(\mathrm{t})\right)$. This study exploits the benefits of gaseous $\mathrm{H}_{2}$ and a $\mathrm{Cu}$ function to confer unprecedented catalyst stability, thus allowing detailed mechanistic inquiries on stable catalysts. These mechanistic studies include kinetic, isotopic, spectroscopic, and theoretical methods, which are combined here to probe plausible ketonization elementary steps and their kinetic relevance on $\mathrm{TiO}_{2}(\mathrm{a})$, an active and stable catalyst for these reactions, and on $\mathrm{TiO}_{2}(\mathrm{r})$, the least active catalyst among those examined. A parallel examination of such ketonization pathways on $\mathrm{ZrO}_{2}$ has confirmed the involvement of elementary steps similar to those reported here on $\mathrm{TiO}_{2}$. Reactivities are reported here as ketonization turnover rates, using the number of acid-base $\mathrm{M}-\mathrm{O}(\mathrm{M}=\mathrm{Ti}, \mathrm{Zr})$ pairs determined by titration with propanoic acid during catalysis; such rates allow comparisons of the intrinsic properties of acid-base pairs on different metal oxides and rigorous benchmarking of theoretical methods against experiments. These data provide compelling evidence for the involvement of acid-base pairs in ketonization steps and for the consequences of their acid-base properties and geometry on the intrinsic ketonization reactivity of metal oxide surfaces.

These experimental and theoretical methods show that acid-base pairs are saturated with monodentate carboxylates on $\mathrm{TiO}_{2}(\mathrm{a})$ and with bidentate carboxylates on $\mathrm{TiO}_{2}(\mathrm{r})$ during ketonization catalysis. Monodentate carboxylate structures form from dissociation of the carboxylic acid on a Ti-O pair via interactions of their two O-atoms with the Ti center and the abstracted proton bound at the $\mathrm{O}$ site, while bidentate configurations place the two O-atoms at Ti centers of two vicinal Ti-O pairs. Such near-saturation coverages by acid-derived species prevent the re-adsorption and secondary condensation of primary 
alkanone products along the catalyst bed, thus maintaining the high ketonization selectivities typical of $\mathrm{TiO}_{2}\left(\right.$ and $\left.\mathrm{ZrO}_{2}\right)$ catalysts. Infrared spectra during catalysis show that monodentate carboxylates and molecularly adsorbed acids are reactive intermediates on $\mathrm{TiO}_{2}(\mathrm{a})$ and $\mathrm{TiO}_{2}(\mathrm{r})$ surfaces, respectively; bidentate carboxylates, in contrast, act as unreactive spectators on both surfaces. These bidentate carboxylates can be scavenged via hydrogenation of ketene, present as trace gaseous species in equilibrium with bidentate carboxylates; such reactions are mediated by a $\mathrm{Cu}$ function present within diffusion distances from $\mathrm{TiO}_{2}$ surfaces, leading to much slower deactivation for $\mathrm{TiO}_{2}$ (and $\mathrm{ZrO}_{2}$ ) catalysts when $\mathrm{H}_{2}$ and $\mathrm{Cu}$ are present.

The form of the measured rate equations for all carboxylic acids, the observed (H/D) kinetic isotope effect values near unity, the infrared evidence for near saturation coverages of monodentate or bidentate carboxylates, and the effects of alkyl substituents on ketonization turnover rates are consistent with $\mathrm{C}-\mathrm{C}$ bond formation between a 1hydroxy enolate and a coadsorbed acid as the sole kinetically-relevant step. These conclusions are confirmed by DFT treatments on densely-covered $\mathrm{TiO}_{2}(\mathrm{a})$ and $\mathrm{TiO}_{2}(\mathrm{r})$ surfaces, which lead to activation free energy barriers and kinetic isotope effects in excellent agreement with experiment, while also confirming the prevalence of monodentate or bidentate carboxylates. High coverages of monodentate carboxylates are essential for ketonization turnovers on $\mathrm{TiO}_{2}(\mathrm{a})$, because the kinetically-relevant $\mathrm{C}-\mathrm{C}$ coupling transition state (TS) is stabilized by H-bonding interactions with vicinal surface $\mathrm{OH}$ groups, formed upon dissociation of coadsorbed acids to carboxylates; such stabilization decreases the free energy difference between the C-C coupling TS and the two monodentate carboxylate precursors. The Ti-Ti distances in Ti-O-Ti structures are shorter on $\mathrm{TiO}_{2}(\mathrm{r})$ than on $\mathrm{TiO}_{2}(\mathrm{a})$ surfaces. Such shorter distances bring more effective 
orbital overlap between Ti centers and O-atoms in bidentate carboxylates, leading to their prevalence over the monodentate modes, for which closer Ti-Ti centers lead to steric repulsion. Steric hindrance also destabilizes $\mathrm{C}-\mathrm{C}$ coupling TS structures on $\mathrm{TiO}_{2}(\mathrm{r})$ surfaces, rendering such surfaces essentially inactive in ketonization catalysis. The intermediacy of monodentate carboxylates present at near saturation coverages, the unreactive nature of bidentate carboxylates, and the kinetic relevance of the $\mathrm{C}-\mathrm{C}$ coupling TS involving 1-hydroxy enolates and coadsorbed acid reactants appear to be general mechanistic features of ketonization reactions on practical oxide catalysts.

\section{Methods}

\subsection{Catalyst preparation and characterization}

Anatase $\mathrm{TiO}_{2}\left(\mathrm{TiO}_{2}(\mathrm{a}), 99.7 \%, 240 \mathrm{~m}^{2} \mathrm{~g}^{-1}\right.$, Alfa Aesar) and rutile $\mathrm{TiO}_{2}\left(\mathrm{TiO}_{2}(\mathrm{r})\right.$, $99.5 \%, 160 \mathrm{~m}^{2} \mathrm{~g}^{-1}$, Aldrich) were treated in flowing air $\left(99.999 \%, 1.67 \mathrm{~cm}^{3} \mathrm{~g}^{-1} \mathrm{~s}^{-1}\right.$, Praxair) by heating to $673 \mathrm{~K}$ (at $\left.0.167 \mathrm{~K} \mathrm{~s}^{-1}\right)$ and holding for $3 \mathrm{~h}$. Monoclinic $\mathrm{ZrO}_{2}\left(\mathrm{ZrO}_{2}(\mathrm{~m}), 131\right.$ $\left.\mathrm{m}^{2} \mathrm{~g}^{-1}\right)$ was prepared using hydrothermal methods [26]. $\mathrm{ZrO}\left(\mathrm{NO}_{3}\right)_{2}\left(\mathrm{ZrO}\left(\mathrm{NO}_{3}\right)_{2} \cdot 2 \mathrm{H}_{2} \mathrm{O}\right.$, 99.5\%, Sigma-Aldrich) and urea (99\%, Aldrich) were dissolved in $60 \mathrm{~cm}^{3}$ deionized water $\left(0.40 \mathrm{mmol} \mathrm{cm}{ }^{-3} \mathrm{Zr}^{4+}\right.$, urea $/ \mathrm{Zr}^{4+}=10$ mole $)$. This solution was placed in a Teflonlined stainless-steel autoclave $\left(100 \mathrm{~cm}^{3}\right)$ and held stagnant at $433 \mathrm{~K}$ for $20 \mathrm{~h}$ under its autogenous pressure. The resulting solids were washed with deionized water until the filtrate reached a neutral $\mathrm{pH}$, then treated in ambient air at $383 \mathrm{~K}\left(0.167 \mathrm{~K} \mathrm{~s}^{-1}\right)$ overnight and in flowing air $\left(1.67 \mathrm{~cm}^{3} \mathrm{~g}^{-1} \mathrm{~s}^{-1}, 99.999 \%\right.$, Praxair $)$ at $673 \mathrm{~K}\left(0.167 \mathrm{~K} \mathrm{~s}^{-1}\right.$ heating rate, $4 \mathrm{~h}$ hold). Tetragonal $\mathrm{ZrO}_{2}\left(\mathrm{ZrO}_{2}(\mathrm{t}), 167 \mathrm{~m}^{2} \mathrm{~g}^{-1}\right)$ was prepared via hydrolysis of $\mathrm{ZrOCl}_{2}$ $\left(\mathrm{ZrOCl}_{2} \cdot 8 \mathrm{H}_{2} \mathrm{O}, 99.5 \%\right.$, Sigma-Aldrich $)$ in an aqueous solution $\left(0.40 \mathrm{mmol} \mathrm{cm}{ }^{-3} \mathrm{Zr}^{4+} ; 333\right.$ $\mathrm{K})$ at a constant $\mathrm{pH}$ of 10 adjusted by $5.0 \mathrm{M} \mathrm{NH}_{4} \mathrm{OH}$ (99.99\%, Sigma-Aldrich) [27]. The 
precipitate was washed with deionized water until the rinse solution was free of $\mathrm{Cl}^{-}$ions, as determined using $0.2 \mathrm{mmol} \mathrm{cm}$ aqueous $\mathrm{AgNO}_{3}$ (>99.0\%, Sigma-Aldrich). The samples were then treated at $383 \mathrm{~K}\left(0.167 \mathrm{~K} \mathrm{~s}^{-1}\right)$ overnight in ambient air and at $723 \mathrm{~K}$ $\left(0.167 \mathrm{~K} \mathrm{~s}^{-1}\right)$ for $2 \mathrm{~h}$ in flowing air $\left(1.67 \mathrm{~cm}^{3} \mathrm{~g}^{-1} \mathrm{~s}^{-1}, 99.999 \%\right.$, Praxair). The identity and phase purity of these samples were examined by powder X-ray diffraction (XRD) measurements $(\mathrm{Cu} \mathrm{K} \alpha$ radiation, $\lambda=0.15418 \mathrm{~nm}, 40 \mathrm{kV}, 40 \mathrm{~mA}$, Bruker D8 Advance; diffractograms shown in Fig. S1 of Supporting Information (SI)).

$\mathrm{H}_{2}$ and $\mathrm{Cu} / \mathrm{SiO}_{2}$ catalysts (ca. $20 \%$ wt. $\mathrm{Cu}$ ) were used to improve the stability of $\mathrm{TiO}_{2}$ and $\mathrm{ZrO}_{2}$ ketonization catalysts. The $\mathrm{Cu}$-based catalysts were prepared using homogeneous deposition-precipitation methods [24]. $\mathrm{Cu}(\mathrm{OH})_{2}$ was deposited onto colloidal silica (30 wt $\%$, LUDOX SM-30) from an aqueous solution of $\mathrm{Cu}\left(\mathrm{NO}_{3}\right)_{2}$ $\left(\mathrm{Cu}\left(\mathrm{NO}_{3}\right)_{2} \cdot 2.5 \mathrm{H}_{2} \mathrm{O}, 99.99 \%\right.$, Sigma-Aldrich $)$ via urea hydrolysis $\left(\mathrm{CO}\left(\mathrm{NH}_{2}\right)_{2}, 99 \%\right.$, Aldrich) at $363 \mathrm{~K}\left(\right.$ urea $\left./ \mathrm{Cu}^{2+}=3(\mathrm{~mol})\right)$. The resulting suspension was kept at $363 \mathrm{~K}$ $\left(0.167 \mathrm{~K} \mathrm{~s}^{-1}\right)$ for $20 \mathrm{~h}$ while stirring $(12 \mathrm{~Hz})$ and then filtered and washed with deionized water until the filtrate gave a neutral $\mathrm{pH}$ value. The recovered powders were treated in stagnant ambient air by heating to $383 \mathrm{~K}$ (at $0.167 \mathrm{~K} \mathrm{~s}^{-1}$ ) and holding overnight and in flowing dry air $\left(1.67 \mathrm{~cm}^{3} \mathrm{~g}^{-1} \mathrm{~s}^{-1}, 99.999 \%\right.$, Praxair) by heating to $723 \mathrm{~K}$ (at $0.167 \mathrm{~K} \mathrm{~s}^{-1}$ ) and holding for $5 \mathrm{~h}$. These samples were then treated in flowing $10 \% \mathrm{H}_{2} / \mathrm{He}\left(5.56 \mathrm{~cm}^{3} \mathrm{~g}^{-1}\right.$ $\mathrm{s}^{-1}, 99.999 \%$, Praxair) at $573 \mathrm{~K}\left(0.033 \mathrm{~K} \mathrm{~s}^{-1}\right)$ for $2 \mathrm{~h}$, and passivated in flowing $1 \% \mathrm{O}_{2} / \mathrm{He}$ $\left(0.83 \mathrm{~cm}^{3} \mathrm{~g}^{-1} \mathrm{~s}^{-1}, 99.999 \%\right.$, Praxair) at ambient temperature for $1 \mathrm{~h}$ before exposure to ambient air. The mean $\mathrm{Cu}$ crystallite size $(d)$ in $\mathrm{Cu} / \mathrm{SiO}_{2}(7.9 \mathrm{~nm})$ [24] was measured from the breadth of the most intense (111) reflection in diffractograms $\left(2 \theta=43.3^{\circ}\right)$ using the Scherrer equation and $\mathrm{Cu} \mathrm{K}-\alpha$ radiation ( $0.15418 \mathrm{~nm}$ wavelength). 


\subsection{Catalytic rate measurements}

The reactions of gaseous $\mathrm{C}_{2}-\mathrm{C}_{4}$ carboxylic acids (ethanoic acid $\left(\mathrm{CH}_{3} \mathrm{COOH},>99.7 \%\right.$, Sigma-Aldrich), propionic acid $\left(\mathrm{C}_{2} \mathrm{H}_{5} \mathrm{COOH},>99.5 \%\right.$, Sigma-Aldrich), butanoic acid $\left(\mathrm{C}_{3} \mathrm{H}_{7} \mathrm{COOH},>99 \%\right.$, Sigma-Aldrich $\left.)\right)$ were carried out in an isothermal packed-bed reactor $(1.0 \mathrm{~cm} \mathrm{I.D.)} \mathrm{with} \mathrm{plug-flow} \mathrm{hydrodynamics} \mathrm{at} \mathrm{temperatures} \mathrm{between} 503 \mathrm{~K}$ and $533 \mathrm{~K}$. Experiments were carried out on $\mathrm{TiO}_{2}(\mathrm{a}), \mathrm{TiO}_{2}(\mathrm{r}), \mathrm{ZrO}_{2}(\mathrm{~m})$, and $\mathrm{ZrO}_{2}(\mathrm{t})$ and on their respective physical mixtures with $20 \%$ wt. $\mathrm{Cu} / \mathrm{SiO}_{2}$ co-catalysts (oxide $/\left(\mathrm{Cu} / \mathrm{SiO}_{2}\right)=$ 0.5-2 mass); these mixtures were prepared by crushing and mixing the mixtures with a mortar and pestle and then pressed into wafers, crushed, and sieved to retain $125-180 \mu \mathrm{m}$ aggregates. The mixtures were then treated in flowing $10 \% \mathrm{H}_{2} / \mathrm{He}\left(5.56 \mathrm{~cm}^{3} \mathrm{~g}^{-1} \mathrm{~s}^{-1}\right.$, 99.999\%, Praxair) by heating to $543 \mathrm{~K}$ (at $0.0833 \mathrm{~K} \mathrm{~s}^{-1}$ ) and holding for $2 \mathrm{~h}$ within the reactor before catalytic measurements. Liquid carboxylic acids were introduced using a syringe pump (Cole Parmer, 74900 series) at $433 \mathrm{~K}$ into a flow of $\mathrm{H}_{2}$-He mixtures (20 $\mathrm{kPa} \mathrm{H}$, 99.999\%, Praxair) metered using electronic mass flow controllers (Porter, Inc.). All lines were kept at $433 \mathrm{~K}$ to prevent condensation of reactants and products. Isotopic data were obtained using the same procedures and ethanoic acid- $\mathrm{d}_{4}\left(\mathrm{CD}_{3} \mathrm{COOD},>99 \%\right.$, Sigma-Aldrich) and $\mathrm{D}_{2}(>99 \%$, Praxair) as reactants.

Reactant and product concentrations were determined by on-line gas chromatography (Agilent 6890). Carboxylic acids, anhydrides, alkanones, and other oxygenates were detected by a flame ionization detector after separation in a capillary column (Agilent, HP-1, methyl silicone, $50 \mathrm{~m}, 0.32 \mathrm{~mm}$ ID $\times 1.05$ um). $\mathrm{H}_{2}, \mathrm{H}_{2} \mathrm{O}, \mathrm{CO}$, and $\mathrm{CO}_{2}$ were detected by measuring thermal conductivity after chromatographic separation in a packed column (Porapak-Q, 4.8 m, 80-100 mesh). Molecular speciation was confirmed using known standards and mass spectrometry (HP 5972 mass spectrometer). A carbon basis 
was used to calculate all conversions and selectivities. For catalytic rate measurements, reactant conversions were kept below $5 \%$ to ensure the absence of axial reactant concentration gradients.

\subsection{Titration of acid-base pairs during catalysis}

Acid-base pairs on oxide surfaces can be titrated with carboxylic acids during aldol condensation, because acids strongly bind at such pairs and convert via ketonization at much lower rates than aldol condensation turnovers of carbonyl compounds [24]. These acid-base pairs are involved in both condensation and ketonization reactions, as shown in this study, thus allowing the rigorous reporting of the reactivity of each catalyst as turnover rates. These titrations were carried out on $\mathrm{TiO}_{2}(\mathrm{a}), \mathrm{TiO}_{2}(\mathrm{r}), \mathrm{ZrO}_{2}(\mathrm{~m})$, and $\mathrm{ZrO}_{2}(\mathrm{t})$ catalysts using propanoic acid titrants $(20 \mathrm{~Pa})$ during acetone condensation reactions $(0.8$ $\mathrm{kPa}, 453 \mathrm{~K})$ [24]. The titrant and product concentrations in the effluent were measured using the chromatographic protocols described above. The number of accessible acidbase site pairs on the oxides was determined from the amount of adsorbed propionic acid required to fully suppress condensation rates and the specific titrant stoichiometry inferred from infrared evidence and DFT treatments for each oxide. These studies showed that $\mathrm{TiO}_{2}$ (a) favors dissociated acids bound in a monodentate form on a single Ti-O pair via respective interactions of the two $\mathrm{O}$-atoms in the formed carboxylates with the $\mathrm{Ti}$ center and the abstracted proton bound at the O-atom in the Ti-O pair (Sections 3.3 and 3.4), leading to a titrant stoichiometry of one acid per Ti-O pair. In contrast, $\mathrm{TiO}_{2}(\mathrm{r})$ (Sections 3.3 and 3.4), $\mathrm{ZrO}_{2}(\mathrm{~m})$ [3], and $\mathrm{ZrO}_{2}(\mathrm{t})$ [3] favor dissociated acids interacting with two vicinal $\mathrm{M}-\mathrm{O}$ pairs $(\mathrm{M}=\mathrm{Ti}, \mathrm{Zr})$ via interactions of each of the two O-atoms in the carboxylate structures with one of the $\mathrm{M}$ centers and interaction of the abstracted $\mathrm{H}$ - 
atom and one of the lattice $\mathrm{O}$-atoms, to give a stoichiometry of one acid for each two MO pairs.

Measured titration values for these $\mathrm{TiO}_{2}$ and $\mathrm{ZrO}_{2}$ oxides are in reasonable agreement with their low-index-plane site densities except for $\mathrm{TiO}_{2}(\mathrm{r})$ (Table 1). The fast prevalent deactivation of $\mathrm{TiO}_{2}(\mathrm{r})$, caused by desorption hurdles of condensation products, accounts for its lower measured Ti-O pair densities [24]. These densities of acid-base pairs (Table 1) were used to report ketonization reactivity as turnover rates, a measure of intrinsic reactivity that allows rigorous comparisons among oxides and between theory and experiment for each oxide catalyst.

Table 1. Measured acid-base pair densities and values expected from crystal structures and low-index planes for $\mathrm{TiO}_{2}$ and $\mathrm{ZrO}_{2}$ catalysts

\begin{tabular}{cccccc}
\hline Catalyst & \multicolumn{3}{c}{ Crystallographic acid-base pair density ${ }^{\mathrm{a}}\left(\mathrm{nm}^{-2}\right)$} & $\begin{array}{c}\text { Measured areal density } \\
\text { of site pairs }\left(\mathrm{nm}^{-2}\right)\end{array}$ \\
\hline $\mathrm{TiO}_{2}(\mathrm{a})$ & $(101) 5.2$ & $(100) 5.6$ & $(001) 7.0$ & $(010) 5.6$ & $3.7^{\mathrm{b}}$ \\
$\mathrm{TiO}_{2}(\mathrm{r})$ & $(110) 5.2$ & $(100) 7.4$ & $(001) 7.4$ & $(011) 8.0$ & $1.7^{\mathrm{b}}$ \\
$\mathrm{ZrO}_{2}(\mathrm{~m})$ & $(-111) 6.8$ & $(111) 8.1$ & $(-101) 5.7$ & $(011) 5.3$ & $6.0^{\mathrm{c}}$ \\
$\mathrm{ZrO}_{2}(\mathrm{t})$ & $(101) 8.6$ & $(001) 7.5$ & $(100) 5.2$ & $(111) 3.3$ & $5.8^{\mathrm{c}}$ \\
\hline
\end{tabular}

${ }^{a}$ Selected planes are the most stable ones present on each metal oxide [28-30]. ${ }^{b}$ Adapted from Ref [24]. ${ }^{\mathrm{c}}$ Titration data shown in Section S2, SI.

\subsection{Infrared spectroscopy measurements}

Transmission infrared (IR) spectra were measured using a Nicolet 8700 FT-IR spectrometer equipped with a Hg-Cd-Te (MCT) detector. Samples were pressed into selfsupporting wafers $\left(5-15 \mathrm{mg} \mathrm{cm}^{-2}\right)$ and placed in a cell with $\mathrm{KBr}$ windows. The samples were treated at $573 \mathrm{~K}\left(0.0833 \mathrm{~K} \mathrm{~s}^{-1}\right)$ in $\mathrm{He}\left(5.56 \mathrm{~cm}^{3} \mathrm{~g}^{-1} \mathrm{~s}^{-1}, 99.999 \%\right.$, Praxair $)$ for $2 \mathrm{~h}$ and then cooled to $523 \mathrm{~K}$ before collecting spectra. Ethanoic acid ( $>99.7 \%$, Sigma-Aldrich; 0.2-1.6 $\mathrm{kPa}$ ) was injected using a syringe pump using the same procedures as for rate measurements (Section 2.2). All spectra were collected by averaging 64 scans in the 
$4000-650 \mathrm{~cm}^{-1}$ range with a $2 \mathrm{~cm}^{-1}$ resolution and normalized by the $\mathrm{C}=\mathrm{O}$ stretching band intensity of gaseous ethanoic acid $\left(1900-1600 \mathrm{~cm}^{-1}\right)$ at $1.6 \mathrm{kPa}$.

\subsection{Density functional theory methods}

Theoretical treatments of the elementary steps involved in ketonization of ethanoic acid on $\mathrm{TiO}_{2}$ (a) and $\mathrm{TiO}_{2}$ (r) surfaces were carried out using periodic plane-wave density functional theory (DFT) methods [31-34] with the Perdew-Burke-Ernzerhof (PBE) exchange-correlation functional $[35,36]$ as implemented in the Vienna ab initio simulation package (VASP). The $3 p^{6} 4 s^{2} 3 d^{2}, 2 s^{2} 2 p^{4}, 2 s^{2} 2 p^{2}$, and $1 s^{1}$ electrons were treated explicitly for $\mathrm{Ti}, \mathrm{O}, \mathrm{C}$ and $\mathrm{H}$ atoms; core electrons were treated using projector augmented-wave (PAW) pseudopotentials with an energy cutoff of $400 \mathrm{eV}[37,38]$. The Monkhorst-Pack sampling method [39] was used to generate the k-mesh for integration of the first Brillouin zone (i.e. $4 \times 4 \times 4$ for bulk structures of $\mathrm{TiO}_{2}(\mathrm{a})$ and $\mathrm{TiO}_{2}(\mathrm{r})$ and $4 \times 4 \times 1$ for surfaces of $\mathrm{TiO}_{2}(\mathrm{a})$ and $\mathrm{TiO}_{2}(\mathrm{r})$ ). The energy between successive selfconsistent iterations was converged to $1 \times 10^{-6} \mathrm{eV}$, while the structures were optimized until forces were below $0.05 \mathrm{eV} \AA^{-1}$.

The known structures of crystalline $\mathrm{TiO}_{2}(\mathrm{a})$ (tetragonal, $\mathrm{I}_{1} / \mathrm{amd}, \mathrm{a}=\mathrm{b}=0.383 \mathrm{~nm}$, $\mathrm{c}=0.961 \mathrm{~nm}$ ) [40] and $\mathrm{TiO}_{2}(\mathrm{r})$ (tetragonal, $\mathrm{P} 4_{2} / \mathrm{mnm}, \mathrm{a}=\mathrm{b}=0.458 \mathrm{~nm}, \mathrm{c}=0.295 \mathrm{~nm}$ ) [40] were used as the starting point for energy optimizations of bulk $\mathrm{TiO}_{2}(\mathrm{a})$ and $\mathrm{TiO}_{2}(\mathrm{r})$. The DFT-optimized lattice vectors of $\mathrm{TiO}(\mathrm{a})(\mathrm{a}=\mathrm{b}=0.378 \mathrm{~nm}, \mathrm{c}=0.950 \mathrm{~nm})$ and $\mathrm{TiO}(\mathrm{r})$ $(a=b=0.464 \mathrm{~nm}, \mathrm{c}=0.299 \mathrm{~nm})$ determined from fitting of energy-volume data with the Birch-Murnaghan equation of state [41] were both $1.2 \%$ larger than for the respective known structures. $\mathrm{TiO}_{2}$ (a) (101) and $\mathrm{TiO}_{2}(\mathrm{r})$ (110) surfaces are the most stable exposed ones for the respective $\mathrm{TiO}_{2}$ phases [40] and were chosen as the model surfaces. For the 
$\mathrm{TiO}_{2}$ (a) (101) surface, $1 \times 2,1 \times 4,2 \times 3$, and $1 \times 8$ supercells were constructed in order to describe ketonization elementary reactions at 1/8,1/6, 1/4, 1/3, 1/2, and 1 ethanoic acid monolayers (ML) (1-2 acid reactants per supercell), whereas $1 \times 2,1 \times 4$, and $1 \times 8$ supercells were constructed and used for the $\mathrm{TiO}_{2}(\mathrm{r})$ (110) surface correspondingly. Each $(m \times n)$ supercell contained four $\mathrm{Ti}_{m \times n} \mathrm{O}_{2 \times m \times n}$ layers in the z-direction with the fourth layer fixed at its bulk position and the other layers allowed to relax to their minimum energy structures in response to the presence of adsorbed species. Periodic images were separated by $1.5 \mathrm{~nm}$ along the z-direction, and the dipole interaction between images along the z-direction was corrected during each geometric optimization step [42]. Grimme's D3BJ dispersion corrections were also included during the optimization processes to account for van der Waals interactions among atoms [43,44]. Adsorption free energies $\left(\Delta G_{a d s}\right)$ for ethanoic acid on Ti-O pairs of $\mathrm{TiO}_{2}\left(\right.$ a) or $\mathrm{TiO}_{2}(\mathrm{r})$ surfaces to form molecularly bound acids or dissociate to carboxylates is determined by

$$
\Delta G_{a d s}=\frac{1}{\lambda}\left(G_{\lambda \times a c i d *}-G_{T i O 2-(m \times n)}-\lambda G_{\text {acid }}\right)
$$

where $G_{T i O 2-(m \times n)}$ is the free energy of a $(m \times n)$ supercell slab of a $\mathrm{TiO}_{2}$ surface $(m=1, \mathrm{n}$ $=2-8$, as described above), $G_{\lambda \times a c i d *}$ is the free energy of this $\mathrm{TiO}_{2}$ slab with $\lambda$ ethanoic acid molecules $\left(\lambda=1\right.$ or 2 ), and $G_{\text {acid }}$ is the free energy of a gaseous ethanoic acid molecule; $\Delta G_{a d s}$ thus reflects the average adsorption free energy of ethanoic acid on $\mathrm{TiO}_{2}$ surfaces at a surface coverage of $\lambda /(m \times n)$ ML.

Nudged elastic band (NEB) $[45,46]$ and dimer [47] methods were used to determine optimized transition state (TS) structures and energies for all elementary steps. The starting point for each TS structure was obtained using NEB methods with 8-12 images along the reaction coordinate. The electronic structures were converged self-consistently 
to energies of $1 \times 10^{-5} \mathrm{eV}$ using a single $\Gamma$-centered k-point, and the corresponding maximum force on each atom converged to $0.1 \mathrm{eV} \AA^{-1}$. The dimer algorithm was then used to optimize the TS structure using a $4 \times 4 \times 1$ Monkhorst-Pack k-point mesh and more stringent convergence criteria for electronic energies and forces $\left(1 \times 10^{-6} \mathrm{eV}\right.$ and $0.05 \mathrm{eV}$ $\AA^{-1}$, respectively). A frequency analysis was used to confirm that the optimized TS structure exhibited a single imaginary frequency characteristic of the molecular vibration along the reaction coordinate.

Vibrational frequencies for the optimized structures of reactive species and transition states were determined from the Hessian matrix using the same k-point mesh and convergence criteria for the geometric optimizations, while the bottom three layers of each unit cell were all frozen during the frequency analysis in order to reduce computational cost; these frequencies were not corrected by any factors. The enthalpies, entropies, and Gibbs free energies of reactants, transition states, and products were calculated for each elementary step from these frequencies using vibrational partition functions derived from the rigid-rotor harmonic oscillator approximation [48]. Weaklybound adsorbates contain fewer than three low-frequency modes $\left(<60 \mathrm{~cm}^{-1}\right)$. These modes were treated as rotations similar to gaseous molecules, instead of treating as harmonic oscillators, because the latter treatments lead to significant errors in the magnitude of the vibrational partition functions [49].

Hydroxide anion affinity $\left(E_{\mathrm{HA}}\right)$ for an acid site $(\mathrm{A})$ is defined as the energy released from binding of a gaseous hydroxide anion $\left(\mathrm{OH}^{-}\right)$, initially present at non-interacting distances, onto the acid site A:

$$
E_{\mathrm{HA}}=E_{\mathrm{AOH}^{-}}-E_{\mathrm{A}}-E_{\mathrm{OH}^{-}}
$$


where $E_{i}$ represents the electronic energy of species $i$; these $E_{\mathrm{HA}}$ values are used as energy-based descriptors of the strength of a Lewis acid site. Proton affinity $\left(E_{\mathrm{PA}}\right)$ for a basic site (B) is defined in a similar way in order to describe the strength of the basic site B:

$$
E_{\mathrm{PA}}=E_{\mathrm{HB}^{+}}-E_{\mathrm{B}}-E_{\mathrm{H}^{+}}
$$

where $E_{i}$ represents the electronic energy of species $i$. These affinities for the acid-base pairs present on $\mathrm{TiO}_{2}$ (a) (101) surfaces were estimated using a $\mathrm{Ti}_{40} \mathrm{O}_{118} \mathrm{H}_{76}$ cluster model instead of the above slab models, because dipole and quadrupole energy corrections cannot be calculated correctly for periodic systems with a net charge [42]. This cluster was extracted from a $\mathrm{TiO}_{2}$ (a) (101) surface with $\mathrm{H}$-atoms attached to terminal O-atoms to maintain charge neutrality (structure shown in Section S3, SI). Similarly, a $\mathrm{Ti}_{40} \mathrm{O}_{120} \mathrm{H}_{80}$ cluster (Section S3, SI) was constructed in order to estimate $E_{\mathrm{HA}}$ and $E_{\mathrm{PA}}$ for the Ti-O pairs present on $\mathrm{TiO}_{2}(\mathrm{r})(110)$ surfaces.

\section{Results and discussion}

\subsection{Ketonization turnover rates of carboxylic acids on $\mathrm{TiO}_{2}$ and $\mathrm{ZrO}_{2}$ catalysts}

Ketonization reactions of $\mathrm{C}_{2}-\mathrm{C}_{4}$ carboxylic acids $\left(\mathrm{C}_{\mathrm{n}} \mathrm{H}_{2 \mathrm{n}-1} \mathrm{COOH}, \mathrm{n}=1-3\right)$ take place with high selectivity on anatase $\mathrm{TiO}_{2}\left(\mathrm{TiO}_{2}(\mathrm{a})\right)$, rutile $\mathrm{TiO}_{2}\left(\mathrm{TiO}_{2}(\mathrm{r})\right)$, monoclinic $\mathrm{ZrO}_{2}$ $\left(\mathrm{ZrO}_{2}(\mathrm{~m})\right)$, and tetragonal $\mathrm{ZrO}_{2}\left(\mathrm{ZrO}_{2}(\mathrm{t})\right)$ catalysts. Carbon selectivities to ketonization products were above 95\% (at 9\%-11\% acid conversion, 503-533 K, Section S4, SI), consistent with previous studies on $\mathrm{TiO}_{2}$ (a) $[16,17]$ and $\mathrm{ZrO}_{2}(\mathrm{~m})$ [19] catalysts. Side products include acid anhydrides, formed via intermolecular dehydration of the acid reactants, and $\alpha, \beta$-unsaturated alkanones, formed via subsequent aldol condensation of

primary alkanone products (Scheme 2). The formation of acid anhydrides is equilibrium- 
limited, as shown by approach to equilibrium parameters near unity for the acidanhydride interconversion reactions on $\mathrm{TiO}_{2}(\mathrm{a})$ and $\mathrm{TiO}_{2}(\mathrm{r})$ at all conditions (Section $\mathrm{S} 4$, SI). Secondary aldol condensation of alkanones products is inhibited by coadsorbed monodentate or bidentate carboxylates present at near saturation coverages, as shown by the kinetic and infrared data in Sections 3.2 and 3.3.

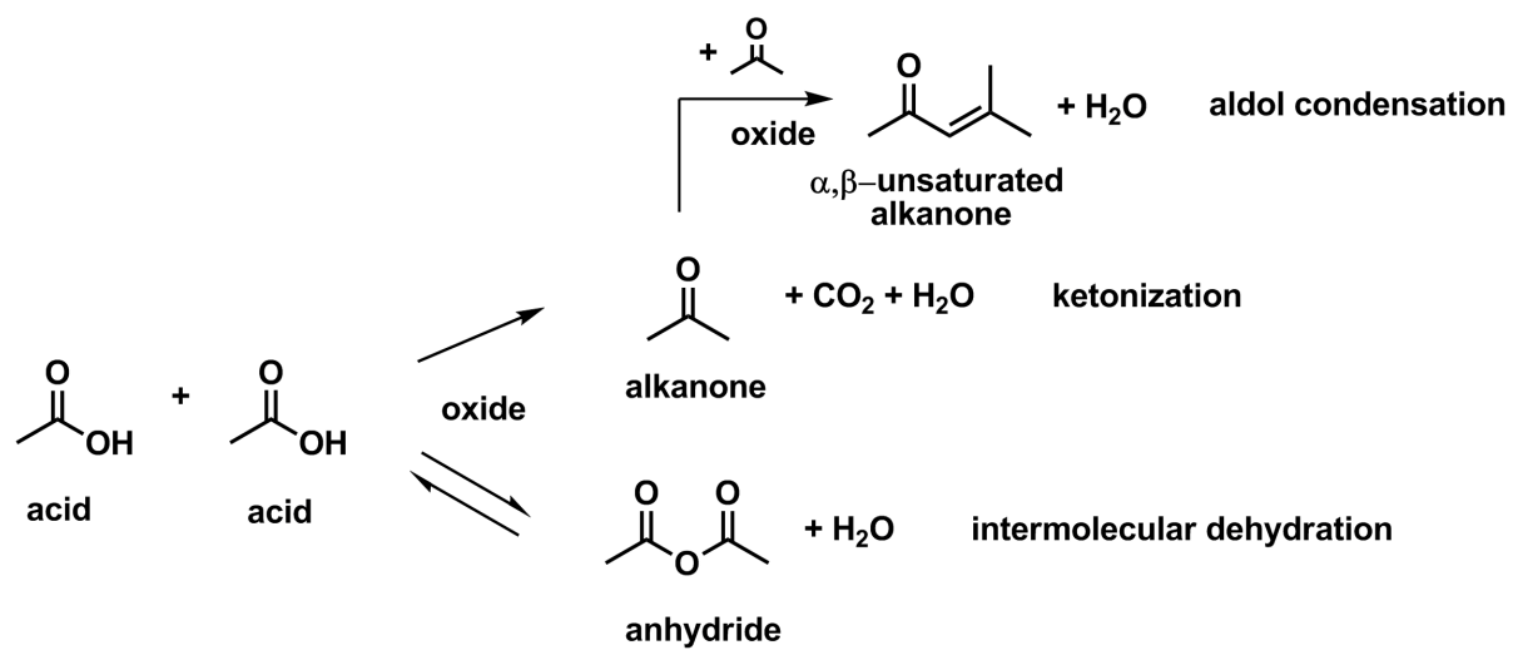

Scheme 2. Reactions of carboxylic acids catalyzed by metal oxides (shown for ethanoic acid as an illustrative example).

Figure 1a shows that ethanoic acid ketonization turnover rates (per acid-base pair) on $\mathrm{TiO}_{2}$ and $\mathrm{ZrO}_{2}$ surfaces decreased with time-on-stream $(523 \mathrm{~K}, 1.0 \mathrm{kPa}$ ethanoic acid). Initial turnover rates $(r(0))$ were obtained by extrapolation of initial rates $(<1 \mathrm{~h})$ to the time of initial contact with reactants. The initial slope in the semi-logarithmic data reflects the value of the first-order deactivation constant $\left(k_{\mathrm{d}}\right)$ :

$$
\frac{r(t)}{\mathrm{r}(0)}=\mathrm{e}^{-k_{\mathrm{d}} t}
$$

where $r(t)$ is the rate at any time $t$. These initial turnover rates were highest on $\mathrm{ZrO}_{2}(\mathrm{~m})$ and lowest on $\mathrm{TiO}_{2}$ (r) (Fig. 1), indicative of $\mathrm{M}(\mathrm{M}=\mathrm{Ti}, \mathrm{Zr})$ and $\mathrm{O}$ centers with different acid and basic strength and geometry on these oxide surfaces, as discussed in Section 3.4. Initial turnover rates were five-fold higher on $\mathrm{TiO}_{2}(\mathrm{a})$ than on $\mathrm{TiO}_{2}(\mathrm{r})$ at $523 \mathrm{~K}$ and 1.0 
$\mathrm{kPa}$ ethanoic acid; similar rate differences were previously reported for acetone condensation turnover rates [24], for which the observed reactivity of $\mathrm{TiO}_{2}(\mathrm{r})$ surfaces was ultimately attributed to residual anatase surfaces present as minority species. The measured $k_{\mathrm{d}}$ values for $\mathrm{TiO}_{2}$ and $\mathrm{ZrO}_{2}$ catalysts suggest that acid-base pairs that are more active also deactivate more rapidly (Fig. 1a); such trends render $\mathrm{TiO}_{2}(\mathrm{a}), \mathrm{ZrO}_{2}(\mathrm{~m})$, and $\mathrm{ZrO}_{2}(\mathrm{t})$ similarly effective as practical ketonization catalysts, in spite of the slightly lower initial turnover rates on $\mathrm{TiO}_{2}(\mathrm{a})$.
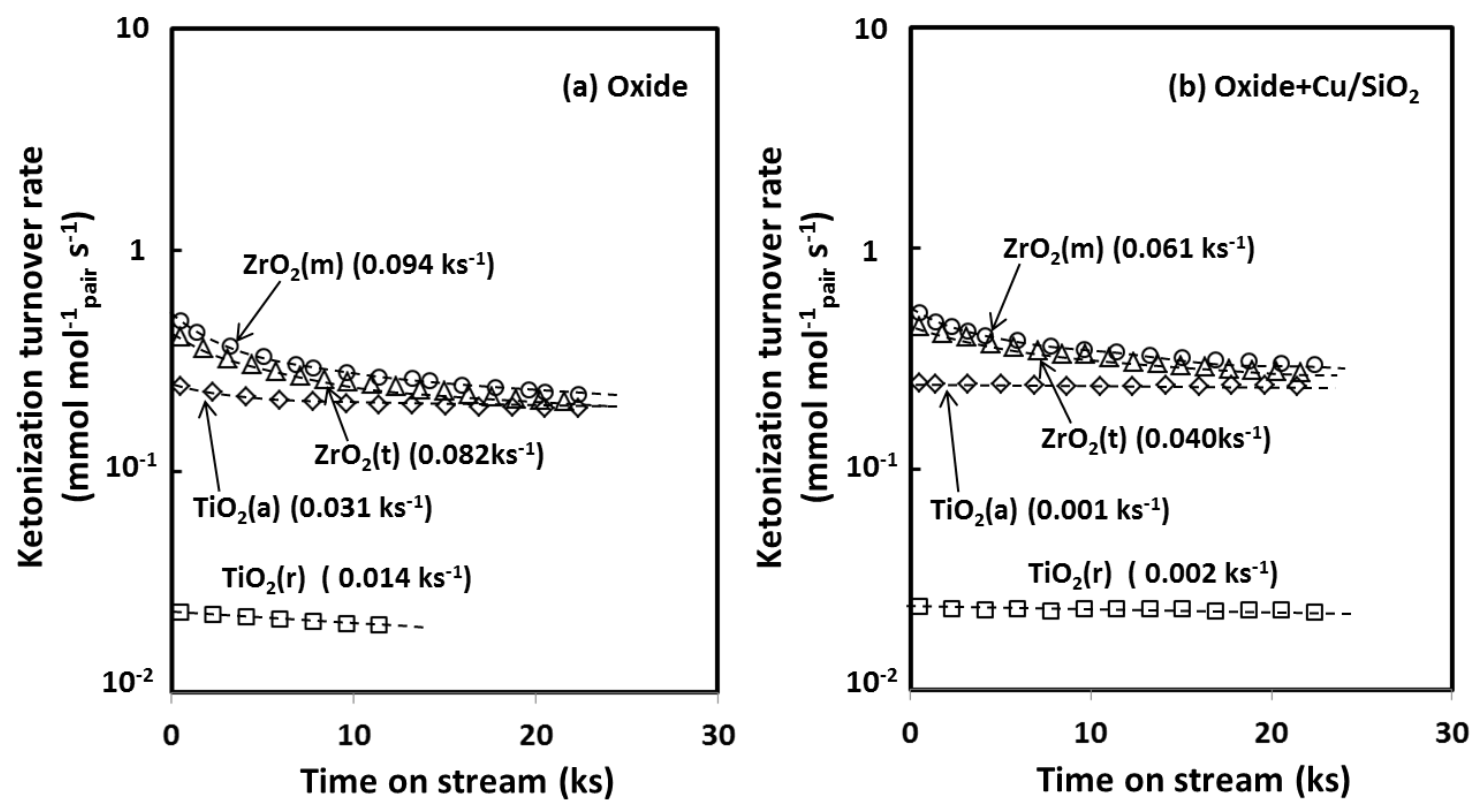

Figure 1. Semi-logarithmic plots of ethanoic acid ketonization turnover rates (per acidbase pair measured by propanoic acid titration during catalysis; Table 1) as a function of time-on-stream (a) on $\mathrm{TiO}_{2}$ and $\mathrm{ZrO}_{2}$ catalysts and (b) on these catalysts as physical mixtures with $\mathrm{Cu} / \mathrm{SiO}_{2}\left(1: 1\right.$ mass) $\left(523 \mathrm{~K}, 1.0 \mathrm{kPa}\right.$ ethanoic acid, $20 \mathrm{kPa} \mathrm{H} \mathrm{H}_{2}$ for the mixtures). First-order deactivation constants (Eq. 5) are shown in parenthesis. Dashed curves indicate qualitative trends.

Initial ketonization rates and deactivation constants $\left(k_{\mathrm{d}}\right)$ were similar on $\mathrm{TiO}_{2}(\mathrm{a})$ samples treated in $\mathrm{He}$ or $\mathrm{H}_{2}$ at $543 \mathrm{~K}$ for $2 \mathrm{~h}$ before reaction (Section $\mathrm{S} 5, \mathrm{SI}$ ). These similarities indicate that either reduced centers do not form during the treatments, consistent with the higher temperatures typically required to form O-vacancies in $\mathrm{TiO}_{2}(\mathrm{a})$ 
[10], or that any reduced centers present are inconsequential for ketonization. The number of acid-base pairs measured by titration methods [24] resembles those expected from low-index crystal planes (Table 1), indicating that active centers do not reflect defects that would be present merely as minority species. Such defects may be essential in "dose-and-react" stoichiometric experiments [9], because species must be kept bound at surfaces up to the temperatures required for their reactions, a requirements that is inconsequential in the presence of gaseous reactants during steady-state ketonization turnovers.

Initial rates were essentially recovered after deactivation for $48-72 \mathrm{~h}$ on all $\mathrm{TiO}_{2}$ and $\mathrm{ZrO}_{2}$ catalysts by extended treatments in flowing $\mathrm{He}$ at $523 \mathrm{~K}$ (Section S6, SI), suggesting that the site blockage occurs via the gradual formation of unreactive species that can be desorbed slowly, but without the need for a reactive environment (i.e. $\mathrm{H}_{2}$ or $\mathrm{O}_{2}$ treatments). Infrared spectra showed that such unreactive residues consist of bidentate carboxylates formed via dissociative adsorption of carboxylic acids on two vicinal acidbase pairs (Scheme 3; Section 3.3); the time scale for the appearance and disappearance of bidentate carboxylate vibrational features coincides with that for deactivation and regeneration, respectively (Section 3.3). DFT treatments of ketonization elementary steps on $\mathrm{TiO}_{2}(\mathrm{a})$ and $\mathrm{TiO}_{2}(\mathrm{r})$ surfaces also indicate that bidentate carboxylates are not involved in ketonization turnovers (Section 3.4); they act instead as unreactive spectators that occupy acid-base pairs, thus rendering them inaccessible for catalytic turnovers.

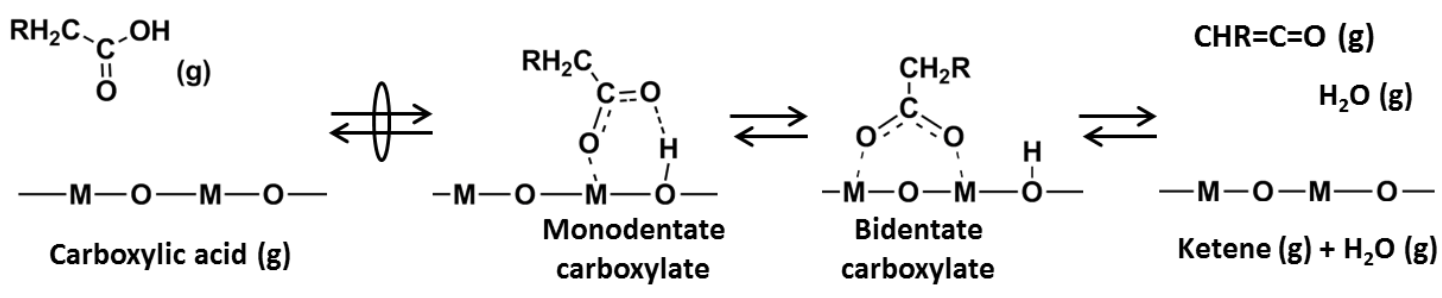


Scheme 3. Formation of surface carboxylates and gaseous ketenes on oxide surfaces during ketonization of carboxylic acids $(\mathrm{R}=\mathrm{H}$, alkyl; $\mathrm{M}=\mathrm{Zr}$, Ti).

Ethanoic acid ketonization rates on $\mathrm{TiO}_{2}(\mathrm{a})$ and $\mathrm{TiO}_{2}(\mathrm{r})$ catalysts remained essentially constant with time in the presence of gaseous $\mathrm{H}_{2}$ and a $\mathrm{Cu}$ function $\left(k_{\mathrm{d}} \leq 0.002 \mathrm{ks}^{-1} ; 20\right.$ $\mathrm{kPa} \mathrm{H},\left(\mathrm{Cu} / \mathrm{SiO}_{2}\right) /$ oxide $=1$ (mass); Fig. 1b). These conditions and catalyst mixtures led to the concurrent appearance of ethanal and ethanol, which form via hydrogenolysis of ethanoic acid or hydrogenation of its ketene derivatives $\left(\mathrm{CH}_{2}=\mathrm{C}=\mathrm{O}\right.$; from dehydration of ethanoic acid [11]) on $\mathrm{Cu}$ surfaces (Scheme 4). The combined formation rates of these hydrogenation products were much lower than ketonization rates (Section S7, SI). Ketonization rates of propanoic acid and butanoic acid were also rendered stable over time by these bifunctional strategies $\left(k_{\mathrm{d}} \leq 0.002 \mathrm{ks}^{-1}\right.$ on $\mathrm{TiO}_{2}$ (a); Fig. 2).

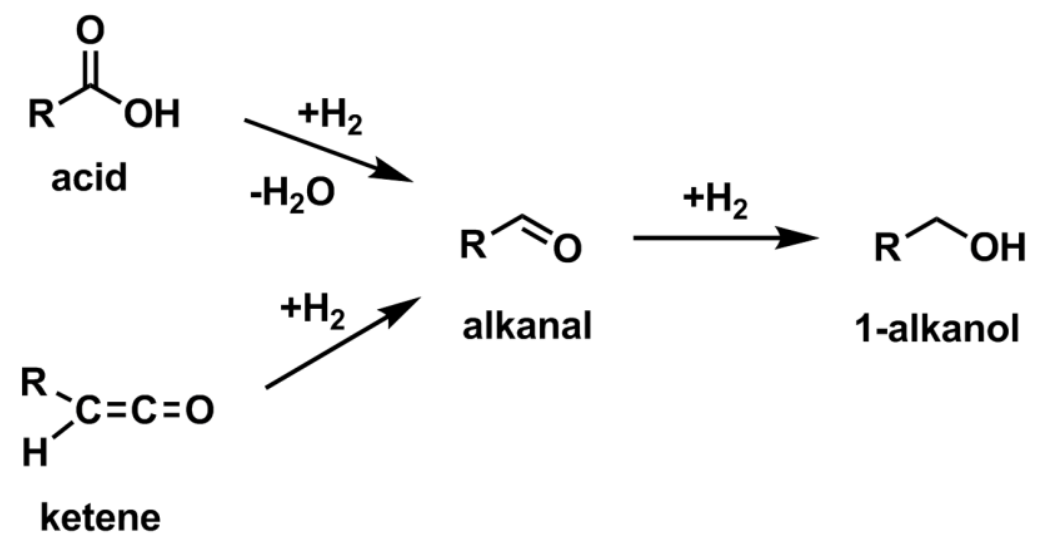

Scheme 4. Hydrogenation of carboxylic acid and ketene to alkanal and 1-alkanol $(\mathrm{R}=\mathrm{H}$, alkyl). 


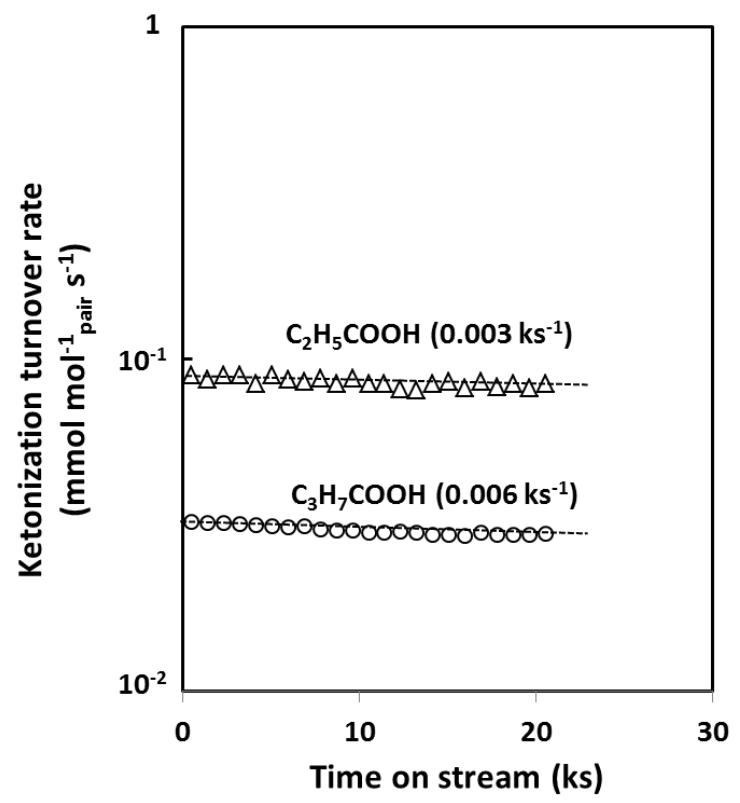

Figure 2. Semi-logarithmic plots of ketonization turnover rates of propanoic acid and butanoic acid as a function of time-on-stream $\left(\mathrm{TiO}_{2}(\mathrm{a})+20 \% \mathrm{wt} . \mathrm{Cu} / \mathrm{SiO}_{2}\right.$ (1:1 mass), 523 $\mathrm{K}, 1.0 \mathrm{kPa}$ acid reactant, $20 \mathrm{kPa} \mathrm{H}$ ). First-order deactivation constants (Eq. 5) are shown in parenthesis. Dashed lines indicate qualitative exponential trends.

We surmise that the bidentate carboxylates can dehydrate to form gaseous ketenes in trace amounts (Scheme 3), as evident from DTF calculations (Section S8, SI); these ketene concentrations are set by their unfavorable formation thermodynamics and are well below detection limits. Steady-state coverages of bidentate carboxylates can thus be decreased by the continuous slow scavenging of ketene species to form ethanal and ethanol $[4,50]$ on a $\mathrm{Cu}$ function present within diffusion distances from Ti-O centers. Such scavenging into stable products prevents ketene re-adsorption and the re-formation of the unreactive bidentate carboxylates. These stable ketonization rates on $\mathrm{TiO}_{2}(\mathrm{a})$ and $\mathrm{TiO}_{2}(\mathrm{r})$ allow the rigorous assessment of the ketonization mechanism through combined kinetic and isotopic methods, as described in Section 3.2.

The deactivation of $\mathrm{ZrO}_{2}(\mathrm{~m})$ and $\mathrm{ZrO}_{2}(\mathrm{t})$ catalysts in ketonization of ethanoic acid was suppressed less effectively by the gaseous $\mathrm{H}_{2}(20 \mathrm{kPa})$ and the $\mathrm{Cu}$ function 
$\left(\left(\mathrm{Cu} / \mathrm{SiO}_{2}\right) /\right.$ oxide $=1$ (mass) $)$ than on $\mathrm{TiO}_{2}(\mathrm{a})$ or $\mathrm{TiO}_{2}(\mathrm{r})$. The $k_{\mathrm{d}}$ values decreased from 0.094 to $0.061 \mathrm{ks}^{-1}$ on $\mathrm{ZrO}_{2}(\mathrm{~m})$ and from 0.082 to $0.040 \mathrm{ks}^{-1}$ on $\mathrm{ZrO}_{2}$ (t) (Fig. 1), in contrast with the essential suppression of deactivation processes on $\mathrm{TiO}_{2}$ (a) and $\mathrm{TiO}_{2}(\mathrm{r})$ using similar strategies and conditions $\left(k_{\mathrm{d}} \leq 0.002 \mathrm{ks}^{-1}\right.$; Fig. $\left.1 \mathrm{~b}\right)$. Higher $\left(\mathrm{Cu} / \mathrm{SiO}_{2}\right) /$ oxide mass ratios did not lead to further stabilization of these $\mathrm{ZrO}_{2}$ catalysts $\left(0.060 \mathrm{ks}^{-1}\right.$ on $\mathrm{ZrO}_{2}(\mathrm{~m})$ at $\left(\mathrm{Cu} / \mathrm{SiO}_{2}\right) /$ oxide $=2$ (mass); Section S9, SI). Such findings appear to indicate that desorption of bidentate carboxylates from $\mathrm{ZrO}_{2}(\mathrm{~m})$ and $\mathrm{ZrO}_{2}(\mathrm{t})$ exhibits kinetic hurdles that inhibit their equilibration with gaseous ketene and thus the continuous scavenging of bidentate carboxylates via irreversible ketene hydrogenation on the $\mathrm{Cu}$ function. DFT treatments show that the conversion of bidentate carboxylates to ketenes on $\mathrm{ZrO}_{2}(\mathrm{~m})(-111)$ and $\mathrm{TiO}_{2}(\mathrm{a})(101)$ surfaces is limited by the $\mathrm{C}-\mathrm{O}$ bond cleavage in bidentate carboxylates; its free energy barrier is higher on $\mathrm{ZrO}_{2}(\mathrm{~m})(-111)$ than on $\mathrm{TiO}_{2}(\mathrm{a})$ (101), because $\mathrm{Zr}$ centers on $\mathrm{ZrO}_{2}(\mathrm{~m})$ are weaker Lewis acids than Ti centers on $\mathrm{TiO}_{2}(\mathrm{a})$ (Section S8, SI); as a result, the C-O cleavage TS that mediates ketene formation is less stable on $\mathrm{ZrO}_{2}(\mathrm{~m})$ because its two O-atoms interact more weakly with $\mathrm{Zr}$ than they do with Ti centers on $\mathrm{TiO}_{2}(\mathrm{a})$.

\subsection{Effects of reactant pressure on ketonization rates and implications for elementary} steps and their kinetic relevance on anatase and rutile $\mathrm{TiO}_{2}$.

All rates reported hereinafter were obtained on stable $\mathrm{TiO}_{2}(\mathrm{a})$ and $\mathrm{TiO}_{2}(\mathrm{r})$ catalysts, present as mixtures with $\mathrm{Cu} / \mathrm{SiO}_{2}$ and in the presence of $20 \mathrm{kPa} \mathrm{H}$ (Fig. 1b). These rates were not influenced detectably by the prevalent pressure of the ketonization products (i.e. alkanones, $\mathrm{H}_{2} \mathrm{O}$ and $\mathrm{CO}_{2} ; 0.02-0.2 \mathrm{kPa}$ ), which was varied by changes in space velocity (Section S10, SI), consistent with the weak binding of such product molecules on Ti-O 
pairs of moderate acid-base strength [24]. These product concentrations do not therefore appear as terms in the denominator of the ketonization rate equations derived below.

Figure 3a shows ketonization turnover rates for ethanoic acid- $\mathrm{d}_{0}$ and ethanoic acid- $\mathrm{d}_{4}$ reactants as a function of their respective pressures $(0.1-3.0 \mathrm{kPa})$ on $\mathrm{TiO}_{2}(\mathrm{a})+\mathrm{Cu} / \mathrm{SiO}_{2}$ mixtures $\left(523 \mathrm{~K}, 20 \mathrm{kPa} \mathrm{H} / \mathrm{D}_{2}\right)$. Rates increased with increasing reactant pressure, but became less sensitive to the concentration of reactants at higher ethanoic acid pressures. Similar trends were observed for propanoic and butanoic acids (Fig. 3a) and for ethanoic acid at other temperatures (503-533 K; Fig. 3b). The nearly zero-order kinetic dependences at higher reactant pressure $(>1.2 \mathrm{kPa})$ are consistent with the strong adsorption and monolayer coverages of surface carboxylates derived from acid reactants on $\mathrm{TiO}_{2}(\mathrm{a})$ at the conditions of catalysis.
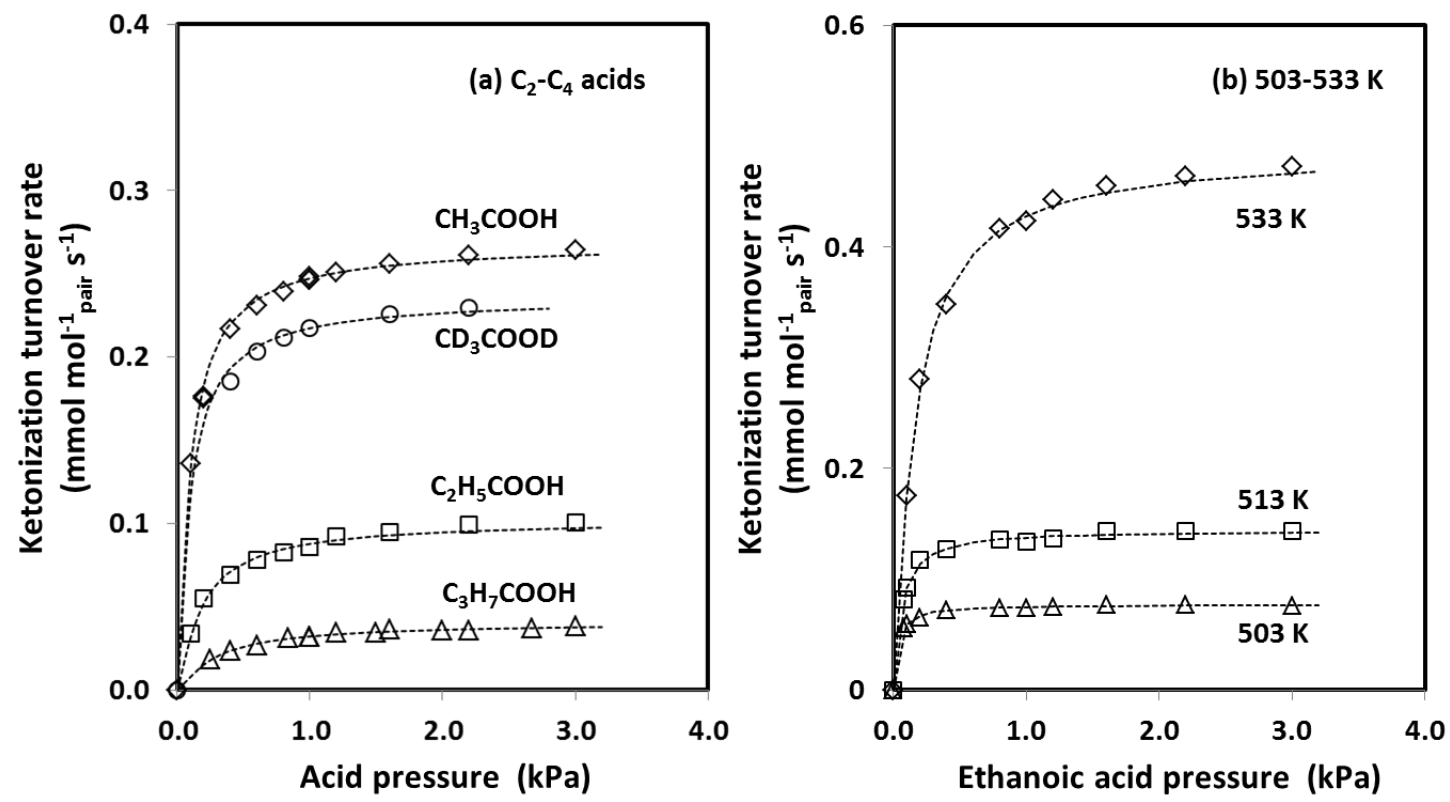

Figure 3. Effects of reactant pressure on ketonization rates (a) for $\mathrm{C}_{2}-\mathrm{C}_{4}$ carboxylic acids at $523 \mathrm{~K}$ and (b) for ethanoic acid at 503-533 K ( $\mathrm{TiO}_{2}(\mathrm{a})+20 \%$ wt. $\mathrm{Cu} / \mathrm{SiO}_{2}$ (1:1 mass), $20 \mathrm{kPa} \mathrm{H}_{2}$ for undeuterated reactants, $20 \mathrm{kPa} \mathrm{D}$ for deuterated reactants). Dashed lines represent the regressed fits to the mechanism-based functional form of Equation 7. 
A plausible sequence of ketonization elementary steps on $\mathrm{TiO}_{2}(\mathrm{a})$ is shown for the specific case of ethanoic acid in Scheme 5. This sequence leads to rate equations consistent with the rate data and isotope effects shown in Figure 3 and with theoretical assessment of free energies for these elementary steps shown in Section 3.4. The $\overrightarrow{k_{x}}$ and $\overleftarrow{k_{x}}$ parameters in Scheme 5 represent the rate constants for the forward and reverse directions of Step $x$, respectively, and $K_{x}$ is the corresponding equilibrium constant for each $\operatorname{step}\left(K_{x}=\overrightarrow{k_{x}} / \overleftarrow{k_{x}}\right)$

These elementary steps involve the dissociation of ethanoic acid at a Ti-O pair $\left(\mathrm{AcO}^{*}\right.$; monodentate carboxylate; Step 1, Scheme 5), with an O-atom in the carboxylic group bound at the $\mathrm{Ti}$ center and the other one $\mathrm{H}$-bonded to the $\mathrm{H}$-atom that is abstracted from the acid and bound at the Ti-O pair. These carboxylates can also bind to two vicinal Ti-O pairs (*AcO*; bidentate carboxylate; Step 2, Scheme 5), with each of its two O-atoms bound at one of the two Ti centers and the abstracted $\mathrm{H}$-atom bound at a lattice O-atom. Infrared spectra during ketonization catalysis show that $\mathrm{AcO}^{*}$ species are the most abundant surface intermediates (MASI) (Section 3.3) during ketonization on $\mathrm{TiO}_{2}(\mathrm{a})$. Ethanoic acid is not preferentially bound as bidentate carboxylate species (*AcO*), a configuration previously proposed as the prevalent MASI during catalysis and claimed as the reactive intermediate in ketonization reactions on $\mathrm{TiO}_{2}(\mathrm{a})[16,17,22], \mathrm{ZrO}_{2}(\mathrm{~m})$ $[19,21], \mathrm{CeO}_{2}[14,18,22]$, and $\mathrm{ZnO}-\mathrm{Cr}_{2} \mathrm{O}_{3}[20]$ based on infrared spectra of pre-adsorbed ethanoic acids at conditions removed from practical ketonization catalysis [21,22] and on DFT-derived estimates of electronic energies at low surface coverages [19]. The explicit treatment of these densely-covered surfaces and of the thermal corrections and entropy effects required for accurate energies and free energies in DFT calculations lead to the 
conclusion that monodentate carboxylates, instead of bidentate species, prevail as adsorbed species and that they act as the reactive intermediates in ketonization catalytic sequences on $\mathrm{TiO}_{2}$ (a) (Section 3.4) and also on $\mathrm{ZrO}_{2}$ surfaces, as we shall report separately.

In Scheme 5, 1-hydroxy enolates form from acids via $\alpha-\mathrm{C}-\mathrm{H}$ cleavage in $\mathrm{AcO}^{*}$ species at Ti-O pairs (Step 3, Scheme 5); these enolates nucleophilically attack the carboxyl C-atom in a neighboring $\mathrm{AcO}^{*}$ to form $\alpha$-hydroxy $\gamma$-carboxy alkoxides containing a new C-C bond (Step 4, Scheme 5); these steps resemble those involved in aldol condensation of carbonyl compounds on acid-base pairs (Scheme 1; Ref [24]). Aldol condensation turnovers involve cleavage of $\alpha-\mathrm{C}-\mathrm{H}$ bonds to form enolate species and subsequent $\mathrm{C}-\mathrm{C}$ bond formation between the enolate and a co-adsorbed carbonyl reactant bound at a vicinal Ti center to form $\gamma$-keto alkoxide species, as the precursors to the aldol products. In contrast to these $\gamma$-keto alkoxide intermediates prevalent in condensation reactions, the alkoxides formed via C-C coupling between species derived from two carboxylic acids (Step 4, Scheme 5) retain the $-\mathrm{OH}$ group at the $\alpha$-C-atom and the $-\mathrm{COOH}$ group at the $\gamma$-C-atom; dehydration of these groups can be catalyzed by a vicinal lattice $O$ center to from $\beta$-keto carboxylates (Steps 5-7, Scheme 5), which then reprotonate to $\beta$-keto acids (Step 8 , Scheme 5). These $\beta$-keto acid intermediates are very reactive and decarboxylate to form $\mathrm{C}_{3}$ enolates (i.e. propen-2-olates) and $\mathrm{CO}_{2}$ (Steps 9-11, Scheme 5). The propen-2-olate species subsequently reprotonate to form acetone, completing a ketonization turnover (Steps 12-13, Scheme 5). The lack of space velocity effects on rates (Section S10, SI) indicates that the adsorption constants $\left(K_{\mathrm{x}}^{-1}\right.$; Scheme 5) for $\mathrm{H}_{2} \mathrm{O}\left(K_{7}^{-1}\right), \mathrm{CO}_{2}\left(K_{11}{ }^{-1}\right)$, and acetone $\left(K_{13}{ }^{-1}\right)$ are very small and that the coverages of 
these species are thus kinetically-negligible on $\mathrm{TiO}_{2}(\mathrm{a})$ surfaces during ketonization catalysis.

1. Dissociation of ethanoic acid on a Ti-O pair to form AcO*

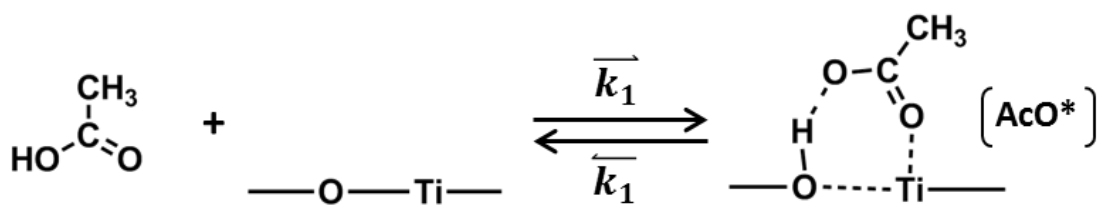

2. Dissociation of ethanoic acid on two Ti-O pairs to form *AcO*

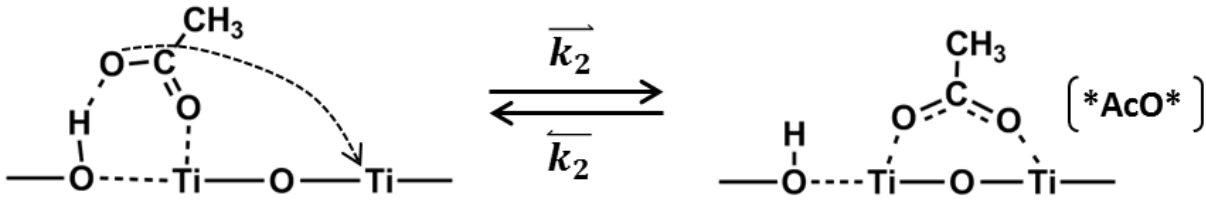

3. $\alpha$-C-H cleavage from AcO* to form 1-hydroxy enolate

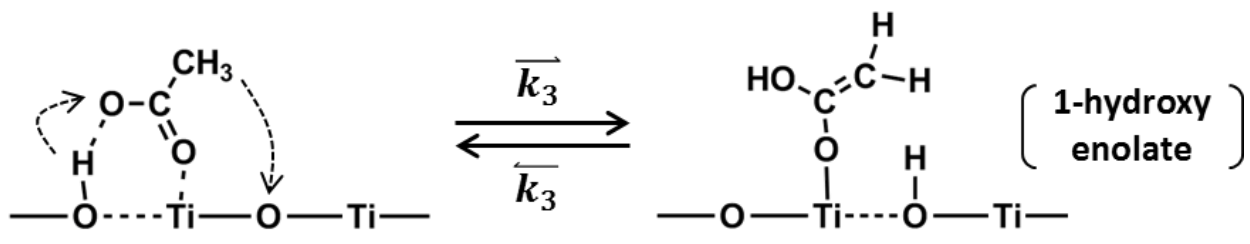

4. C-C coupling between 1-hydroxyl enolate and co-adsorbed AcO* to form $\alpha$-hydroxy $\gamma$-carboxy alkoxide

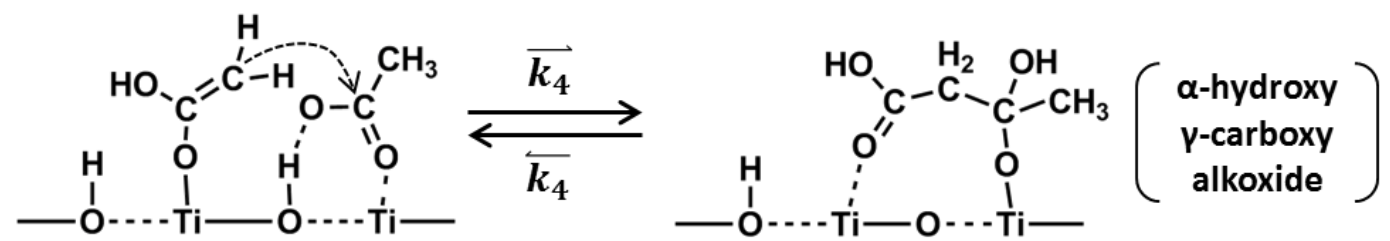

5. Dissociation of $\mathrm{O}-\mathrm{H}$ bond in $\alpha$-hydroxy $\gamma$-carboxy alkoxide to form $\gamma$-hydroxy $\gamma$-oxido carboxylate

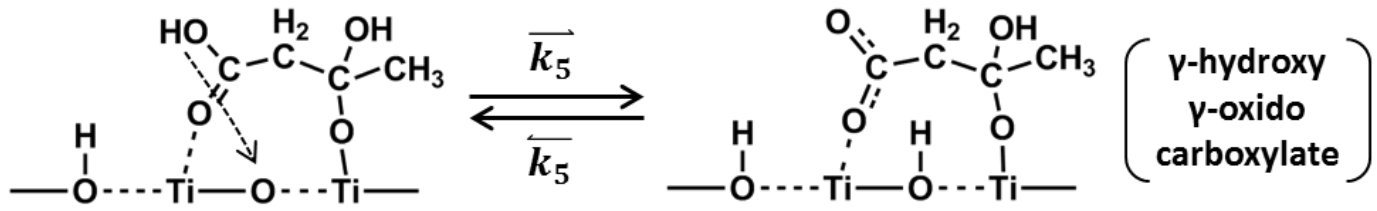

6. $\mathrm{H}_{2} \mathrm{O}$ elimination from $\gamma$-hydroxy $\gamma$-oxido carboxylate to $\beta$-keto carboxylate

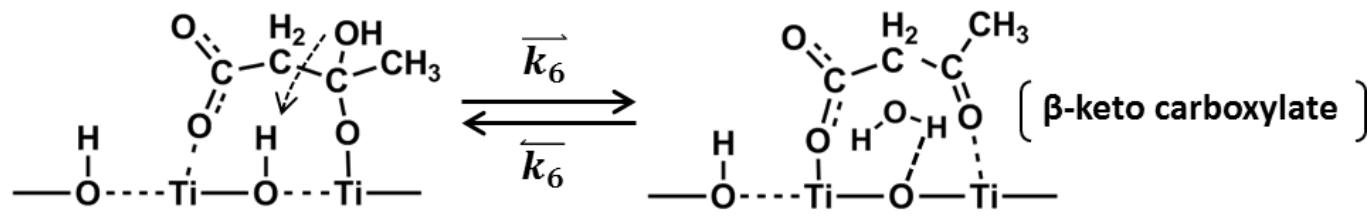


7. $\mathrm{H}_{2} \mathrm{O}$ desorption

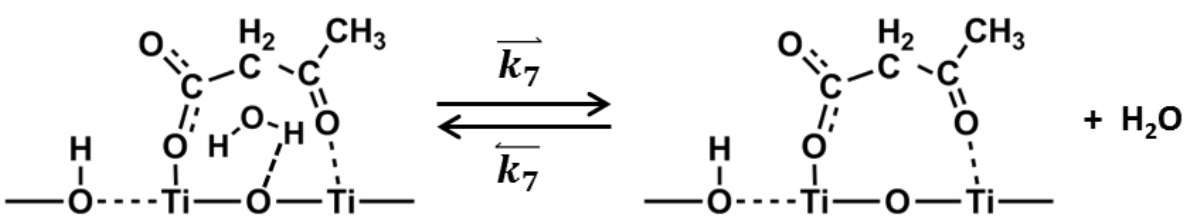

8. Protonation of $\beta$-keto carboxylate to form $\beta$-keto acid

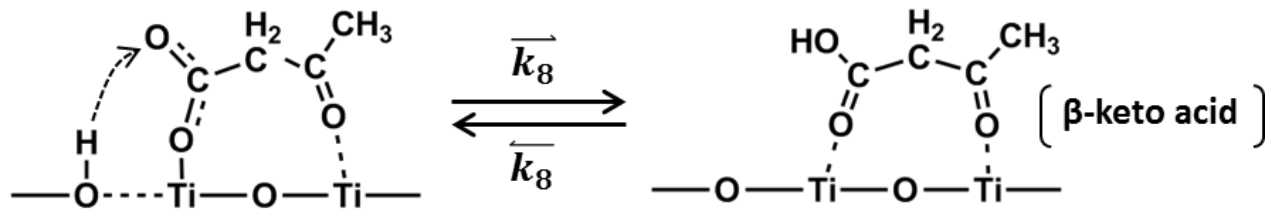

9. Dissociation of $\beta$-keto acid on a Ti-O-Ti structure<smiles>CO[Al]1O[Al](C)OC(=O)C2CC(C)O[Al](O2)O1</smiles><smiles>c1ccccc1</smiles><smiles></smiles>

10. Decarboxylation to form propen-2-olate<smiles>CO[Al](OC)O[Al](C)OC(=O)CC(C)=O</smiles>
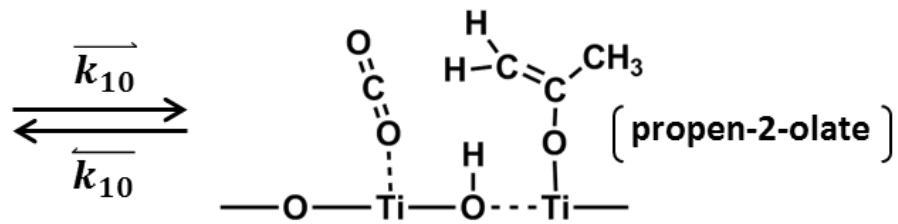

11. $\mathrm{CO}_{2}$ desorption

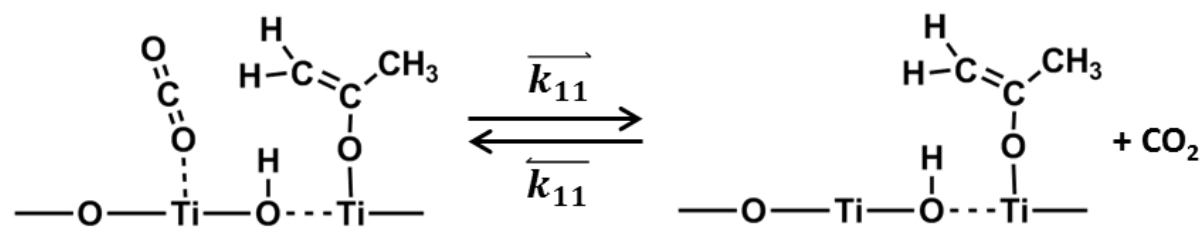

12. Protonation of propen-2-olate to acetone<smiles>CO[Al](C)OC</smiles>
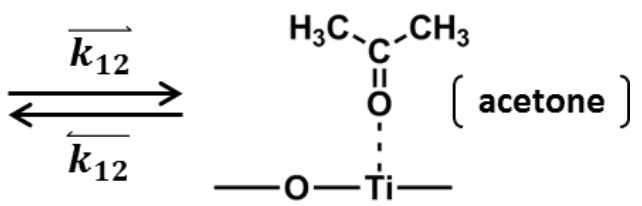

13. Acetone desorption

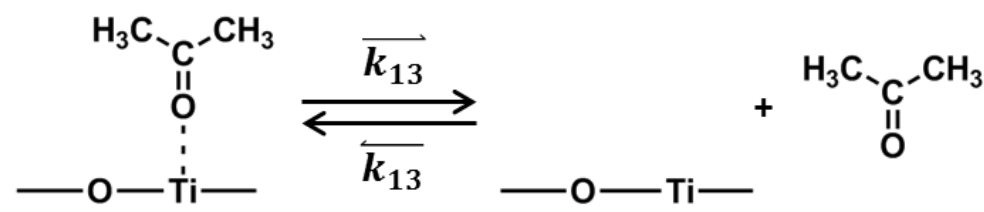

Scheme 5. Proposed elementary steps for carboxylic acid ketonization on acid-base pairs of $\mathrm{TiO}_{2}$ (a) (shown for ethanoic acid as the illustrative example). 
Significant kinetic $\mathrm{H} / \mathrm{D}$ isotope effects would indicate that bonds containing a H-atom form or cleave in kinetically-relevant steps. For instance, enolate formation, the kinetically-relevant step in acetone condensation on $\mathrm{TiO}_{2}(\mathrm{a})$, gives a $\mathrm{H} / \mathrm{D}$ isotope effect of $2.4\left(523 \mathrm{~K}\right.$; Ref [24]). The ketonization rates measured for ethanoic acid- $\mathrm{d}_{0}$ and ethanoic acid- $\mathrm{d}_{4}$ are, however, very similar $\left(r_{\mathrm{H}} / r_{\mathrm{D}}=1.1 \pm 0.1\right.$ at $0.6-2.2 \mathrm{kPa}, \mathrm{TiO}_{2}(\mathrm{a}) ; \mathrm{Fig}$. 3a) and rule out the kinetic relevance of the $\alpha-\mathrm{C}-\mathrm{H}$ cleavage step that forms 1-hydroxy enolates from monodentate carboxylates (Step 3, Scheme 5). Such small observed H/D isotope effects would also be inconsistent with the kinetic relevance of any other step involving activation or cleavage of a C-H/O-H bond in Scheme 5 (i.e. Steps 5, 6, 8, 9, and 12). Thus, C-C coupling between 1-hydroxy enolates and coadsorbed $\mathrm{AcO}^{*}$ (Step 4, Scheme 5) and decarboxylation of $\beta$-keto carboxylates (Step 10, Scheme 5) are the only plausible kinetically-relevant elementary steps consistent with measured H/D kinetic isotope effects.

The elementary steps in Scheme 5, taken together with (i) the pseudo-steady-state approximation for all bound species; (ii) the quasi-equilibrated nature of all steps except C-C coupling (Step 4, Scheme 5) and decarboxylation (Step 10, Scheme 5) steps; (iii) an irreversible decarboxylation step; and (iv) $\mathrm{AcO}^{*}$ and * (bare Ti-O pairs) as the most abundant surface intermediates (MASI; from infrared spectra; Section 3.3) give the rate equation:

$$
\frac{r}{[L]}=\frac{\overrightarrow{k_{4}} \overrightarrow{k_{10}} K_{3} K_{1}^{2}\left(P_{\mathrm{acid}}\right)^{2}}{\left(\frac{\overleftarrow{k_{4}} P_{\mathrm{H} 2 \mathrm{O}}}{\prod_{z=5}^{9} K_{z}}+\overrightarrow{k_{10}}\right)\left(1+K_{1} P_{\mathrm{acid}}\right)^{2}}
$$

Here, $\overrightarrow{k_{x}}, \overleftarrow{k_{x}}$ and $K_{\mathrm{x}}$ are the respective forward and reverse rate constants and equilibrium constant for Step $x$ in Scheme 5, and $[L]$ is the number of catalytically relevant acid-base 
pairs on oxide surfaces (derivation in Section S11, SI). The weak effects of conversion and of $\mathrm{H}_{2} \mathrm{O}$ pressure $(0.02-0.2 \mathrm{kPa})$ on ketonization rates (Section S10, SI) indicate that the $\overleftarrow{k_{4}} P_{\mathrm{H} 2 \mathrm{O}}\left(\prod_{z=5}^{9} K_{z}\right)^{-1}$ term in Equation 5 is much smaller than the $\overrightarrow{k_{10}}$ constant, which indicates, in turn, that the C-C coupling step (Step 4, Scheme 5) is irreversible and the sole kinetically-relevant step. Equation 6 then becomes:

$$
\frac{r}{[L]}=\frac{\overrightarrow{k_{4}} K_{3} K_{1}^{2}\left(P_{\mathrm{acid}}\right)^{2}}{\left(1+K_{1} P_{\mathrm{acid}}\right)^{2}}
$$

The functional form of Equation 7 accurately describes all rate data for ethanoic acid at 503-533 K (Fig. 3; regressed parameters shown in Tables 2-3) and leads to isotopic effects near unity for the $\overrightarrow{k_{4}} K_{3}$ and $K_{1}$ terms in Equation $7\left(\left(\overrightarrow{k_{4}} K_{3}\right)_{\mathrm{H}} /\left(\overrightarrow{k_{4}} K_{3}\right)_{\mathrm{D}}=1.1\right.$, $\left(K_{1}\right)_{\mathrm{H}} /\left(K_{1}\right)_{\mathrm{D}}=1.0,523 \mathrm{~K}$, Table 2$)$, consistent with the kinetic relevance of the $\mathrm{C}-\mathrm{C}$ coupling step (Step 4, Scheme 5) and with the involvement of H-atoms only in quasiequilibrated steps, a conclusion confirmed by DFT treatments in Section 3.4, as also inferred above from the magnitude of the rates with perdeuterated and undeuterated reactants.

Table 2. Regressed $K_{1}, \overrightarrow{k_{4}} K_{3}, \Delta G_{\mathrm{AcO}}$ and $\Delta G_{\mathrm{CC}, \mathrm{a}}^{\star}$ values (to the functional form of Eq. 7) for ketonization of $\mathrm{C}_{2}-\mathrm{C}_{4}$ carboxylic acids on $\mathrm{TiO}_{2}$ (a) and $\mathrm{TiO}_{2}(\mathrm{r})$ catalysts. ${ }^{\mathrm{a}}$

\begin{tabular}{|c|c|c|c|c|c|}
\hline Catalyst & Reactant & $\begin{array}{r}K_{1}{ }^{\mathrm{b}} \\
\left(\mathrm{kPa}^{-1}\right) \\
\end{array}$ & $\begin{array}{l}\Delta G_{\mathrm{AcO}^{*}}{ }^{\mathrm{c}} \\
\left(\mathrm{kJ} \mathrm{mol}{ }^{-1}\right)\end{array}$ & $\begin{array}{c}\overrightarrow{k_{4}} K_{3}^{\mathrm{b}} \\
\left(10^{-6}(\mathrm{Ti}-\mathrm{O})^{-1} \mathrm{~s}^{-1}\right)\end{array}$ & $\begin{array}{r}\Delta G^{\sharp}{ }_{\mathrm{CC}, \mathrm{a}}^{\mathrm{d}} \\
\left(\mathrm{kJ} \mathrm{mol}^{-1}\right) \\
\end{array}$ \\
\hline \multirow{4}{*}{$\mathrm{TiO}_{2}(\mathrm{a})$} & $\mathrm{CH}_{3} \mathrm{COOH}$ & $24 \pm 2$ & $-33 \pm 1$ & $269 \pm 3$ & $166 \pm 1$ \\
\hline & $\mathrm{CD}_{3} \mathrm{COOD}$ & $24 \pm 2$ & $-33 \pm 1$ & $236 \pm 4$ & $167 \pm 1$ \\
\hline & $\mathrm{C}_{2} \mathrm{H}_{5} \mathrm{COOH}$ & $13 \pm 2$ & $-30 \pm 1$ & $102 \pm 3$ & $170 \pm 1$ \\
\hline & $\mathrm{C}_{3} \mathrm{H}_{7} \mathrm{COOH}$ & $7.9 \pm 0.6$ & $-28 \pm 1$ & $41 \pm 1$ & $175 \pm 1$ \\
\hline \multirow{2}{*}{$\mathrm{TiO}_{2}(\mathrm{r})$} & $\mathrm{CH}_{3} \mathrm{COOH}$ & $5.4 \pm 0.3$ & $-27 \pm 1$ & $34 \pm 1$ & $175 \pm 1$ \\
\hline & $\mathrm{CD}_{3} \mathrm{COOD}$ & $5.4 \pm 0.3$ & $-27 \pm 1$ & $30 \pm 1$ & $176 \pm 1$ \\
\hline
\end{tabular}


a $523 \mathrm{~K}$; fitted data adopted from Fig. 3a for $\mathrm{TiO}_{2}$ (a) and Fig. 4 for $\mathrm{TiO}_{2}(\mathrm{r}) .{ }^{\mathrm{b}}$ Fitted using Equation 7. ${ }^{\mathrm{c}}$ Fitted using Equation 9. ${ }^{\mathrm{d}}$ Fitted using Equation 13.

Table 3. Regressed $K_{1}, \overrightarrow{k_{4}} K_{3}, \Delta G_{\mathrm{AcO}}$, and $\Delta G^{\ddagger}$ C,a values (to the functional form of Eq. 7) for ketonization of ethanoic acid on $\mathrm{TiO}_{2}$ (a) at temperatures between 503 and $533 \mathrm{~K}$ and corresponding enthalpy and entropy components of free energies. ${ }^{a}$

\begin{tabular}{ccccccccc}
\hline$T(\mathrm{~K})$ & $\begin{array}{c}K_{1}{ }^{\mathrm{c}} \\
\left(\mathrm{kPa}^{-1}\right)\end{array}$ & $\begin{array}{c}\Delta G_{\mathrm{AcO} *}{ }^{\mathrm{d}} \\
\left(\mathrm{kJ} \mathrm{mol}^{-1}\right)\end{array}$ & $\begin{array}{c}\Delta H_{\mathrm{AcO} *} \\
\left(\mathrm{~kJ} \mathrm{~mol}^{-1}\right)\end{array}$ & $\begin{array}{c}\Delta S_{\mathrm{AcO} *} \\
\left(\mathrm{~J} \mathrm{~mol}^{-1} \mathrm{~K}^{-1}\right)\end{array}$ & $\begin{array}{c}\overrightarrow{k_{4}} K_{3}{ }^{\mathrm{c}} \\
\left(10^{-6}\left(\mathrm{Ti}^{-\mathrm{O}}\right)^{-1} \mathrm{~s}^{-1}\right)\end{array}$ & $\begin{array}{c}\Delta G^{\ddagger} \mathrm{CC}, \mathrm{a}^{\mathrm{e}} \\
\left(\mathrm{kJ} \mathrm{mol}^{-1}\right)\end{array}$ & $\begin{array}{c}\Delta H^{\ddagger} \mathrm{CC,a} \\
\left(\mathrm{kJ} \mathrm{mol}^{-1}\right)\end{array}$ & $\begin{array}{c}\Delta S_{\mathrm{CC}, \mathrm{a}} \\
\left(\mathrm{J} \mathrm{mol}^{-1} \mathrm{~K}^{-1}\right)\end{array}$ \\
\hline 503 & $71 \pm 7$ & $-36 \pm 1$ & & & $77 \pm 1$ & $165 \pm 1$ & \\
513 & $39 \pm 4$ & $-35 \pm 1$ & & & $145 \pm 3$ & $166 \pm 1$ & & \\
$523^{\mathrm{b}}$ & $24 \pm 2$ & $-33 \pm 1$ & $-114 \pm 3$ & $-155 \pm 6$ & $269 \pm 3$ & $166 \pm 1$ & & \\
533 & $15 \pm 2$ & $-32 \pm 1$ & & & $488 \pm 7$ & $167 \pm 1$ & & \\
\hline
\end{tabular}

${ }^{a}$ Fitted data adopted from Fig. 3b. ${ }^{b}$ Adopted from Table 2. ${ }^{c}$ Fitted using Equation 7. ${ }^{d}$ Fitted using Equation 9. ${ }^{\mathrm{e}}$ Fitted using Equation 13.

The $K_{1}$ term in Equation 7 determines the fractional coverage $\left(\theta_{\mathrm{AcO}^{*}}\right)$ of monodentate AcO* species bound at a Ti-O pair $\left(\theta_{\mathrm{AcO}}\right.$; Step 1 , Scheme 5):

$$
\theta_{\mathrm{AcO} *}=\frac{K_{1} P_{\mathrm{acid}}}{1+K_{1} P_{\mathrm{acid}}}
$$

The $\theta_{\mathrm{AcO}} *$ values range from 0.70 to $0.99 \mathrm{ML}(523 \mathrm{~K}, 0.1-3.0 \mathrm{kPa}$ ethanoic acid) when using $\mathrm{K}_{1}$ values from ketonization rates and the functional form of Equation 7 (24 \pm 2 $\mathrm{kPa}^{-1}$; Table 2). These values indicate that ketonization turnovers occur on $\mathrm{TiO}_{2}(\mathrm{a})$ surfaces nearly saturated with AcO* species, a conclusion confirmed by in-situ infrared data (Section 3.3) and by DFT-derived adsorption energies (Section 3.4).

Ketonization rates of propanoic and butanoic acids are also described accurately by Equation 7 (Fig. 3a). The regressed $\mathrm{K}_{1}$ values for propanoic and butanoic acids $(13 \pm 2$, $7.9 \pm 0.6 \mathrm{kPa}^{-1} ; 523 \mathrm{~K}$, Table 2$)$ also lead to near saturation coverages $\left(\theta_{\mathrm{AcO}} * 0.56-0.97\right.$, propanoic acid; 0.44-0.96, butanoic acid; $523 \mathrm{~K}, 0.1-3.0 \mathrm{kPa}$ acid). Thus, the kinetic relevance of the C-C coupling step (Step 4, Scheme 5) and the high coverages of 
monodentate carboxylates prevalent during catalysis seem to apply also for the ketonization of $\mathrm{C}_{2}-\mathrm{C}_{4}$ carboxylic acids on $\mathrm{TiO}_{2}$ (a) surfaces.

Ketonization rates for ethanoic acid- $\mathrm{d}_{0}$ and ethanoic acid- $\mathrm{d}_{4}$ on rutile $\mathrm{TiO}_{2}$ powders $\left(\mathrm{TiO}_{2}(\mathrm{r})\right)$ are also consistent with the functional form of Equation 7 (Fig. 4; Table 2); these reactants give $\mathrm{H} / \mathrm{D}$ isotope effects near unity for both $\overrightarrow{k_{4}} K_{3}$ and $K_{1}$ $\left(\left(\overrightarrow{k_{4}} K_{3}\right)_{\mathrm{H}} /\left(\overrightarrow{k_{4}} K_{3}\right)_{\mathrm{D}}=1.1,\left(K_{1}\right)_{\mathrm{H}} /\left(K_{1}\right)_{\mathrm{D}}=1.0\right.$, Table 2$)$, indicative of similar pathways and active Ti-O pairs on $\mathrm{TiO}_{2}(\mathrm{r})$ and $\mathrm{TiO}_{2}(\mathrm{a})$. The regressed values of $\mathrm{K}_{1}\left(5.4\right.$ vs. $24 \mathrm{kPa}^{-1}$ ) and $\overrightarrow{k_{4}} K_{3}\left(3.4 \times 10^{-5}\right.$ vs. $\left.2.7 \times 10^{-4}(\mathrm{Ti}-\mathrm{O})^{-1} \mathrm{~s}^{-1}\right)$ are, however, much smaller on $\mathrm{TiO}_{2}(\mathrm{r})$ than on $\mathrm{TiO}_{2}(\mathrm{a})$. Infrared spectra of $\mathrm{TiO}_{2}(\mathrm{r})$ during ketonization show that $\mathrm{TiO}_{2}(\mathrm{r})$ samples are covered with bidentate carboxylates bound at two vicinal Ti-O pairs $(* \mathrm{AcO} *$; 0.2-1.6 kPa ethanoic acid, $523 \mathrm{~K}$; Section 3.3), inconsistent with the high coverages of AcO* $\left(\theta_{\mathrm{AcO}^{*}} 0.52-0.90\right.$; Eq.8) predicted from $\mathrm{K}_{1}$ values regressed from rate data $(5.4 \pm$ $0.3 \mathrm{kPa}^{-1}$, Table 2). Such discrepancies indicate that ketonization does not take place on the majority low-index planes of $\mathrm{TiO}_{2}(\mathrm{r})$, the coverage on which is reflected in the infrared spectra, leading us to conclude, as in the case of aldol condensation of carbonyl compound on these materials [24], that it occurs instead on minority exposed planes of $\mathrm{TiO}_{2}$ (r) or on residual $\mathrm{TiO}_{2}$ (a) surfaces. This speculative hypothesis is confirmed by DFT-derived energies of ketonization elementary steps on $\mathrm{TiO}_{2}(\mathrm{r})$ (Section 3.4), which show a preference for $* \mathrm{AcO}^{*}$ over $\mathrm{AcO}^{*}$ species on $\mathrm{TiO}_{2}(\mathrm{r})$ surfaces and predict much lower ketonization rates on $\mathrm{TiO}_{2}(\mathrm{r})$ than on $\mathrm{TiO}_{2}(\mathrm{a})$. 


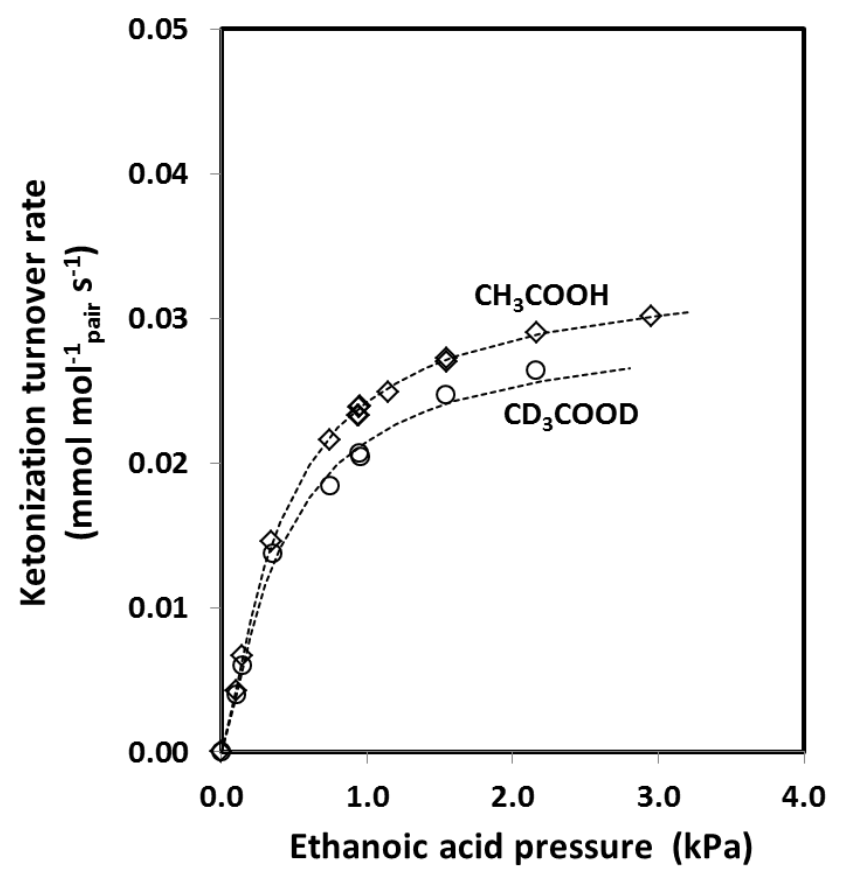

Figure 4. Effects of ethanoic acid pressure on ketonization turnover rates (ethanoic acid and ethanoic acid- $\mathrm{d}_{4} ; \mathrm{TiO}_{2}(\mathrm{r})+20 \%$ wt. $\mathrm{Cu} / \mathrm{SiO}_{2}\left(1: 1\right.$ mass), $523 \mathrm{~K}, 20 \mathrm{kPa} \mathrm{H}_{2}$ for undeuterated reactants, $20 \mathrm{kPa} \mathrm{D}_{2}$ for deuterated reactants). Dashed lines represent the regressed fits to the mechanism-based functional form of Equation 7.

The $K_{1}$ term in Equation 7 reflects the free energy of carboxylic acid dissociation to form a monodentate carboxylate on a Ti-O pair ( $\Delta G_{\mathrm{AcO}^{*}}$, Scheme 6$)$ :

$$
\begin{aligned}
K_{1} & =\exp \left(-\Delta G_{\mathrm{AcO} *} / R T\right) \\
\Delta G_{\mathrm{AcO} *} & =G_{A c O *}-G_{\text {acid }}-G_{T i-O}
\end{aligned}
$$

Here $G_{\mathrm{AcO}^{*}}, G_{\text {acid }}$, and $G_{\mathrm{Ti}-\mathrm{O}}$ are the free energies of the bound monodentate carboxylate (Step 1, Scheme 5), the gaseous carboxylic acid, and the Ti-O pair. The $\overrightarrow{k_{4}} K_{3} K_{1}^{2}$ numerator term in Equation 7 reflects, in turn, the free energy difference between the C-C coupling TS ( $G^{\ddagger}$ CC; Step 4, Scheme 5) and two gaseous acid reactants and two bare Ti-O pairs $\left(\Delta G^{\ddagger}\right.$ CC, Scheme 6):

$$
\begin{gathered}
\overrightarrow{k_{4}} K_{3} K_{1}^{2}=\frac{k_{\mathrm{B}} T}{h} \exp \left(-\Delta G_{\mathrm{CC}}^{\ddagger} / R T\right) \\
\Delta G_{\mathrm{CC}}^{\ddagger}=G_{\mathrm{CC}}^{\ddagger}-2 G_{\text {acid }}-2 G_{T i-O}
\end{gathered}
$$


The $\overrightarrow{k_{4}} K_{3}$ term, determined from measured $\overrightarrow{k_{4}} K_{3} K_{1}^{2}$ (Eq. 11) and $K_{1}$ (Eq. 9) values, represents the maximum ketonization turnover rate $\left(r_{\max }\right)$; it is achieved as monodentate $\mathrm{AcO}^{*}$ species reach saturation coverages:

$$
r_{\text {max }}=\overrightarrow{k_{4}} K_{3}=\frac{k_{\mathrm{B}} T}{h} \exp \left(-\Delta G_{\mathrm{CC}, \mathrm{a}}^{\ddagger} / R T\right)
$$

Here $\Delta G^{\ddagger} \mathrm{CC}$, two bound $\mathrm{AcO}^{*}$ species on $\mathrm{TiO}_{2}$ (a) surfaces (Scheme 6):

$$
\Delta G_{\mathrm{CC}, \mathrm{a}}^{\ddagger}=G_{\mathrm{CC}}^{\ddagger}-2 G_{\mathrm{AcO} *}
$$

Table 2 reports $\Delta G_{\mathrm{AcO}^{*}}$ and $\Delta G^{\ddagger}$ CC,a values from the $K_{1}$ and $\overrightarrow{k_{4}} K_{3}$ parameters from all rate data regressed to the functional form of Equation 6 for $\mathrm{C}_{2}-\mathrm{C}_{4}$ carboxylic acids on $\mathrm{TiO}_{2}$ (a). The $\Delta G_{\mathrm{AcO}} *$ values ( $523 \mathrm{~K}$; Table 2 ) become less negative as the alkyl chain in the carboxylic acid lengthens $\left(-33 \pm 1 \mathrm{~kJ} \mathrm{~mol}^{-1}\right.$, ethanoic acid; $-28 \pm 1 \mathrm{~kJ} \mathrm{~mol}^{-1}$, butanoic acid), indicative of steric effects that weaken $\mathrm{AcO}^{*}$ binding at the nearly saturated $\mathrm{TiO}_{2}(\mathrm{a})$ surfaces present during ketonization catalysis.

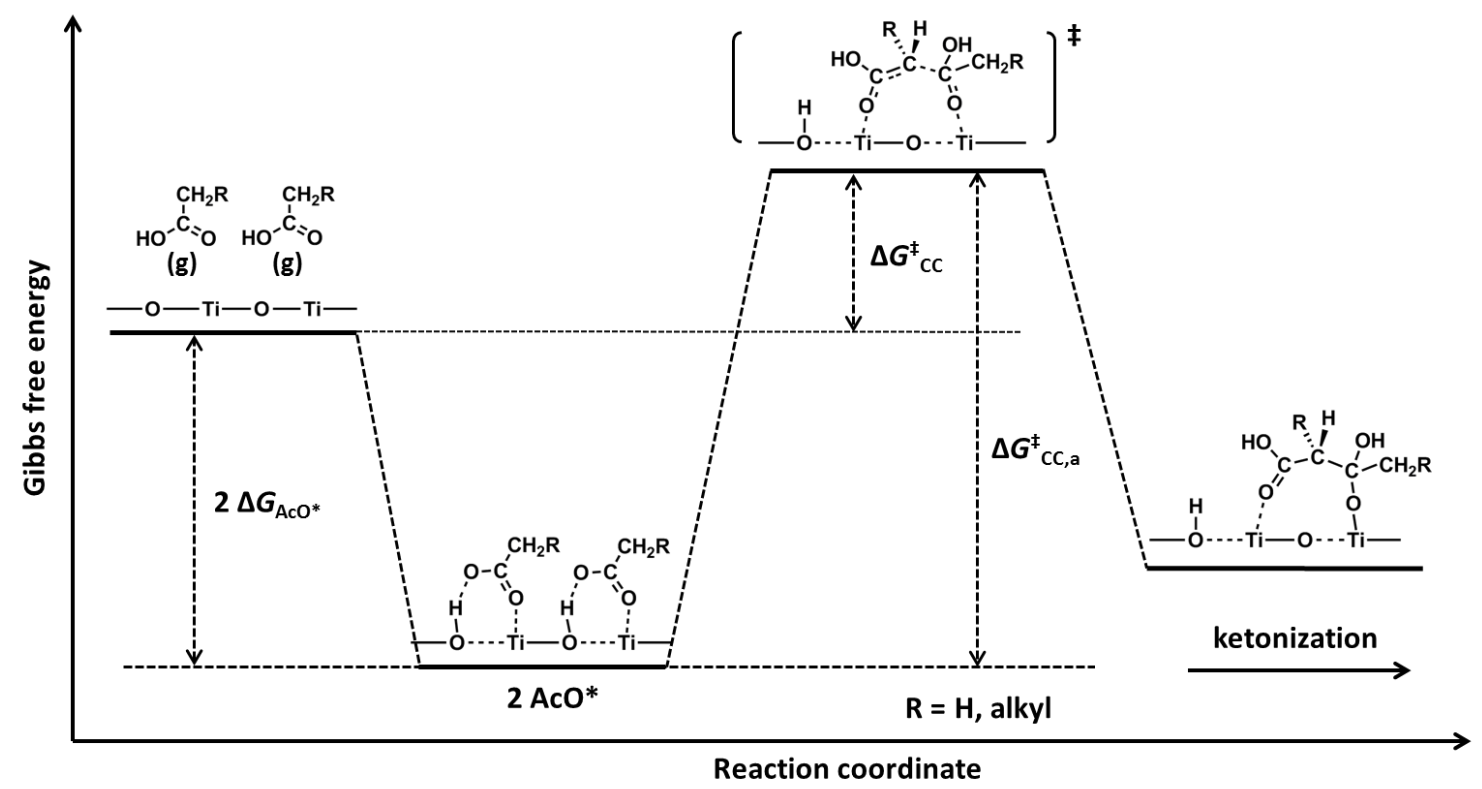

Scheme 6. Schematic reaction coordinate diagram for carboxylic acid ketonization on $\mathrm{TiO}_{2}$ (a). 
$\Delta G^{\ddagger}$ CC,a values (523 K; Table 2) became more positive with increasing alkyl chain length (166 $\pm 1 \mathrm{~kJ} \mathrm{~mol}^{-1}$, ethanoic acid; $175 \pm 1 \mathrm{~kJ} \mathrm{~mol}^{-1}$, butanoic acid). These trends reflect, in part, the stronger steric hindrance imposed by the larger alkyl groups in the 1hydroxy enolate and coadsorbed AcO* components of the C-C coupling TS than for its two AcO* precursors (Step 4, Scheme 5); they also arise, to some extent, from electrondonating alkyl substituents that make the $\alpha$-C-atom in 1-hydroxy enolate a weaker nucleophile [51]. Alkyl substituents have the opposite effects on the decarboxylation of $\beta$-keto carboxylates (Step 10, Scheme 5) than on the C-C coupling step. Stronger repulsion between the larger alkyl groups at the $\alpha-\mathrm{C}$ and $\beta$-C positions of $\beta$-keto carboxylates favor $\mathrm{CO}_{2}$ elimination. The alkyl group at the $\alpha-\mathrm{C}$ position also stabilizes the decarboxylation TS via $\mathrm{p}-\pi$ conjugation with the incipiently formed $\mathrm{C}=\mathrm{C}$ bond. The consequent higher decarboxylation rates as alkyl chains lengthen provides additional evidence for the kinetic irrelevance of this step, because measured $\Delta G^{\ddagger} \mathrm{CC}$,a values increase with increasing alkyl substitution (Table 2).

The enthalpy and entropy components of measured $\Delta G_{\mathrm{AcO}^{*}}$ and $\Delta G^{\ddagger} \mathrm{CC}, \mathrm{a}$ values for ethanoic acid were obtained by regressing the rate and equilibrium constants in Equation 7 from rate data at different temperatures $(503-533 \mathrm{~K} ; \Delta G=\Delta H-T \Delta S$; Table 3). The $\Delta H_{\mathrm{AcO}}$ and $\Delta S_{\mathrm{AcO}} *$ values for the adsorption of ethanoic acid as monodentate carboxylates on $\mathrm{TiO}_{2}$ (a) are $-114 \pm 3 \mathrm{~kJ} \mathrm{~mol}^{-1}$ and $-155 \pm 6 \mathrm{~J} \mathrm{~mol}^{-1} \mathrm{~K}^{-1}$, respectively (Table 3), reflecting the predominant enthalpic component in $\Delta G_{\mathrm{AcO}^{*}}$ values at these temperatures. Measured $\Delta H^{\ddagger} \mathrm{CC}$,a and $\Delta S^{\ddagger} \mathrm{CC}$,a values for ethanoic acid ketonization on $\mathrm{TiO}_{2}$ (a) are $137 \pm 1 \mathrm{~kJ} \mathrm{~mol}^{-1}$ and $-56 \pm 1 \mathrm{~J} \mathrm{~mol}^{-1} \mathrm{~K}^{-1}$ (Table 3). These enthalpy and entropy values, taken together with the respective free energies, allow accurate benchmarking of experimental and theoretical methods in determining the preferred 
ketonization pathways and the kinetic relevance of the steps and intermediates that mediate ketonization turnovers on $\mathrm{TiO}_{2}$ (a) surfaces (Section 3.4).

The evidence presented above indicates that ketonization of $\mathrm{C}_{2}-\mathrm{C}_{4}$ carboxylic acids proceeds via kinetically-relevant C-C coupling transition states on Ti-O pairs of $\mathrm{TiO}_{2}(\mathrm{a})$ surfaces essentially saturated with monodentate carboxylates bound at acid-base pairs. These conclusions are confirmed below by the infrared detection of the adsorbed species prevalent during ketonization catalysis (Section 3.3) and by theoretical assessments of the stability of adsorbed species and transition states over a broad range of surface coverages (1/8-1 ML) (Section 3.4).

\subsection{Infrared study of adsorbed species derived from ethanoic acid adsorption on anatase} and rutile $\mathrm{TiO}_{2}$ at catalytic temperatures.

Infrared spectra were collected during ethanoic acid ketonization on $\mathrm{TiO}_{2}(\mathrm{a})$ and $\mathrm{TiO}_{2}(\mathrm{r})$ at $523 \mathrm{~K}$ and $0.2-1.6 \mathrm{kPa}$ ethanoic acid in order to assess the type, coverage, and kinetic involvement of adsorbed species. Ethanoic acid $(\mathrm{AcOH})$ can dissociate to form monodentate (AcO*; Step 1, Scheme 5) or bidentate (*AcO*; Step 2, Scheme 5) carboxylates at one or two Ti-O pairs; it can also bind molecularly via H-bonding at a Ti$\mathrm{O}$ pair $\left(\mathrm{AcOH}^{*}\right)$ [3]. DFT-derived binding energies show that the relative coverages of $\mathrm{AcO}^{*}$ and $\mathrm{AcOH}^{*}$ depend the strength of the basic lattice $\mathrm{O}$-atom (Scheme 3.4). $\mathrm{AcO} *$ is much more stable than $\mathrm{AcOH}^{*}$ on Ti-O pairs in $\mathrm{TiO}_{2}(\mathrm{a})$; in contrast, $\mathrm{AcOH}^{*}$ is the most stable monodentate form on $\mathrm{TiO}_{2}(\mathrm{r})$, because its coordinatively-unsaturated $\mathrm{O}$-atoms are more weakly basic than those on $\mathrm{TiO}_{2}$ (a) ( $E_{\mathrm{PA}}-1097$ vs. -1175 ; Scheme 3.4$)$. These carboxylate and molecular forms can be distinguished by stretching modes of their respective carboxyl or carboxylate moieties $(-\mathrm{C}(=\mathrm{O}) \mathrm{OH},-\mathrm{C}(=\mathrm{O}) \mathrm{O}-)$. AcOH* binds with 
its $\mathrm{O}$-atom at the $\mathrm{Ti}$ center of a Ti-O pair and its hydroxy $\mathrm{H}$-atom at the $\mathrm{O}$-atom of this Ti-O pair (Scheme 7a). AcO* species binds in monodentate form with its two O-atoms at the Ti center of a Ti-O pair and at the abstracted $\mathrm{H}$-atom, which is bound at the $\mathrm{O}$-atom in the Ti-O pair (Scheme $7 b$ ). In contrast, ${ }^{*} \mathrm{AcO}^{*}$ species binds in bidentate form with each of its two O-atoms at one Ti center in two vicinal Ti-O pairs (Scheme 7c).

(a) $\mathrm{ACOH}^{*}$ on a single $\mathrm{Ti}-\mathrm{O}$ pair

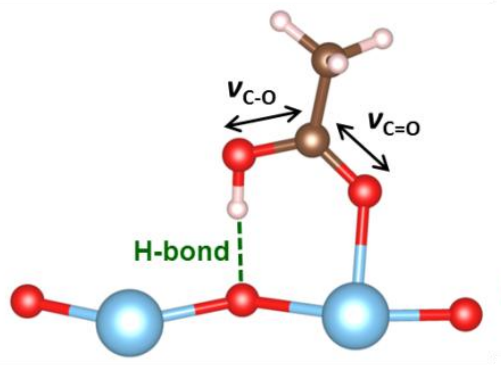

(b) $\mathrm{ACO}^{*}$ on a single Ti-O pair

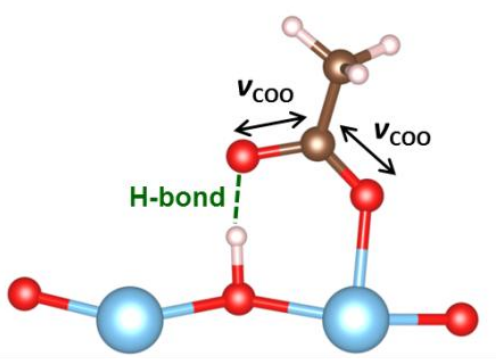

(c) *AcO* on two vicinal Ti-O pairs

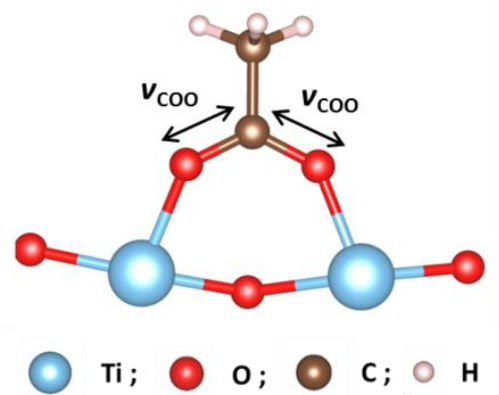

Scheme 7. DFT-derived adsorption modes for ethanoic acid on Ti-O pairs (PBE+D3BJ, PAW, $\mathrm{TiO}_{2}$ (a) (101) surfaces).

DFT-derived vibrational frequencies for these modes were used to assign these bands and to determine the relative stability of these species as a function of coverage on $\mathrm{TiO}_{2}$ surfaces. Surface coverages $\left(\theta_{\text {acid }}\right)$ are defined here based on Ti-O pairs:

$$
\theta_{\text {acid }}=\frac{n_{\mathrm{acid}}}{n_{\mathrm{Ti}-\mathrm{O}}}
$$

where $n_{\text {acid }}$ is the number of adsorbed carboxylic acid molecules and $n_{\text {Ti-O }}$ is the number of exposed Ti-O pairs. The maximum $\theta_{\text {acid }}$ value for each form is set by their respective binding stoichiometries ( 1 for $\mathrm{AcOH}^{*}$ and $\mathrm{AcO}^{*}, 1 / 2$ for $* \mathrm{AcO}^{*}$ ). DFT-derived frequencies for $\mathrm{C}=\mathrm{O}$ and $\mathrm{C}-\mathrm{O}$ stretches of $\mathrm{AcOH}^{*}$ on $\mathrm{TiO}_{2}(\mathrm{a})$ are $1641-1659 \mathrm{~cm}^{-1}$ and 1480-1493 $\mathrm{cm}^{-1}$, respectively (at 1/6-1 ML; Table 4). The antisymmetric $v_{\mathrm{COO}}\left(v_{\mathrm{COO}, \mathrm{as}}\right)$ and symmetric $v_{\mathrm{COO}}\left(v_{\mathrm{COO}, \mathrm{s}}\right)$ vibrations in $\mathrm{AcO}^{*}$ on $\mathrm{TiO}_{2}(\mathrm{a})$ appear at $1540-1564 \mathrm{~cm}^{-1}$ and 
$1379-1409 \mathrm{~cm}^{-1}$, respectively (at 1/6-1 ML; Table 4); these frequencies are at $1529-1531$ $\mathrm{cm}^{-1}\left(v_{\mathrm{COO}, \mathrm{as}}\right)$ and $1435-1437 \mathrm{~cm}^{-1}\left(v_{\mathrm{COO}, \mathrm{s}}\right)$ for $* \mathrm{AcO}^{*}$ (at 1/8-1/2 ML; Table 4).

Table 4. DFT-derived frequencies for $\mathrm{AcOH}^{*}, \mathrm{AcO}^{*}$, and $* \mathrm{AcO}^{*}$ on $\mathrm{TiO}_{2}$ surfaces. ${ }^{\mathrm{a}}$

\begin{tabular}{|c|c|c|c|c|c|}
\hline Oxide & Mode & $\theta_{\text {acid }}$ range (ML) & & equency $(\mathrm{cm}$ & \\
\hline \multirow{5}{*}{$\mathrm{TiO}_{2}(\mathrm{a})$} & & & $v_{\mathrm{C}=\mathrm{O}}$ & $v_{\mathrm{C}-\mathrm{O}}$ & $v_{\mathrm{CH} 3}$ \\
\hline & $\mathrm{AcOH}^{*}$ & $1 / 6-1$ & $1641-1659$ & $1480-1493$ & 2985-2991 \\
\hline & & & $v_{\mathrm{COO}, \mathrm{as}}$ & $v_{\mathrm{COO}, \mathrm{s}}$ & $v_{\mathrm{CH} 3}$ \\
\hline & $\mathrm{AcO}^{*}$ & $1 / 6-1$ & $1540-1564$ & 1379-1409 & $2982-2990$ \\
\hline & $* \mathrm{AcO}^{*}$ & $1 / 8-1 / 2$ & $1529-1531$ & $1435-1437$ & $2988-2990$ \\
\hline \multirow{4}{*}{$\mathrm{TiO}_{2}(\mathrm{r})^{\mathrm{b}}$} & & & $v_{\mathrm{C}=\mathrm{O}}$ & $v_{\mathrm{C}-\mathrm{O}}$ & $v_{\mathrm{CH} 3}$ \\
\hline & $\mathrm{AcOH}^{*}$ & $1 / 4-1$ & $1584-1604$ & $1473-1485$ & 2989-2997 \\
\hline & & & $v_{\mathrm{COO}, \mathrm{as}}$ & $v_{\mathrm{COO}, \mathrm{s}}$ & $v_{\mathrm{CH} 3}$ \\
\hline & $* \mathrm{AcO}^{*}$ & $1 / 8-1 / 2$ & $1514-1522$ & $1432-1444$ & 2989-2993 \\
\hline
\end{tabular}

${ }^{\mathrm{a}} \mathrm{PBE}+\mathrm{D} 3 \mathrm{BJ}, \mathrm{PAW}$, using $\mathrm{TiO}_{2}$ (a) (101) and $\mathrm{TiO}_{2}$ (r) (110) surfaces as the respective models; computational details described in Section 2.4. ${ }^{\mathrm{b}}$ No stable $\mathrm{AcO} *$ structures can be isolated during energy and geometry optimizations because of the weak nature of the $\mathrm{O}$-atoms on $\mathrm{TiO}_{2}(\mathrm{r})$ surfaces.

The infrared spectra on $\mathrm{TiO}_{2}(\mathrm{a})$ after treatments of $\mathrm{He}$ at $573 \mathrm{~K}$ for $2 \mathrm{~h}$ exhibit $\mathrm{O}-\mathrm{H}$ bands (3667 $\mathrm{cm}^{-1}$; Fig. 5a), assigned to titanol species at surface defects ubiquitous on oxide crystallites $[52,53]$. Contact with ethanoic acid $(1.0 \mathrm{kPa})$ at $523 \mathrm{~K}$ caused these $\mathrm{O}-$ $\mathrm{H}$ bands on $\mathrm{TiO}_{2}$ (a) surfaces to shift to lower wavenumbers and to merge with a broader and more intense band centered at $3150 \mathrm{~cm}^{-1}$, which is assigned to $\mathrm{OH}$ species derived from the dissociation of ethanoic acid to form either $\mathrm{AcO}^{*}$ or *AcO* (Schemes 7b-c); such a frequency shift relative to isolated $\mathrm{Ti}-\mathrm{OH}$ species reflects the effects of $\mathrm{H}$-bonding [22] at the prevalent dense adlayers. These isolated titanols are present as minority species and are thus not explicitly considered as active structures in the DFT treatments of ketonization elementary steps (Section 3.4). 

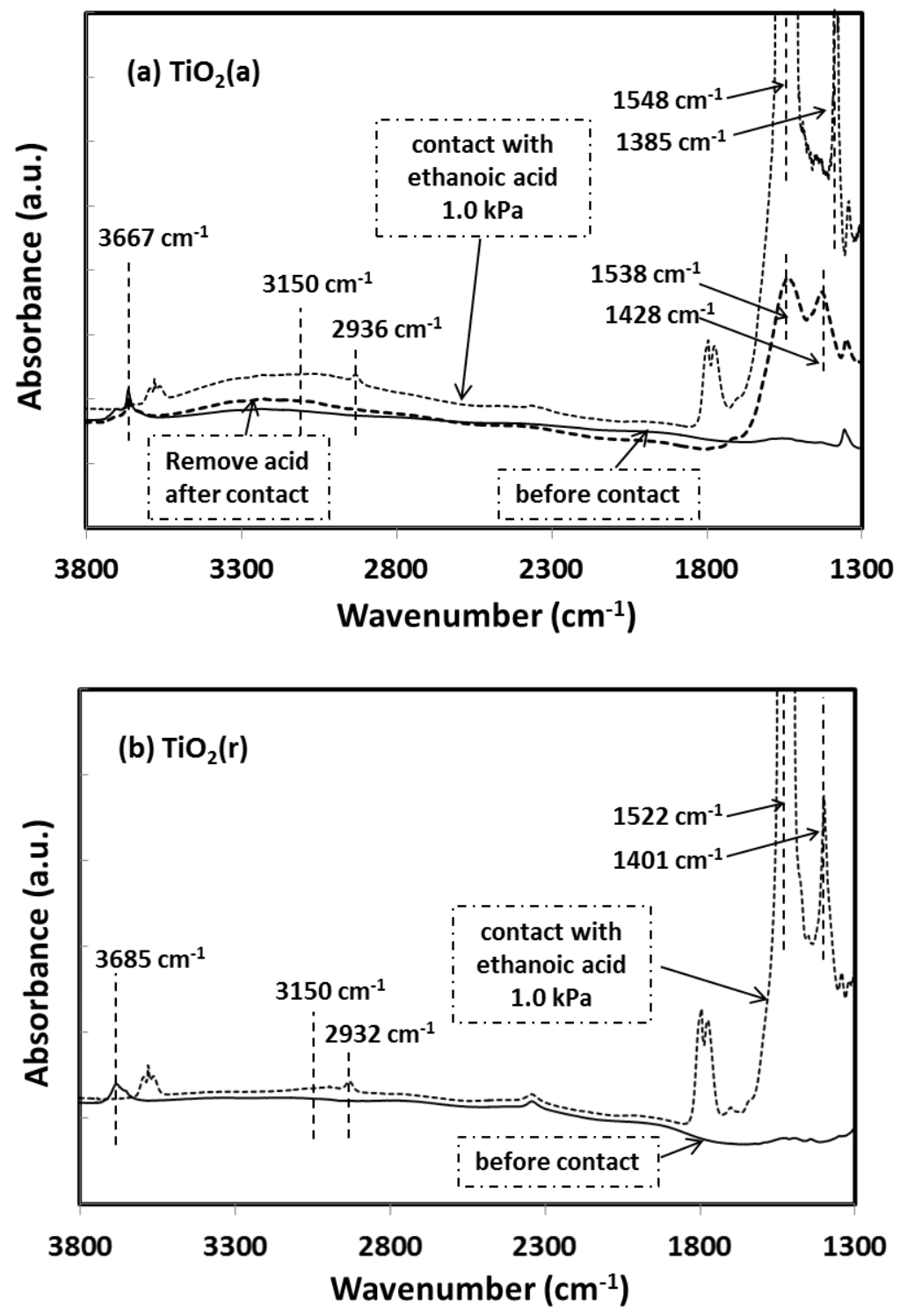

Figure 5. IR spectra of (a) $\mathrm{TiO}_{2}(\mathrm{a})$ and (b) $\mathrm{TiO}_{2}(\mathrm{r})$ with $1.0 \mathrm{kPa}$ ethanoic acid during steady-state ketonization at $523 \mathrm{~K}$ (spectra before and after the acid contact shown as reference).

Three distinct bands appeared upon contact of $\mathrm{TiO}_{2}$ (a) with ethanoic acid at $523 \mathrm{~K}$ $\left(2936,1548\right.$, and $\left.1385 \mathrm{~cm}^{-1}\right)$ together with those for the gaseous reactants $(3596,3581$, $\left.3566,1796,1776 \mathrm{~cm}^{-1}\right)[53]$ and the $\mathrm{CO}_{2}(\mathrm{~g})$ ketonization product $\left(2362 \mathrm{~cm}^{-1}\right)$ [54]. DFT treatments show that the bands at 1548 and $1385 \mathrm{~cm}^{-1}$ correspond to $v_{\mathrm{COO} \text {,as }}$ and $v_{\mathrm{COO}, \mathrm{s}}$ vibrations in AcO*, respectively (DFT: $1540-1564 \mathrm{~cm}^{-1}, 1379-1409 \mathrm{~cm}^{-1}$; Table 4). The band at $2936 \mathrm{~cm}^{-1}$ corresponds to the $-\mathrm{CH}_{3}$ stretch $\left(v_{\mathrm{CH} 3}\right)$ in AcO* (DFT: $2982-2990 \mathrm{~cm}^{-1}$; 
Table 4) [55]. The frequencies of these $v_{\mathrm{COO}, \mathrm{as}}$ and $v_{\mathrm{COO}, \mathrm{s}}$ bands were essentially unperturbed by changes in ethanoic acid pressure (0.2-1.6 kPa; Fig. 6a), indicating that $\mathrm{AcO}^{*}$ is the predominant carboxylate and that it is present at near-saturation coverages on $\mathrm{TiO}_{2}$ (a) at all conditions. The intensity of the $-\mathrm{CH}_{3}$ stretch band increased with increasing ethanoic acid pressure in a Langmuir manner (Fig. 6a; Eq. 8) with a $K_{1}$ value $\left(24 \pm 3 \mathrm{kPa}^{-1}\right.$, Fig. 6a) that is similar to that derived from ketonization rate data and Equation $6\left(24 \pm 2 \mathrm{kPa}^{-1}\right.$, Table 2; Fig. 3a). These $K_{1}$ values show that monodentate carboxylates $\left(\mathrm{AcO}^{*}\right)$ are present at high coverages $\left(\theta_{\mathrm{AcO}^{*}} 0.83-0.97 \mathrm{ML}\right)$ as the predominant adsorbed species on $\mathrm{TiO}_{2}(\mathrm{a})$ at all conditions of relevant ketonization catalysis.

The removal of ethanoic acid from the contacting gas phase led to the gradual disappearance of the bands for $\mathrm{AcO}^{*}$ and $\mathrm{CO}_{2}(\mathrm{~g})$ on $\mathrm{TiO}_{2}$ (a) samples (Fig. 5a) over $2 \mathrm{~h}$ at $523 \mathrm{~K}$ and to the concurrent appearance of bands at 1538 and $1428 \mathrm{~cm}^{-1}$ (Fig. 5a); these bands correspond to $v_{\mathrm{COO}, a s}$ and $v_{\mathrm{COO}, \mathrm{s}}$ stretches in bidentate carboxylates $\left({ }^{*} \mathrm{AcO} \mathrm{O}^{*}\right)$ according to DFT estimates $\left(1529-1531 \mathrm{~cm}^{-1}, 1435-1437 \mathrm{~cm}^{-1}\right.$; Table 4). The intensity of these *AcO* bands decreased very gradually with time and the bands became undetectable after treatment in $\mathrm{He}$ at $523 \mathrm{~K}$ for $26 \mathrm{~h}$. These treatments in $\mathrm{He}$ at $523 \mathrm{~K}$ also led to the full recovery of initial ketonization rates on $\mathrm{TiO}_{2}$ (a) samples deactivated (for 22 $\mathrm{h}$ to 0.76 of initial rates; $523 \mathrm{~K}, 1.0 \mathrm{kPa}$ ethanoic acids; Section 3.1). The recombinative desorption of the active $\mathrm{AcO}^{*}$ species leads to a decrease in their coverage with time; the concomitant increase in vacant sites $(*)$ then allow the gradual formation of *AcO* as the stable form of adsorbed ethanoic acid on $\mathrm{TiO}_{2}$ (a) surfaces. The slow removal of these *AcO* species in an inert environment is consistent with the nature of the regeneration treatments that led to the recovery of initial ketonization rates on deactivated samples and 
also with the proposal that bidentate carboxylates act as unreactive spectator species that prevent access to the Ti-O pairs required for ketonization turnovers.
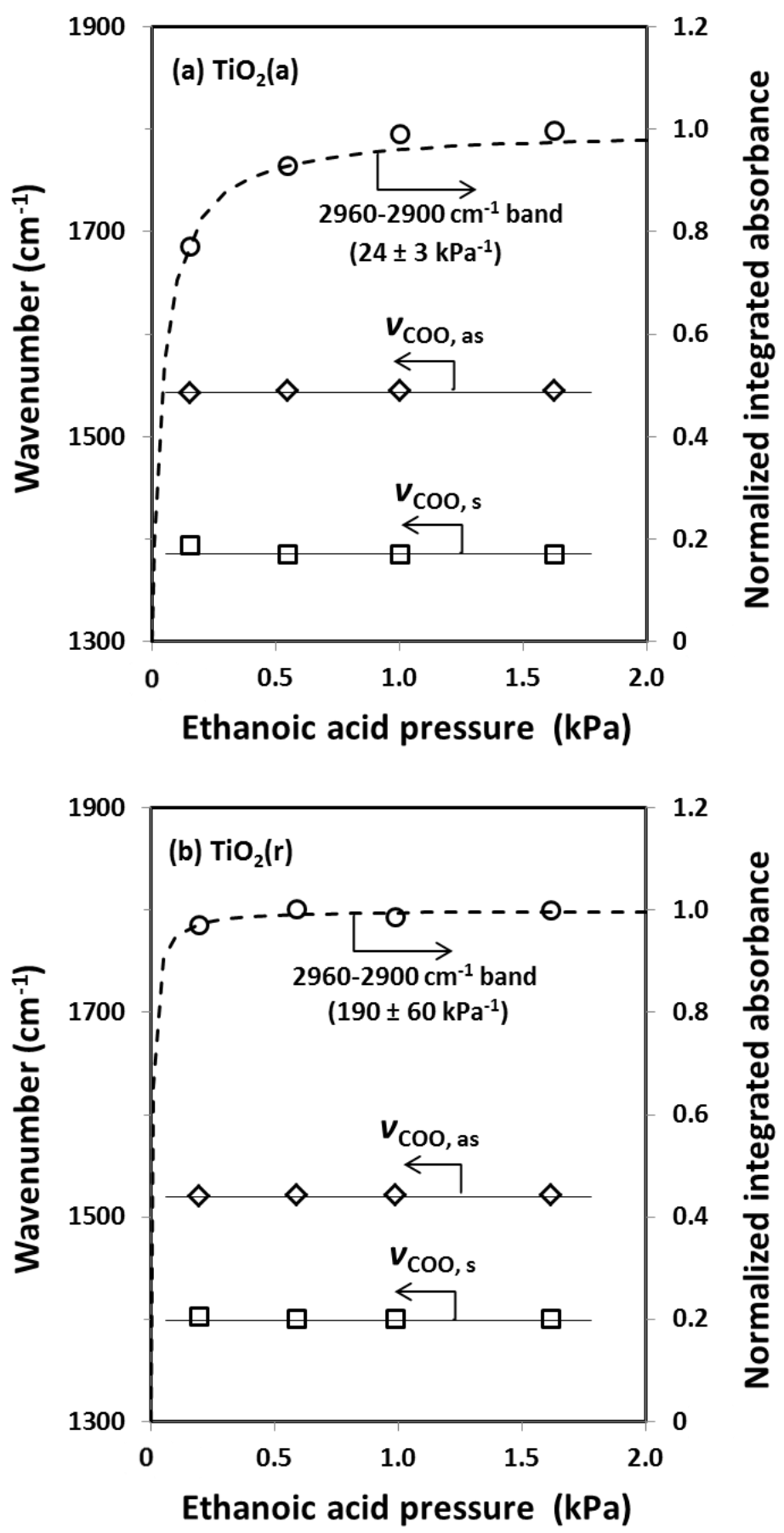

Figure 6. Frequencies for $v_{\mathrm{COO}, \text { as }}$ and $v_{\mathrm{COO}, \mathrm{s}}$ bands and the integrated intensity of the infrared bands for adsorbed ethanoic acid $\left(2960-2900 \mathrm{~cm}^{-1}\right)$ on (a) $\mathrm{TiO}_{2}$ (a) and (b) $\mathrm{TiO}_{2}(\mathrm{r})$ as a function of ethanoic acid pressure $(523 \mathrm{~K})$. The integrated intensities were normalized by their maximum values $(1.6 \mathrm{kPa})$. Solid lines indicate qualitative trends. 
Dashed curves represent the regressed fits to the functional form of Equation 8 with the regressed parameter $K_{1}$ shown in parenthesis.

Exposure of $\mathrm{TiO}_{2}(\mathrm{r})$ to gaseous ethanoic acid $(1.0 \mathrm{kPa}, 523 \mathrm{~K}$; Fig. $5 \mathrm{~b})$ led to bands similar to those observed on $\mathrm{TiO}_{2}(\mathrm{a})$, but at lower frequencies $\left(1522,1401 \mathrm{~cm}^{-1}\right)$. These bands correspond to $v_{\mathrm{COO} \text {,as }}$ and $v_{\mathrm{COO}, \mathrm{s}}$ stretches in bidentate carboxylates $\left({ }^{*} \mathrm{AcO}^{*}\right)$, an assignment based on DFT-derived frequencies $\left(1514-1522 \mathrm{~cm}^{-1}, 1432-1444 \mathrm{~cm}^{-1}\right.$, Table 4) and on spectroscopic and theoretical evidence for the prevalence of *AcO* over $\mathrm{AcOH}^{*}$ and $\mathrm{AcO}^{*}$ on $\mathrm{TiO}_{2}(\mathrm{r})[3,52]$. These $v_{\mathrm{COO} \text {,as }}$ and $v_{\mathrm{COO}, \mathrm{s}}$ frequencies did not change with ethanoic acid pressure (0.2-1.6 kPa; Fig. 6b) or after removal of ethanoic acid from contact with the catalysts for $0.5 \mathrm{~h}$ (Section S12, SI); thus, we conclude that bidentate carboxylates $\left(* \mathrm{AcO}^{*}\right)$ are the MASI on $\mathrm{TiO}_{2}(\mathrm{r})$ during ketonization catalysis, in distinct contrast with the prevalence of monodentate $\mathrm{AcO}^{*}$ species on $\mathrm{TiO}_{2}(\mathrm{a})$ surfaces. The integrated intensity of the $v_{\mathrm{CH} 3}$ band $\left(2932 \mathrm{~cm}^{-1}\right)$ on $\mathrm{TiO}_{2}(\mathrm{r})$ was unaffected by the ethanoic acid pressure (0.2-1.6 kPa; Fig. 6b), indicative of the presence of *AcO* species at near saturation coverages. The regressed fits of these coverages on $\mathrm{TiO}(\mathrm{r})$ to the Langmuir form of Equation 8 give a $K_{1}$ value of $190 \pm 3 \mathrm{kPa}^{-1}$ (Fig. 6b), a value that differs markedly from that derived from the rate data and Equation 7 on $\mathrm{TiO}_{2}(\mathrm{r})(5.4 \pm$ $0.3 \mathrm{kPa}^{-1}$, Table 2; Fig. 4). Thus, the species detected in the infrared spectra on $\mathrm{TiO}_{2}(\mathrm{r})$ surfaces differ from those that account for the denominator term in Equation 7. These different $K_{1}$ values can only be reconciled by considering the carboxylate species that occupy the Ti-O pairs responsible for catalytic turnovers to be present only as minority species, with the bidentate carboxylates prevalent in the infrared spectra as the majority species but without their detectable catalytic involvement. 
We conclude based on this evidence that ketonization reactivity reflects such minority sites and that they are likely to reflect the presence of anatase-like structures in these $\mathrm{TiO}_{2}(\mathrm{r})$. Ultraviolet Raman spectra have shown that the phase transformation from anatase to rutile $\mathrm{TiO}_{2}$ requires a higher temperature at the surface than in the bulk crystal ( 973 vs. $823 \mathrm{~K}$ ) [56], indicating that anatase-like structures may be retained at the surface of some of the crystallites present in $\mathrm{TiO}_{2}(\mathrm{r})$ samples even after the bulk of most crystals has converted to the rutile structure. These conclusions are consistent with the lower turnover rates observed on $\mathrm{TiO}_{2}(\mathrm{r})$ compared with $\mathrm{TiO}_{2}(\mathrm{a})$ and with DFT-derived energetics that would lead to areal ketonization rates on $\mathrm{TiO}_{2}(\mathrm{r})$ (110) surfaces even lower than those measured on $\mathrm{TiO}_{2}(\mathrm{r})$ powders (Section 3.4).

These spectra and their theoretical analysis indicate that monodentate $\mathrm{AcO}^{*}$ species predominate on $\mathrm{TiO}_{2}$ (a) and act as reactive intermediates in ketonization turnovers. Bidentate $* \mathrm{AcO}^{*}$ species prevail on $\mathrm{TiO}_{2}(\mathrm{r})$ but are not involved in ketonization turnovers. These data and conclusions contradict the previously proposed involvement of bidentate carboxylates $\left({ }^{*} \mathrm{AcO}{ }^{*}\right)$ as reactive intermediates in ketonization turnovers on $\mathrm{TiO}_{2}$ and $\mathrm{ZrO}_{2}$ surfaces $[14,16-21]$. These unreactive bidentate species desorb slowly as gaseous ketene molecules; their scavenging by hydrogenation on $\mathrm{Cu}$ sites accounts for both the formation of ethanal and ethanol and for the inhibition of deactivation brought forth by the presence of gaseous $\mathrm{H}_{2}$ and a $\mathrm{Cu}$ function during ketonization of ethanoic acid on $\mathrm{TiO}_{2}$ and $\mathrm{ZrO}_{2}$ (Section 3.1).

\subsection{Theoretical assessment of ketonization elementary steps and adsorbed species on} anatase and rutile $\mathrm{TiO}_{2}$ surfaces 
$\mathrm{TiO}_{2}(\mathrm{a})$ and $\mathrm{TiO}_{2}(\mathrm{r})$ surfaces preferentially expose their most stable (101) and (110) planes, respectively [40]. These surface planes are used here as periodic slab models in DFT estimates of the binding and reactive properties of Ti-O pairs. We address the involvement of Ti-O pairs in the stabilization of adsorbed species and transition states involved in the elementary steps that mediate ethanoic acid ketonization turnovers (Scheme 5). In doing so, we also assess the influence of the strength of the acid and base sites and the Ti-O distances on adsorption and activation free energies.

(a) Side view of $\mathrm{TiO}_{2}(\mathrm{a})$ (101) surface

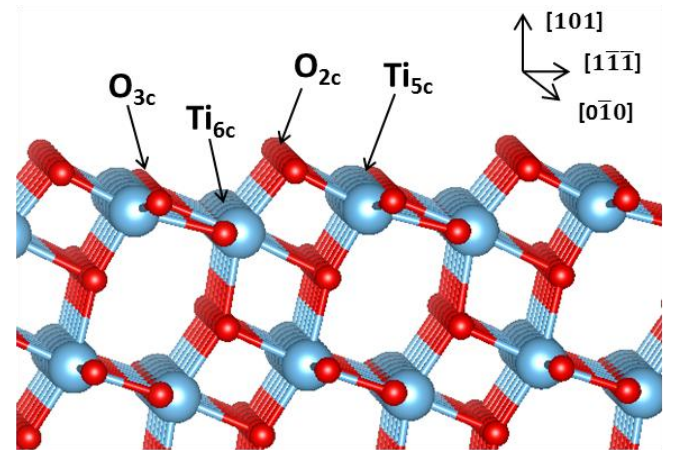

(c) Side view of $\mathrm{TiO}_{2}(\mathrm{r})(110)$ surface

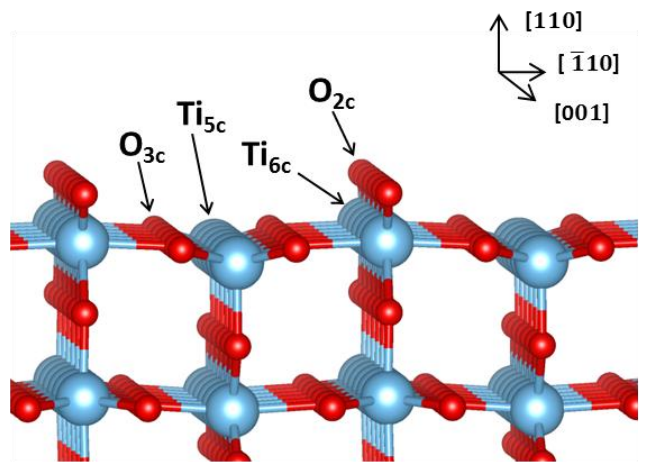

(b) Top view of $\mathrm{TiO}_{2}(\mathrm{a})$ (101) surface

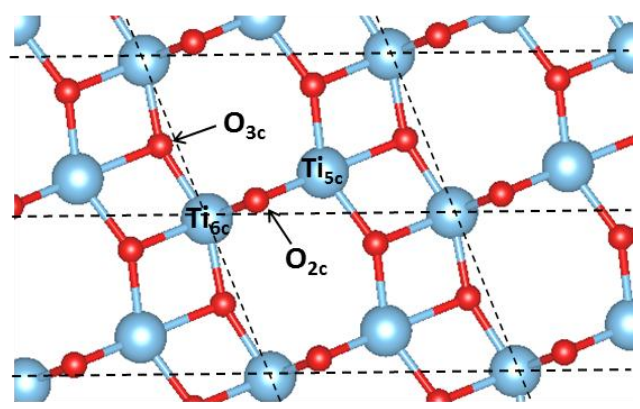

(d) Top view of $\mathrm{TiO}_{2}(\mathrm{r})(\mathbf{1 1 0})$ surface

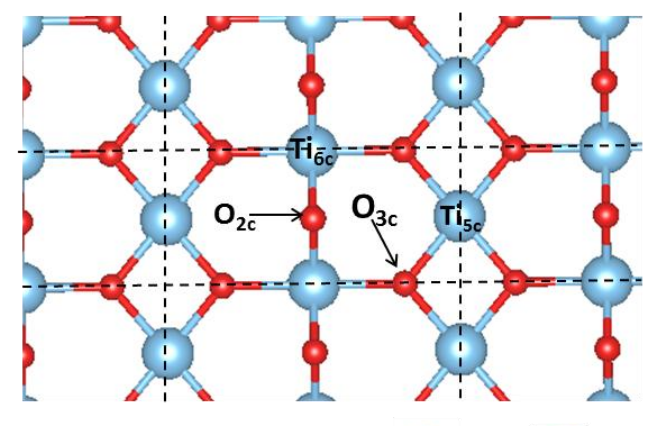

$\mathrm{Ti}$;

Scheme 8. Structures of $\mathrm{TiO}_{2}(\mathrm{a})(101)$ and $\mathrm{TiO}_{2}(\mathrm{r})$ (110) surfaces.

$\mathrm{TiO}_{2}$ (a) (101) surfaces exhibit sawtooth-like corrugations that expose two types of $\mathrm{Ti}$ cations and two types of $\mathrm{O}$ anions (Schemes 8a,b) [22]. One of the Ti centers exhibits sixfold coordinative saturation, as the $\mathrm{Ti}$ atoms do in the anatase bulk $\left(\mathrm{Ti}_{6 \mathrm{c}}\right.$, coordination number $(\mathrm{CN})$ of 6$)$, while the other Ti center is five-coordinate and is coordinatively- 
unsaturated $\left(\mathrm{Ti}_{5 \mathrm{c}}, \mathrm{CN} 5\right)$. Their connecting O-atoms have either two-fold $\left(\mathrm{O}_{2 \mathrm{c}}, \mathrm{CN} 2\right)$ or three-fold $\left(\mathrm{O}_{3 \mathrm{c}}, \mathrm{CN} 3\right)$ coordination.

The affinity of a gaseous $\mathrm{OH}^{-}$anion $\left(E_{\mathrm{HA}}\right.$; Eq. 3$)$ can be used to assess the acid strength of these two types of Ti Lewis centers. The affinity of a gaseous proton $\left(E_{\mathrm{PA}} ; \mathrm{Eq}\right.$. 4) can be used, in turn, to assess the strength of the basic O-anions. These $\mathrm{OH}^{-}$and $\mathrm{H}^{+}$ affinities are more negative on $\mathrm{Ti}$ and $\mathrm{O}$ centers with lower coordination numbers (Table 5), as expected from their coordinative unsaturation, which allows effective orbital overlap with adsorbed molecules. In fact, the $\mathrm{OH}^{-}$affinity of coordinatively-saturated $\mathrm{Ti}_{6 \mathrm{c}}$ centers $\left(E_{\mathrm{HA}}\left(\mathrm{Ti}_{6 \mathrm{c}}\right)\right)$ is near zero $\left(<-1 \mathrm{~kJ} \mathrm{~mol}^{-1}\right.$, Table 5); they cannot bind intermediates and transition states, thus rendering $\mathrm{Ti}_{6 c}$ sites inactive in ketonization catalysis, as also concluded in the case of condensation reactions on $\mathrm{TiO}_{2}$ (a) surfaces [24]. We surmise, and then show below, that $\mathrm{Ti}_{5 \mathrm{c}}$ sites $\left(E_{\mathrm{HA}}-246 \mathrm{~kJ} \mathrm{~mol}^{-1}\right.$, Table 5) are the only Ti centers able to stabilize adsorbed acid molecules and the transition states that mediate their reactions; therefore, they are the $\mathrm{Ti}$ centers in the Ti-O pairs responsible for ketonization turnovers on $\mathrm{TiO}_{2}$ (a) (101) surfaces. In contrast, the $E_{\mathrm{PA}}$ values for the $\mathrm{O}_{2 \mathrm{c}}$ and $\mathrm{O}_{3 \mathrm{c}}$ sites are both significant in magnitude and differ by $37 \mathrm{~kJ} \mathrm{~mol}^{-1}$ (-1175 vs. $-1138 \mathrm{~kJ} \mathrm{~mol}^{-1}$, Table 5), suggesting that both basic sites can interact with the acidic proton at the $\mathrm{OH}$ group in the acid reactants.

Table 5. DFT-derived hydroxide anion affinities $\left(E_{\mathrm{HA}}\right)$, proton affinities $\left(E_{\mathrm{PA}}\right)$, and the shortest distances between two $\mathrm{Ti}_{5 \mathrm{c}}$ sites $\left(d_{\mathrm{Ti} 5 \mathrm{c}-\mathrm{Ti5c}}\right)$ and between one $\mathrm{Ti}_{5 \mathrm{c}}$ site and one $\mathrm{O}_{2 \mathrm{c}}$ site $\left(d_{\mathrm{Ti5c-O2c}}\right)$ on $\mathrm{TiO}_{2}(\mathrm{a})(101)$ and $\mathrm{TiO}_{2}(\mathrm{r})(110)$ surfaces. ${ }^{\mathrm{a}}$

\begin{tabular}{|c|c|c|c|c|c|c|}
\hline \multirow{2}{*}{ Surface } & \multicolumn{2}{|c|}{$E_{\mathrm{HA}}\left(\mathrm{kJ} \mathrm{mol}^{-1}\right)$} & \multicolumn{2}{|c|}{$E_{\mathrm{PA}}\left(\mathrm{kJ} \mathrm{mol}^{-1}\right)$} & \multirow{2}{*}{$d_{\text {Ti5c-Ti5c }}(\mathrm{nm})$} & \multirow{2}{*}{$d_{\mathrm{Ti5c-02 \textrm {c }}}(\mathrm{nm})$} \\
\hline & $\mathrm{Ti}_{5 \mathrm{c}}$ & $\mathrm{Ti}_{6 \mathrm{c}}$ & $\mathrm{O}_{2 \mathrm{c}}$ & $\mathrm{O}_{3 \mathrm{c}}$ & & \\
\hline $\mathrm{TiO}_{2}(\mathrm{a})(101)$ & -246 & $<-1$ & -1175 & -1138 & 0.383 & 0.184 \\
\hline $\mathrm{TiO}_{2}(\mathrm{r})(110)$ & -369 & $<-1$ & -1093 & -1008 & 0.299 & 0.360 \\
\hline
\end{tabular}

${ }^{\mathrm{a}} \mathrm{PBE}+\mathrm{D} 3 \mathrm{BJ}, \mathrm{PAW}$. 
$\mathrm{TiO}_{2}(\mathrm{r})$ (110) surfaces also expose $\mathrm{Ti}_{5 \mathrm{c}}, \mathrm{Ti}_{6 \mathrm{c}}, \mathrm{O}_{2 \mathrm{c}}$, and $\mathrm{O}_{3 \mathrm{c}}$ ions (Schemes 8c,d) but with very different connectivity than on $\mathrm{TiO}_{2}(\mathrm{a})$ (101), as expected from the different crystal symmetry of these two $\mathrm{TiO}_{2}$ phases $\left(\mathrm{TiO}_{2}(\mathrm{r})\right.$ : tetragonal, $\mathrm{P} 4_{2} / \mathrm{mnm} ; \mathrm{TiO}_{2}(\mathrm{a})$ : tetragonal, $\left.\mathrm{I}_{1} / \mathrm{amd}\right)$ [40]. The coordinatively-unsaturated $\mathrm{Ti}_{5 \mathrm{c}}$ sites on $\mathrm{TiO}_{2}(\mathrm{r})(110)$ are linked by $\mathrm{O}_{3 c}$ atoms and do not exhibit direct bonding with any $\mathrm{O}_{2 c}$ atoms (Table 5). Such surface arrangements lead to shorter distances between two neighboring $\mathrm{Ti}_{5 \mathrm{c}}$ sites $\left(d_{\mathrm{Ti} 5 \mathrm{c}-}\right.$ Ti5c $=0.299 \mathrm{~nm})$ but longer $\mathrm{Ti}_{5 \mathrm{c}}-\mathrm{O}_{2 \mathrm{c}}$ distances $\left(d_{\mathrm{Ti5c}-\mathrm{O} 2 \mathrm{c}}=0.360 \mathrm{~nm}\right)$ than on $\mathrm{TiO}_{2}(\mathrm{a})(101)$ surfaces $\left(0.383 \mathrm{~nm}, 0.184 \mathrm{~nm}\right.$, Table 5). Also, the $E_{\mathrm{HA}}\left(\mathrm{Ti}_{5 \mathrm{c}}\right)$ values on $\mathrm{TiO}_{2}(\mathrm{r})(110)$ surfaces are much more negative than on $\mathrm{TiO}_{2}$ (a) (101) surfaces (-369 vs. $-246 \mathrm{~kJ}$ mol${ }^{-1}$, Table 5), indicative of much stronger Lewis acid centers. In contrast, the $E_{\mathrm{PA}}\left(\mathrm{O}_{2 \mathrm{c}}\right)$ and $E_{\mathrm{PA}}\left(\mathrm{O}_{3 \mathrm{c}}\right)$ values are less negative on $\mathrm{TiO}_{2}(\mathrm{r})(110)\left(-1093 \mathrm{~kJ} \mathrm{~mol}^{-1},-1008 \mathrm{~kJ} \mathrm{~mol}^{-1}\right.$, Table 5) than on $\mathrm{TiO}_{2}$ (a) (101) surfaces $\left(-1175 \mathrm{~kJ} \mathrm{~mol}^{-1},-1138 \mathrm{~kJ} \mathrm{~mol}^{-1}\right.$, Table 5), indicating that $\mathrm{O}$-atoms are less basic on $\mathrm{TiO}_{2}(\mathrm{r})$. Not unexpectedly, these differences in $\mathrm{Ti}-\mathrm{O}$ distances and acid-base strength lead to very different binding modes and reactivity of adsorbed acid molecules on $\mathrm{TiO}_{2}(\mathrm{a})$ and $\mathrm{TiO}_{2}(\mathrm{r})$, as discussed in detail below.

Ethanoic acid can form molecular $\mathrm{AcOH}^{*}$ or dissociated $\mathrm{AcO}^{*}$ at $\mathrm{Ti}_{5 \mathrm{c}}-\mathrm{O}_{2 \mathrm{c} / 3 \mathrm{c}}$ pairs on $\mathrm{TiO}_{2}$ (a) (101) surfaces. Their relative abundance depends on the basicity of the accessible lattice $\mathrm{O}$-atoms that must interact with the $-\mathrm{OH}$ group in ethanoic acid. The weaker $\mathrm{O}_{3 \mathrm{c}}$ site preserves the $\mathrm{O}-\mathrm{H}$ bond intact upon adsorption $(\mathrm{O}-\mathrm{H}$ distance: $0.105 \mathrm{~nm}$ vs. $0.099 \mathrm{~nm}$ in $\mathrm{AcOH}(\mathrm{g})$, Scheme 9a) and forms weakly-adsorbed $\mathrm{AcOH}^{*}$ species at $\mathrm{Ti}_{5 \mathrm{c}}-\mathrm{O}_{3 c}$ pairs. The $\mathrm{O}-\mathrm{H}$ bond in $\mathrm{AcOH}$ is cleaved to form $\mathrm{AcO}^{*}(\mathrm{O}-\mathrm{H}$ distance: 0.139-0.143 nm, Schemes $9 b, c)$ at $\mathrm{Ti}_{5 c}-\mathrm{O}_{2 c}$ pairs consisting of $\mathrm{Ti}_{5 \mathrm{c}}$ centers with $\mathrm{O}_{2 \mathrm{c}}$ sites at either the first or second coordination shell $\left(\mathrm{Ti}_{5 \mathrm{c}}-\mathrm{O}_{2 \mathrm{c}}\right.$ distance: 0.184 vs. $0.413 \mathrm{~nm}$, Schemes $\left.9 \mathrm{~b}, \mathrm{c}\right)$; this 
is also evident from the nearly-formed $\mathrm{H}-\mathrm{O}_{2 c}$ bond on both $\mathrm{Ti}_{5 c}-\mathrm{O}_{2 c}$ structures $\left(\mathrm{H}-\mathrm{O}_{2 \mathrm{c}}\right.$ distance: $0.108-0.109$ vs. $0.099 \mathrm{~nm}$ in products, Schemes 9b,c). DFT-derived adsorption free energies $\left(\Delta G_{\text {ads }} ; 1 / 2 \mathrm{ML}, 523 \mathrm{~K}, 1\right.$ bar) for the $\mathrm{AcO}^{*}$ modes at these two $\mathrm{Ti}_{5 \mathrm{c}}-\mathrm{O}_{2 \mathrm{c}}$ structures were nearly identical (-52 and $-51 \mathrm{~kJ} \mathrm{~mol}^{-1}$; Section S13, SI) and much more negative than for $\mathrm{AcOH}^{*}$ at the $\mathrm{Ti}_{5 \mathrm{c}}-\mathrm{O}_{3 \mathrm{c}}$ pair $\left(-15 \mathrm{~kJ} \mathrm{~mol}^{-1}\right.$; Section S13, SI), thus making $\mathrm{AcO}^{*}$ species the predominant monodentate form of adsorbed ethanoic acid on $\mathrm{TiO}_{2}(\mathrm{a})$. The most stable $* \mathrm{AcO}^{*}$ structure on $\mathrm{TiO}_{2}$ (a) (101) surfaces is also located at $\mathrm{Ti}_{5 \mathrm{c}}-\mathrm{O}_{2 \mathrm{c}}$ pairs, with the two carboxylate O-atoms each bound to one of two neighboring $\mathrm{Ti}_{5 \mathrm{c}}$ centers and the dissociated $\mathrm{H}$-atom coordinated to the basic $\mathrm{O}_{2 \mathrm{c}}$ site (Scheme $9 \mathrm{~d}$ ). These stronger acid-base $\mathrm{Ti}_{5 \mathrm{c}}-\mathrm{O}_{2 \mathrm{c}}$ pairs are used in the DFT treatments of ketonization elementary steps that are described next.

(a) $\mathrm{AcOH}^{*}$ on a $\mathrm{Ti}_{5 \mathrm{c}}-\mathrm{O}_{3 \mathrm{c}}$ pair

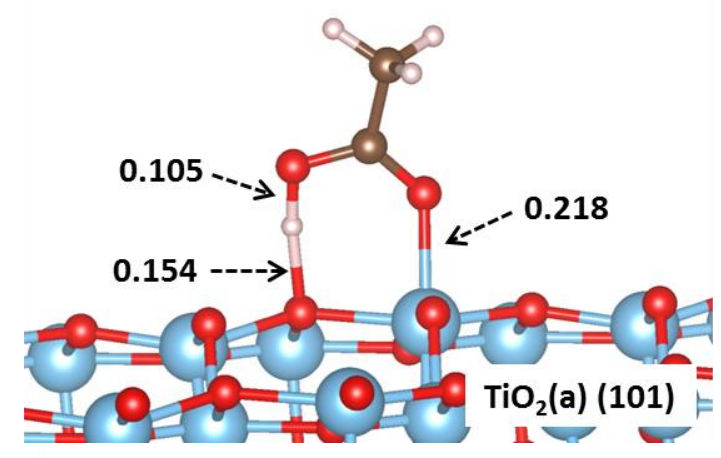

(c) $\mathrm{AcO}^{*}$ on a unbounded $\mathrm{Ti}_{5 \mathrm{c}}-\mathrm{O}_{2 \mathrm{c}}$ pair

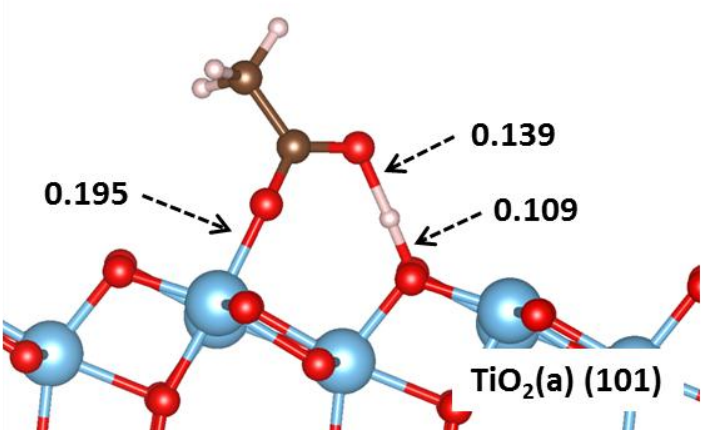

(b) $\mathrm{AcO}^{*}$ on a bonded $\mathrm{Ti}_{5 \mathrm{c}}-\mathrm{O}_{2 \mathrm{c}}$ pair

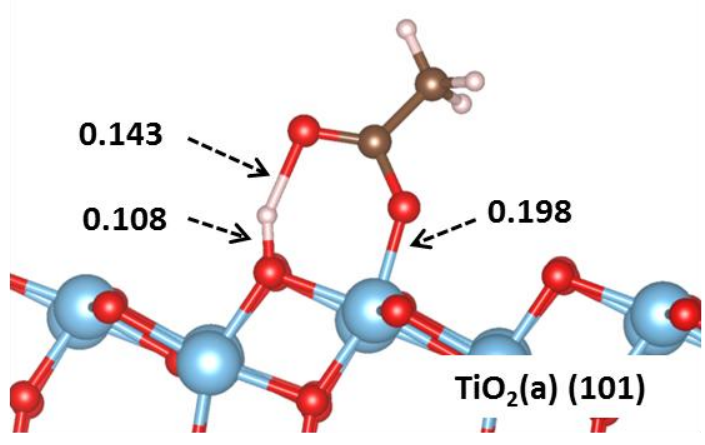

(d) *AcO* on two $\mathrm{Ti}_{5 \mathrm{c}}-\mathrm{O}_{2 \mathrm{c}}$ pairs

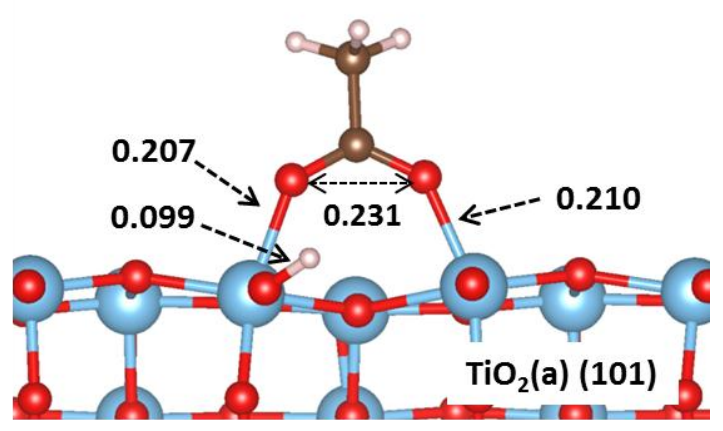


(e) $\mathrm{ACOH}^{*}$ on a $\mathrm{Ti}_{5 c}-\mathrm{O}_{2 \mathrm{c}}$ pair

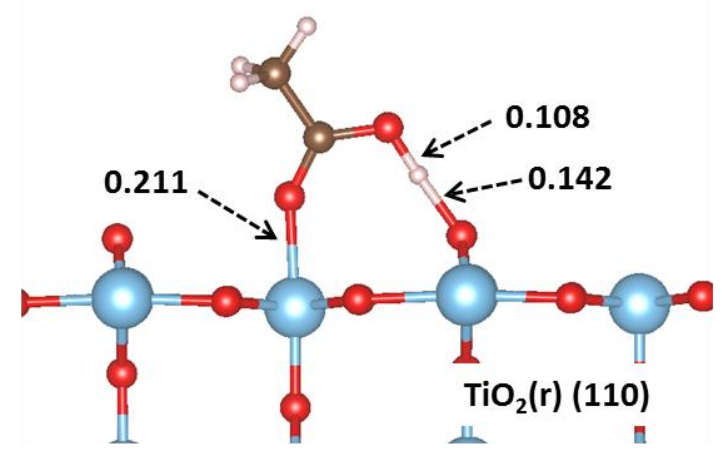

(f) *AcO* on two $\mathrm{Ti}_{5 \mathrm{c}}-\mathrm{O}_{2 \mathrm{c}}$ pairs

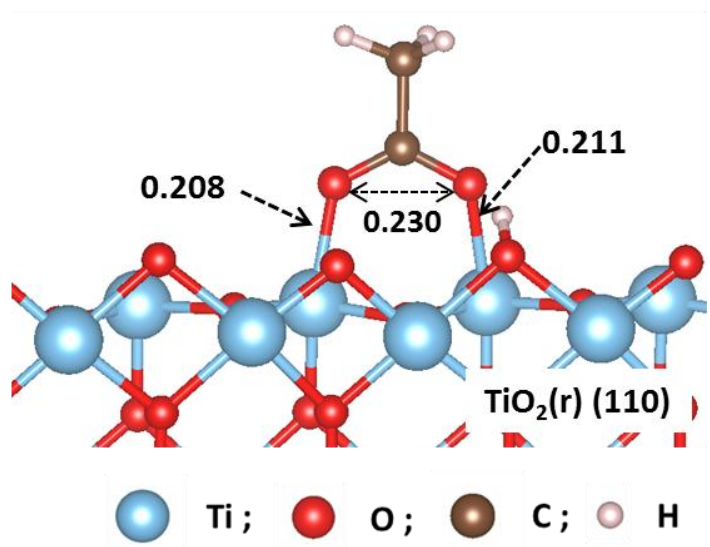

Scheme 9. DFT-derived adsorption modes for ethanoic acid on $\mathrm{TiO}_{2}(\mathrm{a})$ (101) and $\mathrm{TiO}_{2}(\mathrm{r})$ (110) surfaces $\left(\mathrm{PBE}+\mathrm{D} 3 \mathrm{BJ}, \mathrm{PAW}, \theta_{\text {acid }}=1 / 2 \mathrm{ML}\right)$. Only one acid molecule is shown on the surface for clarity; distances are given in $\mathrm{nm}$.

The DFT-derived $\Delta G_{\text {ads }}$ values for AcO* species bound at $\mathrm{Ti}_{5 \mathrm{c}}-\mathrm{O}_{2 \mathrm{c}}$ pairs on $\mathrm{TiO}_{2}(\mathrm{a})$ (101) surfaces vary from -55 to $-50 \mathrm{~kJ} \mathrm{~mol}^{-1}(525 \mathrm{~K}, 1$ bar; Eq. 2) as the acid coverage $\left(\theta_{\text {acid }}\right)$ increases $(1 / 6-1 \mathrm{ML}$, Fig. $7 \mathrm{a})$; the respective adsorption enthalpies $\left(\Delta H_{\text {ads }}\right)$ vary from -132 to $-140 \mathrm{~kJ} \mathrm{~mol}^{-1}$ (Fig. $7 \mathrm{~b}$ ). These small differences in $\Delta G_{\text {ads }}$ and $\Delta H_{\text {ads }}$ values indicate that the distances between $\mathrm{Ti}_{5 \mathrm{c}}$ centers at $\mathrm{TiO}_{2}(\mathrm{a})(101)$ surfaces $\left(d_{\mathrm{Ti} 5 \mathrm{c}-\mathrm{Ti} 5 \mathrm{c}} 0.383\right.$ $\mathrm{nm}$, Table 5) do not lead to strong lateral repulsion among AcO* species, even at the saturation coverages prevalent during ketonization catalysis.

In contrast, DFT-derived $\Delta G_{\text {ads }}$ values for bound $* A c O *$ species at these $\mathrm{Ti}_{5 \mathrm{c}}-\mathrm{O}_{2 \mathrm{c}}$ pairs become much less negative $\left(-82\right.$ to $\left.-43 \mathrm{~kJ} \mathrm{~mol}^{-1}\right)$ with increasing acid coverage $(1 / 8$ to saturation $1 / 2 \mathrm{ML}$ ) (Fig. 7a). Such destabilization predominantly reflects the $\Delta H_{\text {ads }}$ component in $\Delta G_{\text {ads }}$ (Fig. 7b). Similarly, the $\mathrm{Ti}_{5 \mathrm{c}}-\mathrm{Ti}_{5 \mathrm{c}}$ distances in $\mathrm{TiO}_{2}$ (a) (101) preclude repulsive interactions among alkyl groups in vicinal $* \mathrm{AcO} *$ species, as in the case of AcO* above. These $\mathrm{Ti}_{5 \mathrm{c}}-\mathrm{Ti}_{5 \mathrm{c}}$ distances at the two vicinal $\mathrm{Ti}_{5 \mathrm{c}}$ centers linked to the $\mathrm{O}$ atoms in the bound *AcO* (Scheme 9d) increase slightly from $0.381 \mathrm{~nm}$ to $0.384 \mathrm{~nm}$ as acid coverage increases ( $1 / 8$ to saturation $1 / 2 \mathrm{ML})$, while the $\mathrm{O}-\mathrm{O}$ distances in $* \mathrm{AcO} *$ 
remain nearly unchanged ( $d_{\mathrm{O}-\mathrm{O}} 0.231-0.232 \mathrm{~nm}$, Scheme $\left.9 \mathrm{~d}\right)$. These changes with coverage lead to somewhat less effective overlap between $\mathrm{Ti}$ and $\mathrm{O}$ orbitals in * $\mathrm{AcO}^{*}$ and to the concomitant $* \mathrm{AcO}^{*}$ destabilization as coverage increases (Fig. 7a).

The above effects of acid coverage on $\Delta G_{\text {ads }}$ values for $\mathrm{AcO}^{*}$ and $* \mathrm{AcO} *$ species (Fig.7a) indicate that $* \mathrm{AcO}^{*}$ species dominate at acid coverages below 1/4 ML but become minority species at higher coverages, when ${ }^{*} \mathrm{AcO}^{*}$ and $\mathrm{AcO}^{*}$ are equilibrated (Step 3 in Scheme 5). Rate and infrared data showed that $K_{1}$ values did not depend on coverage (Sections 3.2 and 3.3), consistent with the prevalence of $\mathrm{AcO}^{*}$ species and their slow interconversion to $* \mathrm{AcO}^{*}$ during ketonization catalysis.
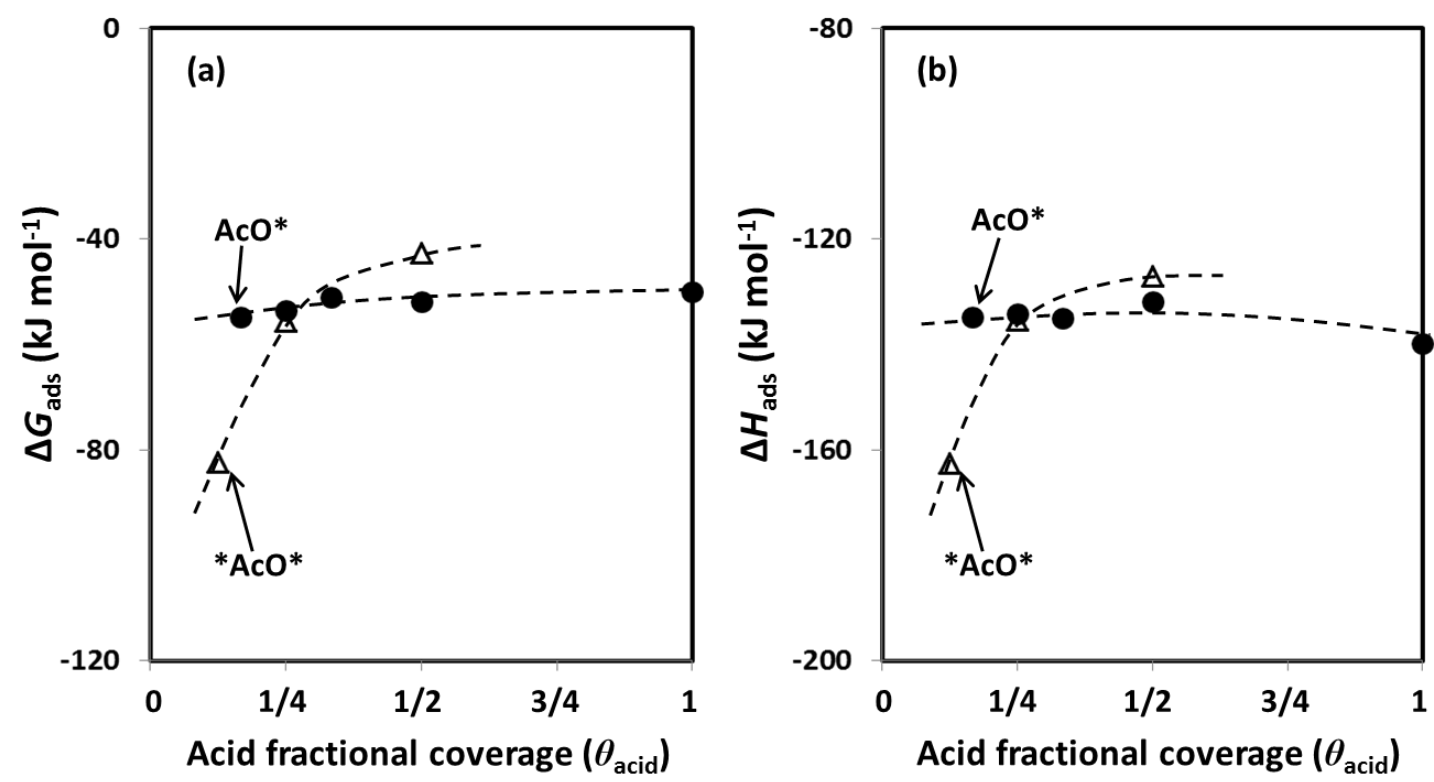

Figure 7. DFT-derived (a) adsorption free energy $\left(\Delta G_{\text {ads }}\right)$ and (b) its enthalpy component $\left(\Delta H_{\text {ads }}\right)$ as a function of acid fractional coverage $\left(\theta_{\text {acid; }}\right.$ Eq. 15) for $\mathrm{AcO}^{*}(\bullet)$ and $* \mathrm{AcO}^{*}$ $(\Delta)$ on $\mathrm{TiO}_{2}$ (a) (101) surfaces (PBE+D3BJ, PAW, $523 \mathrm{~K}, 1$ bar ethanoic acid). Dashed lines indicate qualitative trends.

DFT treatments were also used to assess the relative rates of $\mathrm{AcO}^{*}$ conversion to *AcO* (via Step 2, Scheme 5) and to ketonization products (via Steps 3-13, Scheme 5). The rate of formation of $* \mathrm{AcO}^{*}$ from $\mathrm{AcO}^{*}\left(r_{* \mathrm{AcO} *}\right)$ is given by: 


$$
\frac{r_{* \mathrm{AcO} *}}{[L]}=\overrightarrow{k_{2}} \theta_{\mathrm{AcO} *} \theta_{*}
$$

where $[L]$ is the number of catalytically relevant Ti-O pairs, $\theta_{\mathrm{AcO} *}$ and $\theta_{*}$ are the respective fractional coverages of $\mathrm{AcO}^{*}$ and unoccupied Ti-O pairs $\left(^{*}\right)$, and $\overrightarrow{k_{2}}$ is the forward rate constant for step 2 in Scheme 5. Ketonization rates $\left(r_{\text {keto }}\right)$, in contrast, involve bimolecular reactions between vicinal $\mathrm{AcO}^{*}$ species at rates limited by $\mathrm{C}-\mathrm{C}$ coupling between $\mathrm{AcO}^{*}$ and a 1-hydroxy enolate (Step 4, Scheme 5), as shown by kinetic and isotopic data (Section 3.2) and DFT methods (shown next). Ketonization rates are given by:

$$
\frac{r_{\text {keto }}}{[L]}=\overrightarrow{k_{4}} K_{1} K_{3} \theta_{\mathrm{AcO} *} \theta_{*} P_{\mathrm{AcOH}}
$$

where $[L], \theta_{\mathrm{AcO} *}$ and $\theta_{*}$ are as defined above, $P_{\mathrm{AcOH}}$ is the ethanoic acid pressure, and $\overrightarrow{k_{x}}$, and $K_{\mathrm{x}}$ are the respective rate constant and equilibrium constant for the Step $x$ in Scheme 5. Equations 16 and 17 give the ratio of ketonization to $* \mathrm{AcO} *$ formation rates $\left(r_{\mathrm{keto}} /\right.$ $\left.r_{* \mathrm{AcO} *}\right)$ :

$$
\frac{r_{\text {keto }}}{r_{* \mathrm{AcO} *}}=\frac{\overrightarrow{k_{4}} K_{1} K_{3}}{\overrightarrow{k_{2}}} P_{\mathrm{AcOH}}
$$

As shown in Scheme 10, these $\left(r_{\text {keto }} / r_{* \mathrm{AcO} *}\right)$ ratios reflect the free energy difference $\left(\Delta G_{\mathrm{keto}-* \mathrm{AcO} *}^{\ddagger}\right.$, Eqs. 19 and 20$)$ between the TS for the C-C coupling step $\left(G_{\mathrm{CC}}^{\ddagger}\right.$, Step 4 in Scheme 5) and the sum of the TS for $* \mathrm{AcO}^{*}$ formation from $\mathrm{AcO}^{*}\left(G_{* \mathrm{AcO} *}^{\ddagger}\right.$, Step 2 in Scheme 5) and a gaseous ethanoic acid $\left(G_{\mathrm{AcOH}}\right)$ :

$$
\begin{gathered}
\frac{r_{\text {keto }}}{r_{* \mathrm{AcO} *}}=\exp \left(-\Delta G_{\mathrm{keto}-* \mathrm{AcO} *}^{\ddagger} / R T\right) P_{\mathrm{AcOH}} \\
\Delta G_{\mathrm{keto}-* \mathrm{AcO} *}^{\ddagger}=G_{\mathrm{CC}}^{\ddagger}-G_{* \mathrm{AcO} *}^{\ddagger}-G_{\mathrm{AcOH}}
\end{gathered}
$$




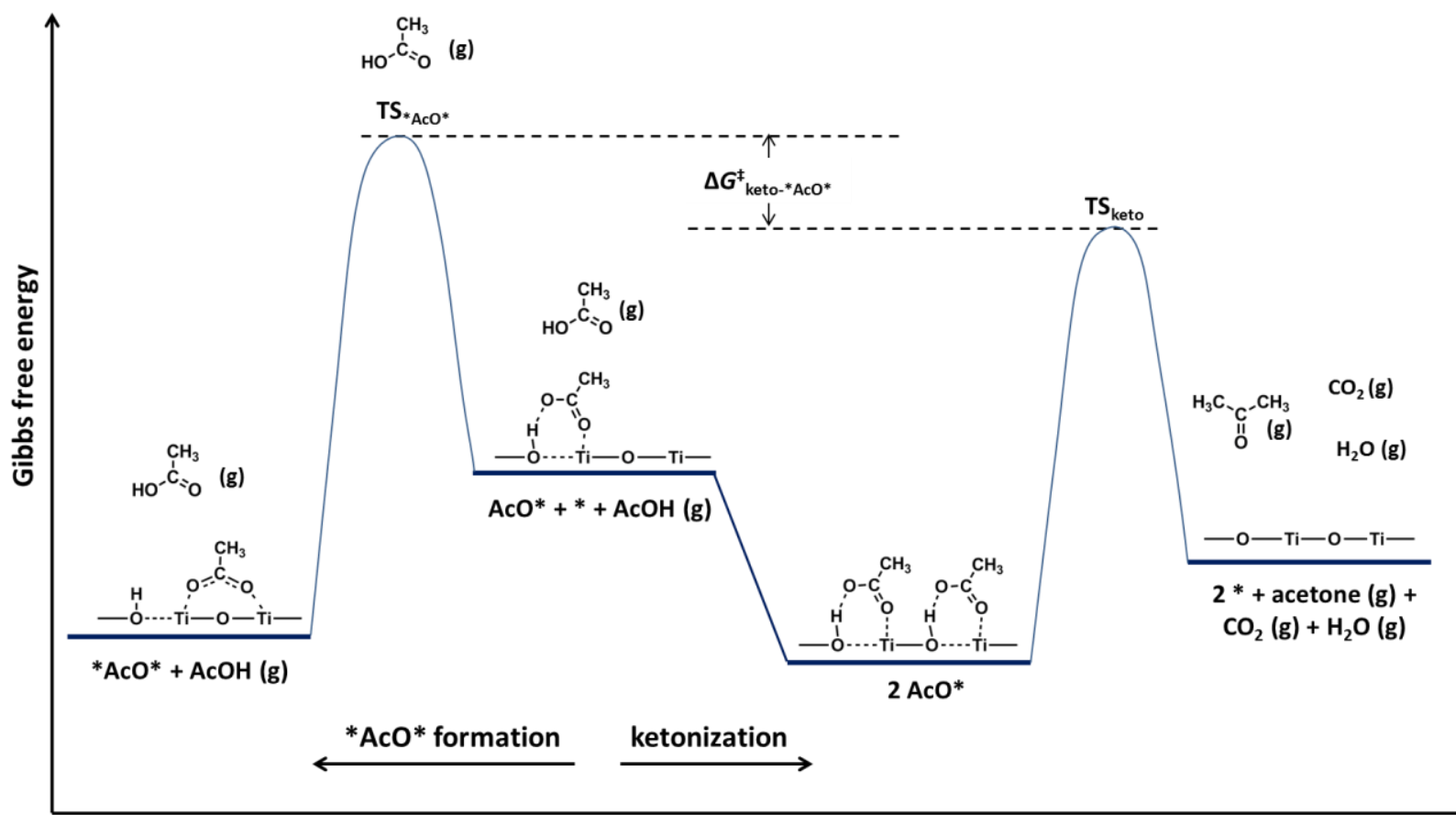

Reaction coordinate

Scheme 10. Schematic reaction coordinate diagram for ketonization and formation of bidentate carboxylates $\left({ }^{*} \mathrm{AcO}{ }^{*}\right)$ from monodentate carboxylates $\left(\mathrm{AcO}{ }^{*}\right)$ on $\mathrm{TiO}_{2}$.

The DFT-derived $\Delta G_{\text {keto-*AcO* }}^{\ddagger}$ value for $\mathrm{AcO}^{*}$ bound at $\mathrm{Ti}_{5 \mathrm{c}}-\mathrm{O}_{2 \mathrm{c}}$ pairs on $\mathrm{TiO}_{2}(\mathrm{a})$ (101) is $45 \mathrm{~kJ} \mathrm{~mol}^{-1}$ (523 K, 1 bar ethanoic acid). The TS for *AcO* formation and its free energy are shown in Section S14 (SI), while the structure and free energy of the C-C coupling TS are shown below. These free energies lead to $\left(r_{\text {keto }} / r_{* \mathrm{AcO} *}\right)$ ratios much smaller than unity at all pressures and temperatures of interest (Section S15, SI). Thus, DFT methods indicate that * $\mathrm{AcO}^{*}$-AcO* equilibration should occur in the time scale of ketonization turnovers, in contradiction to the slow formation and desorption of * $\mathrm{AcO}^{*}$ evident from infrared spectra (Section 3.3), the formation of acetaldehyde and the inhibition of deactivation when $\mathrm{H}_{2}$ and a $\mathrm{Cu}$ function are used (Section 3.1), and the nature of the treatments required to fully recover initial rates after significant deactivation (in the absence of $\mathrm{Cu}$ and $\mathrm{H}_{2}$; Section 3.1). 
The Grimme's D3BJ dispersion component in the PBE functionals $[43,44]$ used in these DFT treatments to account for long and intermediate range van der Waals attractive interactions tends to overestimate the binding of adsorbed species, in this case the binding of acid-derived species at Ti-O pairs; this is evident from DFT-derived AcO* formation free energies $\left(-50\right.$ to $-55 \mathrm{~kJ} \mathrm{~mol}^{-1}$, Fig. 7a) that are much more negative than measured values (-33 $\mathrm{kJ} \mathrm{mol}^{-1}$, Table 2$)$ at the high coverages prevalent in ketonization catalysis (0.70 to $0.99 \mathrm{ML}, 523 \mathrm{~K})$. We expect that the binding of the *AcO* formation and the $\mathrm{C}$ C coupling transition states will also be overestimated by these functionals, which would be more consequential for TS structures that have incipiently formed or cleaved bonds to the Ti-O pairs with a longer bond distance.

The * AcO* formation TS involves the incipient formation of a new Ti-O bond as AcO* reacts with a Ti center ( $\mathrm{Ti}-\mathrm{O}$ bond distance: $0.290 \mathrm{~nm}$ at $\mathrm{TS}, 0.209 \mathrm{~nm}$ in *AcO* products, Scheme S4, SI). In contrast, the C-C coupling TS involves the cleavage of a Ti$\mathrm{O}$ bond in a bound $\mathrm{AcO}^{*}$ as it forms the 1-hydroxy enolate and then a TS with a longer Ti-O bond $(0.189 \mathrm{~nm}$, Scheme $11 \mathrm{~b})$ than in 1-hydroxy enolate $(0.185 \mathrm{~nm})$. The distance of the incipiently formed Ti-O bond at the *AcO* formation TS is much longer that the one incipiently cleaved at the C-C coupling TS $(0.290$ vs. $0.189 \mathrm{~nm})$, indicating the overbinding tendency is more consequential for the *AcO* formation TS. As a result, the free energy for the $* \mathrm{AcO}^{*}$ formation $\mathrm{TS}\left(G_{* \mathrm{AcO} *}^{\ddagger}\right)$ is expected to be underestimated more than that for the C-C coupling TS $\left(G_{\mathrm{CC}}^{\ddagger}\right)$, leading to the overestimation for $\Delta \mathrm{G}_{\mathrm{keto}-* \mathrm{AcO} *}^{\ddagger}$ values (Eq. 20). As shown next, such overbinding tendencies influence the C-C coupling TS and the bound reactants (two adjacent $\mathrm{AcO}^{*}$ ) similarly; their free energy difference $\left(\Delta \mathrm{G}_{\mathrm{CC}}^{\ddagger}\right.$, Eq. 11) is thus nearly independent of the overbinding tendencies and can be used for the benchmarking between experiment and theory. 
DFT-derived $\Delta G_{\text {ads }}$ values show that bidentate $* A c O *$ species at $\mathrm{Ti}_{5 \mathrm{c}}-\mathrm{O}_{2 \mathrm{c}}$ pairs on $\mathrm{TiO}_{2}(\mathrm{r})(110)$ become less stable with increasing acid coverage ( $\left.\theta_{\text {acid }}\right)$ up to saturation coverages (1/2 ML) (Fig. 8a; $\Delta H_{\text {ads }}$ components depicted in Fig. 8b), as found also on $\mathrm{TiO}_{2}$ (a) (101) (Fig. 7a). These $\Delta G_{\text {ads }}$ values for $* A c O *$ are more negative on $\mathrm{TiO}_{2}(\mathrm{r})(110)$ than on $\mathrm{TiO}_{2}$ (a) (101) (e.g. -72 vs. $-43 \mathrm{~kJ} \mathrm{~mol}^{-1}, 1 / 2 \mathrm{ML} * \mathrm{AcO}^{*}, 523 \mathrm{~K}, 1$ bar, Figs. $7 \mathrm{a}$ and $8 \mathrm{a}$ ), as a result of shorter $\mathrm{Ti}_{5 \mathrm{c}}-\mathrm{Ti}_{5 \mathrm{c}}$ distances on $\mathrm{TiO}_{2}(\mathrm{r})(110)$ than on $\mathrm{TiO}_{2}(\mathrm{a})(101)$ surfaces $\left(\mathrm{d}_{\mathrm{Ti5c}-\mathrm{Ti} 5 \mathrm{c}} 0.299\right.$ vs. $0.383 \mathrm{~nm}$, Table 5); these $\mathrm{Ti}_{5 \mathrm{c}}-\mathrm{Ti}_{5 \mathrm{c}}$ distances on $\mathrm{TiO}_{2}(\mathrm{r})(110)$ match more closely the O-O distances in $* A c O *$ species $\left(d_{\mathrm{O}-\mathrm{O}} 0.230 \mathrm{~nm}\right.$, Schemes $\left.9 \mathrm{f}\right)$, thus providing more effective orbital overlap.
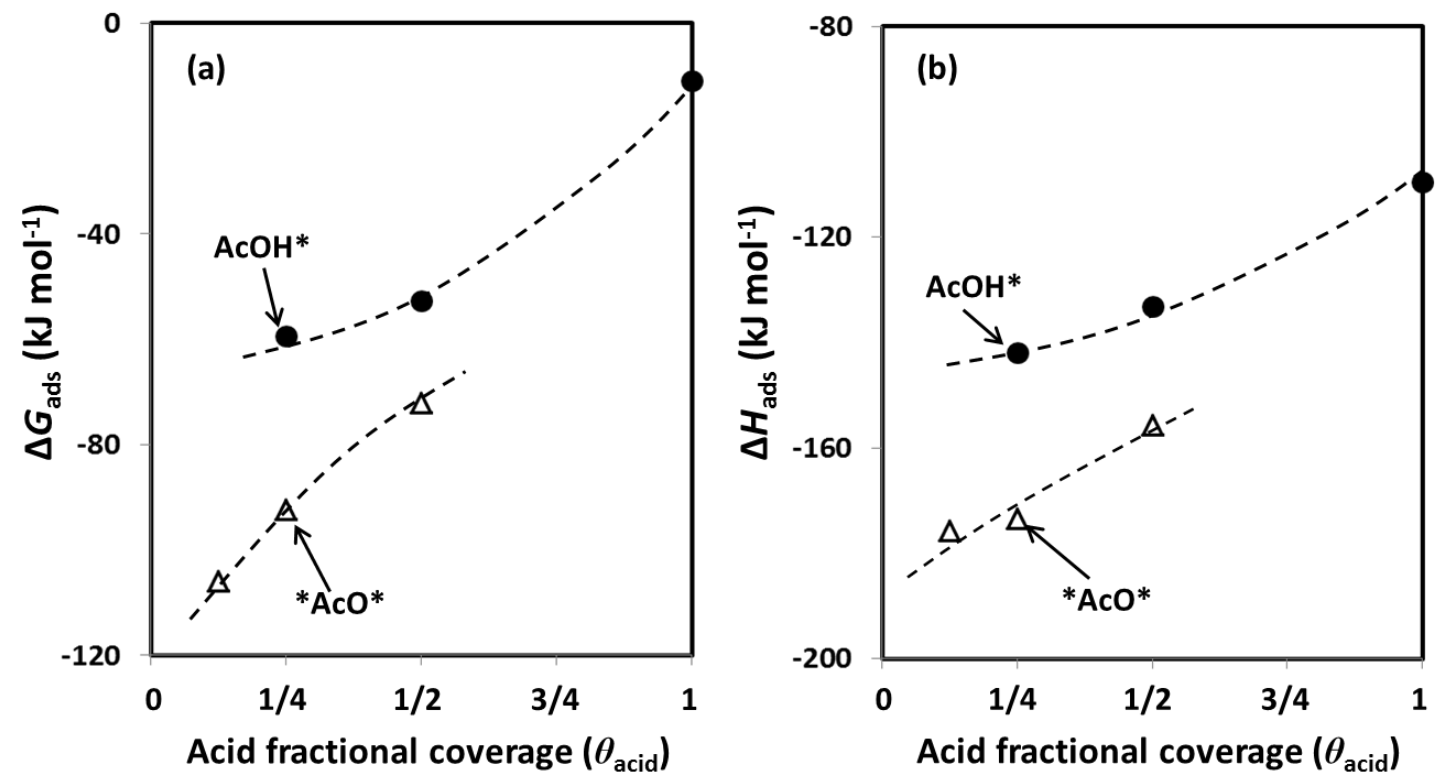

Figure 8. DFT-derived (a) adsorption free energy $\left(\Delta G_{\text {ads }}\right)$ and (b) its enthalpy component $\left(\Delta H_{\text {ads }}\right)$ as a function of acid fractional coverage $\left(\theta_{\text {acid }}\right.$; Eq. 15) for $\mathrm{AcOH}^{*}(\bullet)$ and $* \mathrm{AcO}^{*}$ $(\Delta)$ on $\mathrm{TiO}_{2}(\mathrm{r})(110)$ surfaces (PBE+D3BJ, PAW, $523 \mathrm{~K}, 1$ bar ethanoic acid). Dashed lines indicate qualitative trends.

The DFT-derived $\Delta G_{\text {ads }}$ values for $\mathrm{AcOH}^{*}$ species on $\mathrm{TiO}_{2}(\mathrm{r})(110)$ also become less negative from $-59 \mathrm{~kJ} \mathrm{~mol}^{-1}(1 / 4 \mathrm{ML})$ to $-53 \mathrm{~kJ} \mathrm{~mol}^{-1}(1 / 2 \mathrm{ML})$ and then to $-11 \mathrm{~kJ} \mathrm{~mol}^{-1}$ at saturation coverages (1 ML, Fig. 8a), in contrast to the much smaller $\Delta G_{\text {ads }}$ change on $\mathrm{TiO}_{2}$ (a) (101) in the same range of coverages $\left(-54\right.$ to $-50 \mathrm{~kJ} \mathrm{~mol}^{-1}$, Fig. 7a). This stronger 
influence of coverages on the stability of monodentate modes on $\mathrm{TiO}_{2}(\mathrm{r})$ (110), especially at $\theta_{\text {acid }}$ above $1 / 2 \mathrm{ML}$, is indicative of strong steric repulsion between monodentate species bound to vicinal $\mathrm{Ti}_{5 c}-\mathrm{O}_{2 c}$ pairs in $\mathrm{TiO}_{2}(\mathrm{r})(110)$, with its shorter $\mathrm{Ti}_{5 \mathrm{c}}-\mathrm{Ti}_{5 \mathrm{c}}$ distances than in $\mathrm{TiO}_{2}$ (a) (101). As expected from such repulsion, the effect of acid coverage predominantly reflects the enthalpic component of $\Delta G_{\text {ads }}$ (Fig. 8b). The preference for *AcO* over $\mathrm{AcOH}^{*}$ on $\mathrm{TiO}_{2}$ (r) surfaces at all acid coverages (Fig. 8a) is consistent with the absence of detectable $\mathrm{AcOH}^{*}$ bands in the infrared spectrum of $\mathrm{TiO}_{2}(\mathrm{r})$ during ethanoic acid ketonization reactions (Fig. 5b, Section 3.3).

The proposed elementary steps for ethanoic acid ketonization (Scheme 5) were examined on $\mathrm{TiO}_{2}$ (a) (101) surfaces at $1 \mathrm{ML}$ AcO* coverages $\left(\theta_{\text {acid }}\right.$, Eq. 15) using DFT methods; such high coverages seek to rigorously account for the saturated surfaces prevalent during catalysis. The first step involves the cleavage of the $\alpha-\mathrm{C}-\mathrm{H}$ bond in AcO* to form 1-hydroxy enolates (Step 3 in Scheme 5). The H-atom is abstracted by the vicinal $\mathrm{O}_{2 \mathrm{c}}$ site; the $\alpha-\mathrm{H}-\mathrm{O}_{2 \mathrm{c}}$ distance is $0.113 \mathrm{~nm}$ and the $\alpha-\mathrm{C}-\mathrm{H}$ distance is $0.150 \mathrm{~nm}$ at the TS that mediates the formation of the 1-hydroxy enolate (Scheme 11a). The similar $\alpha$ $\mathrm{H}-\mathrm{O}_{2 \mathrm{c}}$ distances at the TS and in the bound 1-hydroxy enolate $(0.113$ vs. $0.110 \mathrm{~nm})$ demonstrates the late nature of the enolate formation $\mathrm{TS}_{\text {on }} \mathrm{TiO}_{2}(\mathrm{a})$ (101); such a late $\mathrm{TS}$ reflects the strong $\alpha-\mathrm{C}-\mathrm{H}$ bond in carboxylic acids and the endothermic nature of such elementary steps. The transition states for enolate formation from carbonyl compounds in aldol condensation reactions on $\mathrm{TiO}_{2}$ (a) (101) occur earlier along the reaction coordinate than for acid reactants because the $\alpha-\mathrm{C}-\mathrm{H}$ bonds are weaker in carbonyl compounds than in carboxylic acids [24]. 
(a) Enolization of $\mathrm{AcO}^{*}(1 \mathrm{ML} \mathrm{AcO*})$

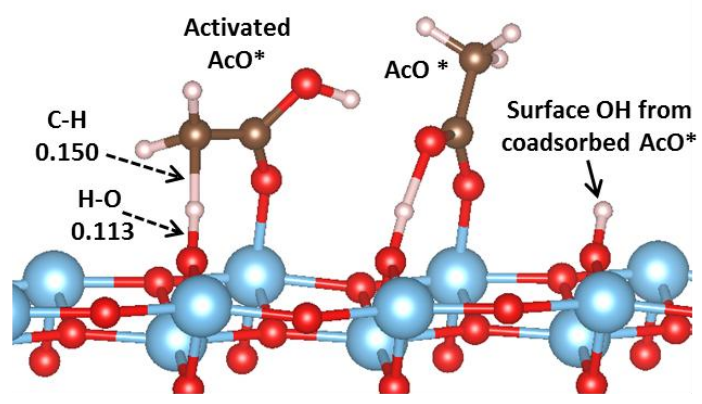

(c) H-transfer to lattice O-atom (1 ML AcO*)

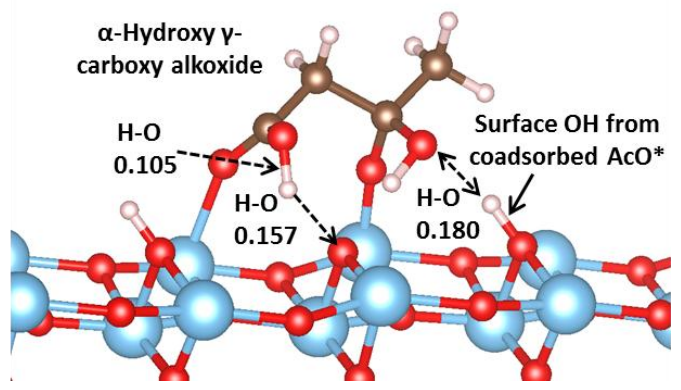

(e) C-C coupling with $\mathrm{AcO}^{*}(1 / 3 \mathrm{ML}$ AcO*)

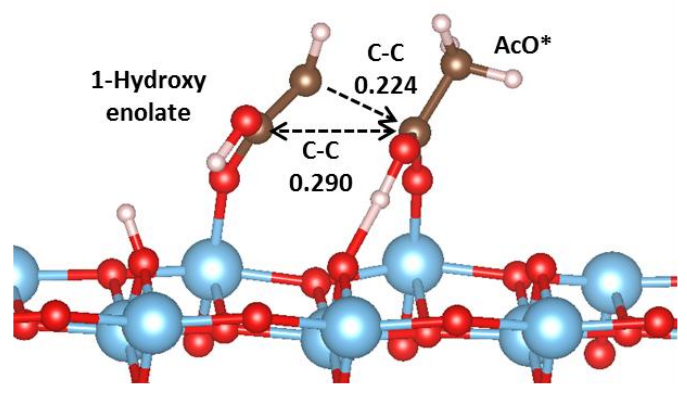

(b) C-C coupling with AcO* (1 ML AcO*)

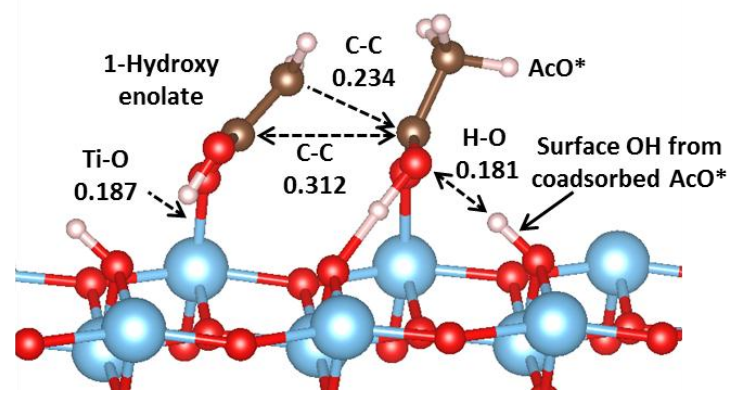

(d) Decarboxylation to enolate (1 ML AcO*)

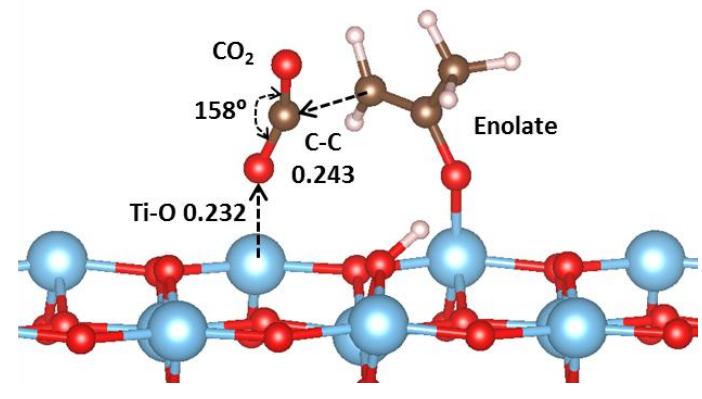

(f) Intramolecular dehydration (1/3 ML AcO*)

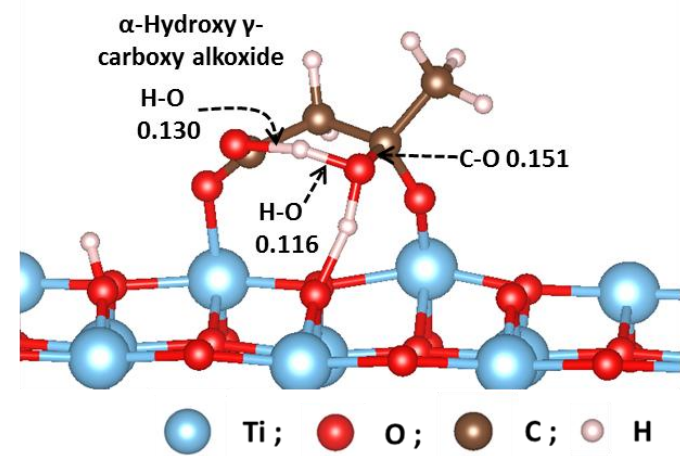

Scheme 11. DFT-derived transition state structures involved in ethanoic acid ketonization on $\mathrm{TiO}_{2}$ (a) (101) surfaces (PBE+D3BJ, PAW). Spectator coadsorbed acids are not shown for clarity; distances are given in $\mathrm{nm}$.

1-Hydroxy enolates can attack the carboxylic $\mathrm{C}$-atom in a vicinal $\mathrm{AcO}^{*}$ via its nucleophilic $\beta$-C-atom to form a new $\mathrm{C}-\mathrm{C}$ bond (Step 4, Scheme 5). The two C-atoms lie farther apart at the TS $(0.234 \mathrm{~nm}$, Scheme $11 \mathrm{~b})$ than in the product state $(0.150 \mathrm{~nm})$, but are closer than their combined van der Waals radii $(0.340 \mathrm{~nm})$, indicating that the C-C coupling TS lies at an intermediate point along the reaction coordinate. The $\mathrm{OH}$ group in the acid moiety of the C-C coupling TS structure is stabilized by H-bonding with a 
neighboring lattice $\mathrm{O}_{2 \mathrm{c}}$ atom and with the bound $\mathrm{OH}$ species formed via dissociation of coadsorbed ethanoic acid to form $\mathrm{AcO}^{*}$ at vicinal $\mathrm{Ti}_{5 \mathrm{c}}-\mathrm{O}_{2 \mathrm{c}}$ pairs (Scheme $11 \mathrm{~b}$ ).

The $\alpha$-hydroxy $\gamma$-carboxy alkoxide formed via $\mathrm{C}$-C coupling undergoes an intramolecular $\mathrm{H}$-shift mediated by the $\mathrm{TiO}_{2}$ (a) (101) surface to form a $\beta$-keto carboxylate and $\mathrm{H}_{2} \mathrm{O}(\mathrm{g})$ (Steps 5-7, Scheme 5). The carboxyl H-atom in the alkoxide first transfers to a vicinal $\mathrm{O}_{2 \mathrm{c}}$ (Step 5, Scheme 5); this TS occurs very early along the reaction coordinate, as evidenced by the similar carboxyl O-H bond lengths in the reactant and the TS (0.104 vs. $0.105 \mathrm{~nm}$, Scheme 11c). The H-shift TS is stabilized by interactions with the bound $\mathrm{OH}$ species derived from coadsorbed $\mathrm{AcO}^{*}$ (Scheme 11c). The H-atom that shifts to the $\mathrm{O}_{2 \mathrm{c}}$ site then combines with the $\alpha-\mathrm{OH}$ group in the alkoxide to form $\mathrm{H}_{2} \mathrm{O}$ (Step 6, Scheme 5). This latter step is mediated by a late TS with a nearly-formed $\mathrm{H}_{2} \mathrm{O}$ molecule at the TS (TS structures in Section S16, SI), consistent with the endothermic nature of this reaction (+94 $\mathrm{kJ} \mathrm{mol}^{-1}, 523 \mathrm{~K}$, Section S17, SI).

The $\beta$-keto carboxylate species then reprotonates to form a $\beta$-keto acid (Step 8, Scheme 5), which decarboxylates to propen-2-olate and $\mathrm{CO}_{2}$ (Steps 9-11, Scheme 5). The C-C bond between the carboxylate and the enolate moiety at the decarboxylation TS $\left(d_{\mathrm{C}-\mathrm{C}}\right.$ $=0.243 \mathrm{~nm}$; Scheme $11 \mathrm{~d})$ is longer than that in the $\beta$-keto carboxylate reactant $\left(d_{\mathrm{C}-\mathrm{C}}=\right.$ $0.152 \mathrm{~nm})$. The elongation of this $\mathrm{C}-\mathrm{C}$ bond at the decarboxylation TS is consistent with the sequential nature of the formation of the $\mathrm{H}_{2} \mathrm{O}$ and $\mathrm{CO}_{2}$ decomposition products (Steps $5-10$, Scheme 5) and indicative of the stable nature of discrete $\beta$-keto carboxylate intermediates formed via endothermic dehydration steps (Steps 5-6, Scheme 5) on $\mathrm{TiO}_{2}(\mathrm{a})$ (101).

The propen-2-olate product formed in the decarboxylation of $\beta$-keto carboxylates (Step 10, Scheme 5) reprotonates to form acetone (Step 12, Scheme 5). The TS structure 
(Section S16, SI) resembles that for enolate formation from $\mathrm{AcO}^{*}$ in its condensation reactions (Scheme 11a), but with a shorter $\alpha-\mathrm{C}-\mathrm{H}$ and a longer $\alpha-\mathrm{H}-\mathrm{O}_{2 \mathrm{c}}$ bond $(0.148$ vs. $0.150 \mathrm{~nm}, 0.114$ vs. $0.113 \mathrm{~nm}$, respectively). Acetone desorption (Step 13, Scheme 5) then completes the catalytic ketonization turnover on $\mathrm{TiO}_{2}(\mathrm{a})$ surfaces.

Figure 9 depicts free energies along the reaction coordinate for the ketonization elementary steps in Scheme $5(523 \mathrm{~K}, 1$ bar ethanoic acid, $1 \mathrm{ML}$ AcO*) relative to two gaseous ethanoic acids and a bare $\mathrm{TiO}_{2}$ (a) surface (enthalpies and entropies; Section S17, SI). AcO* species exhibit the lowest free energy among adsorbed species, consistent with $\mathrm{AcO}^{*}$ as the most abundant surface intermediate (MASI). DFT-derived adsorption free energies for $\mathrm{AcO}^{*}\left(\Delta G_{\mathrm{AcO}^{*}}-50 \mathrm{~kJ} \mathrm{~mol}^{-1}\right.$, Eq. 10; Fig. 9) are slightly more negative than measured values $\left(-33 \pm 1 \mathrm{~kJ} \mathrm{~mol}^{-1}\right.$, Table 3$)$, a trend that reflects the overbinding tendencies of the Grimme's D3BJ dispersion corrections in PBE functionals $[43,44]$; this is also evident from the more negative $\Delta H_{\mathrm{AcO}} *$ values derived from theory $\left(-140 \mathrm{~kJ} \mathrm{~mol}^{-1}\right.$, Table 6) compared with those obtained from the regression of the temperature dependence of measured $K_{1}$ values $\left(-114 \pm 3 \mathrm{~kJ} \mathrm{~mol}^{-1}\right.$, Table 3).

The C-C coupling TS ( $\mathrm{TS}_{4}$ in Fig. 9; Step 4, Scheme 5) gives the highest free energy along the reaction coordinate, consistent with its kinetic relevance in ketonization reactions on $\mathrm{TiO}_{2}$ (a). The DFT-derived $\Delta G^{*}$ CC, value (Eq. 14), given by the difference between the free energies of the C-C coupling TS and two bound $\mathrm{AcO}^{*}$ species, is $160 \mathrm{~kJ}$ $\mathrm{mol}^{-1}(523 \mathrm{~K}, 1$ bar ethanoic acid, $1 \mathrm{ML} \mathrm{AcO} *$; Table 6); its respective enthalpy and entropy components $\left(\Delta H_{\mathrm{CC}, \mathrm{a}}^{\sharp}, \Delta S_{\mathrm{CC}, \mathrm{a}}^{\ddagger}\right)$ are $128 \mathrm{~kJ} \mathrm{~mol}^{-1}$ and $-63 \mathrm{~J} \mathrm{~mol}^{-1} \mathrm{~K}^{-1}$ (Table 6). Measured $\Delta G_{\mathrm{CC}, \mathrm{a}}^{\ddagger} \Delta H_{\mathrm{CC}, \mathrm{a}}^{\star}$ and $\Delta S_{\mathrm{CC}, \mathrm{a}}^{\star}$ values are $166 \pm 1 \mathrm{~kJ} \mathrm{~mol}^{-1}, 137 \pm 1 \mathrm{~kJ} \mathrm{~mol}^{-1}$, and $-56 \pm 1 \mathrm{~J} \mathrm{~mol}^{-1} \mathrm{~K}^{-1}$ (Tables 2 and 3), in good agreement with these DFT estimates. The $\Delta H_{\mathrm{CC}, \mathrm{a}}^{\ddagger}$ difference between DFT-derived and measured values $\left(9 \mathrm{~kJ} \mathrm{~mol}^{-1}\right)$ is much 
smaller than for $\Delta H_{\mathrm{AcO}}\left(27 \mathrm{~kJ} \mathrm{~mol}^{-1}\right)$, because overbinding tendencies influence the bound reactant and TS for $\Delta H_{\mathrm{CC}, \mathrm{a}}^{*}$, but only the product state in the case of $\Delta H_{\mathrm{AcO}}$. DFTderived kinetic isotope effects for the C-C coupling step ( $\overrightarrow{k_{4}} K_{3}$, Eq. 13) and thermodynamic isotope effects for ethanoic acid dissociation to $\mathrm{AcO}^{*}\left(K_{1}\right.$, Eq. 9) are both near unity $\left(\left(\overrightarrow{k_{4}} K_{3}\right)_{\mathrm{H}} /\left(\overrightarrow{k_{4}} K_{3}\right)_{\mathrm{D}}=1.1,\left(K_{1}\right)_{\mathrm{H}} /\left(K_{1}\right)_{\mathrm{D}}=0.9 ; 523 \mathrm{~K}\right.$, Table 6$)$, in agreement with experiments $\left(\left(\left(\overrightarrow{k_{4}} K_{3}\right)_{\mathrm{H}} /\left(\overrightarrow{k_{4}} K_{3}\right)_{\mathrm{D}}=1.1,\left(K_{1}\right)_{\mathrm{H}} /\left(K_{1}\right)_{\mathrm{D}}=1.0 ; 523 \mathrm{~K}\right.\right.$, Table 2$)$.

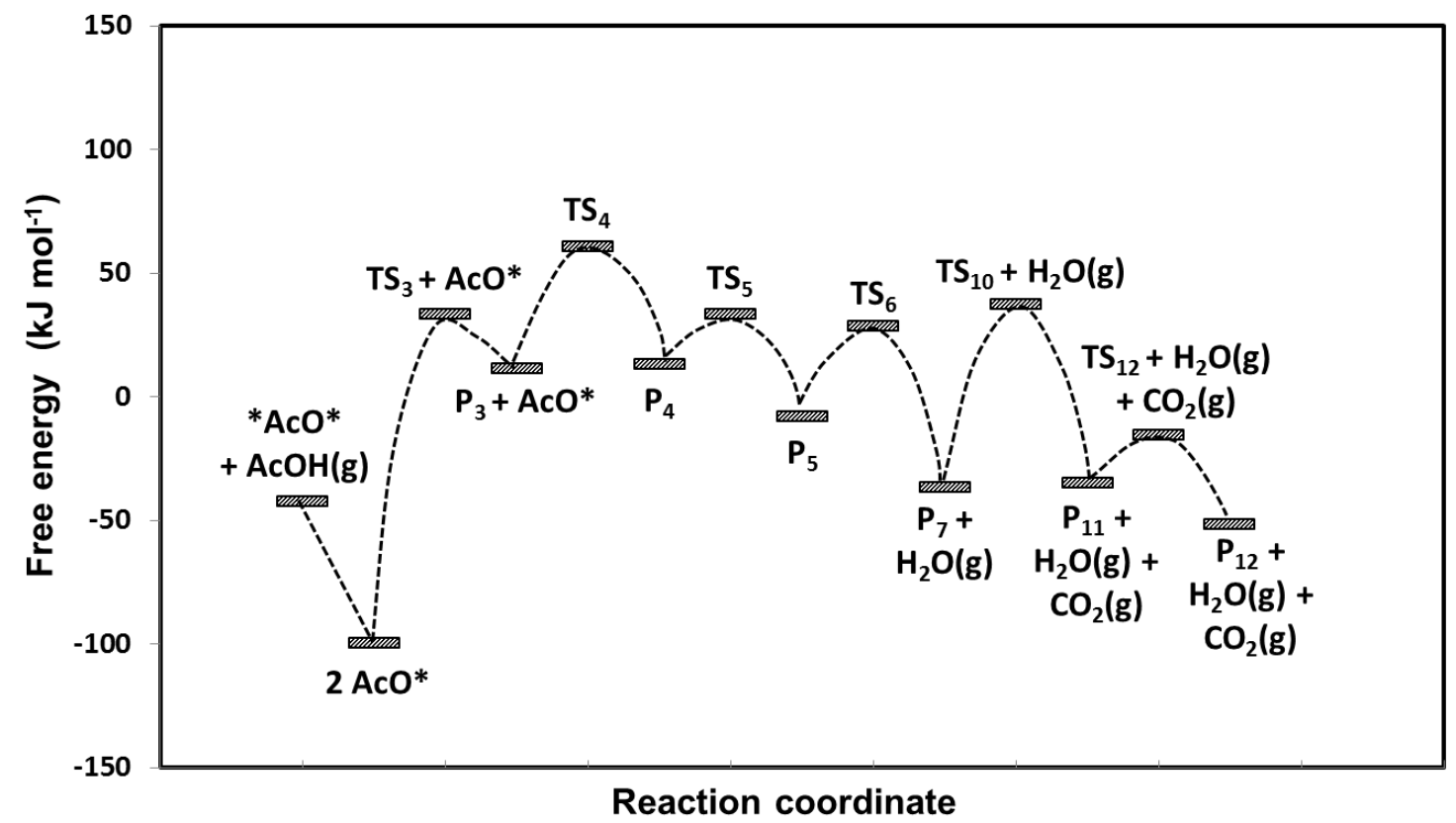

Figure 9. DFT-derived free energy reaction coordinate diagram for ethanoic acid ketonization on $\mathrm{TiO}_{2}$ (a) (101) surfaces (PBE+D3BJ, PAW; $523 \mathrm{~K}, 1$ bar ethanoic acid, 1 ML AcO*). All energy values are reference to two gaseous ethanoic acid reactants and a bare $\mathrm{TiO}_{2}$ (a) surface, which defines the zero energy point in the ordinate. Only key surface intermediates and transition states are shown for clarity. $\mathrm{TS}_{x}$ and $\mathrm{P}_{x}$ represent the transition state and product of Step $x$ in Scheme 5, respectively. 
Table 6. DFT-derived $\Delta G_{\mathrm{AcO} *}, \Delta G^{\ddagger} \mathrm{CC}$,a and corresponding enthalpy and entropy components and isotope effects for ethanoic acid ketonization on $\mathrm{TiO}_{2}$ (a) (101) surfaces at $1 \mathrm{ML}$ and $1 / 3 \mathrm{ML} \mathrm{AcO*}$ coverages. $^{\text {a }}$

\begin{tabular}{|c|c|c|c|c|c|c|c|c|}
\hline $\begin{array}{c}\theta_{\text {acid }} \\
\text { (ML) }\end{array}$ & $\begin{array}{c}\Delta H_{\mathrm{AcO}^{*}} \\
\left(\mathrm{~kJ} \mathrm{~mol}^{-1}\right)\end{array}$ & $\begin{array}{c}\Delta S_{\mathrm{AcO} 0^{*}} \\
\left(\mathrm{~J} \mathrm{~mol}^{-1} \mathrm{~K}^{-1}\right)\end{array}$ & $\begin{array}{c}\Delta G_{\mathrm{AcO}^{*}} \\
\left(\mathrm{~kJ} \mathrm{~mol}^{-1}\right)\end{array}$ & $\begin{array}{c}\Delta H_{\mathrm{CC}, \mathrm{a}}^{*} \\
\left(\mathrm{~kJ} \mathrm{~mol}^{-1}\right)\end{array}$ & $\begin{array}{c}\Delta S_{\mathrm{CC}, \mathrm{a}}^{\sharp} \\
\left(\mathrm{J} \mathrm{mol}^{-1} \mathrm{~K}^{-1}\right)\end{array}$ & $\begin{array}{c}\Delta G^{\ddagger} \mathrm{CC}, \mathrm{a} \\
\left(\mathrm{kJ} \mathrm{mol}^{-1}\right)\end{array}$ & $\frac{\left(K_{1}\right)_{\mathrm{H}}}{\left(K_{1}\right)_{\mathrm{D}}}$ & $\frac{\left(\overrightarrow{k_{4}} K 3\right)_{\mathrm{H}}}{\left(\overrightarrow{k_{4}} K 3\right)_{\mathrm{D}}}$ \\
\hline 1 & -140 & -172 & -50 & 128 & -63 & 160 & 0.9 & 1.1 \\
\hline $1 / 3$ & -135 & -160 & -51 & 149 & -60 & 181 & 0.9 & 1.1 \\
\hline
\end{tabular}

${ }^{a}$ PBE+D3BJ, PAW, $523 \mathrm{~K}, 1$ bar ethanoic acid.

DFT-derived structures for bound intermediates and transition states in Scheme 5 are similar at 1/3 ML and $1 \mathrm{ML} \mathrm{AcO*}$ coverages. The $\mathrm{C}-\mathrm{C}$ bond at the $\mathrm{C}-\mathrm{C}$ coupling $\mathrm{TS}$ (Step 4, Scheme 5) is only slightly shorter at 1/3 ML (0.224 nm, Scheme 11e) than at 1 ML (0.234 nm, Scheme 11b). DFT-derived free energies along the reaction coordinate (Section $\mathrm{S} 18, \mathrm{SI}$ ) show that $\mathrm{AcO}^{*}$ remains the MASI and the $\mathrm{C}-\mathrm{C}$ coupling remains the kinetically-relevant step at both coverages. The $\Delta G_{\mathrm{CC}, \mathrm{a}}^{\ddagger}$ value, however, is larger at lower coverages (181 vs. $160 \mathrm{~kJ} \mathrm{~mol}^{-1}$, Table 6), a difference that predominantly reflects the stabilizing effects of H-bonding on $\Delta H^{\ddagger} \mathrm{CC}$,a at higher coverages (149 vs. $128 \mathrm{~kJ} \mathrm{~mol}^{-1}$, Table 6). We conclude that the prevalent high acid coverages are requisite for ketonization catalysis because of the preferential stabilization of the $\mathrm{C}-\mathrm{C}$ bond formation TS over its relevant precursors on $\mathrm{TiO}_{2}$ (a) (101) by H-bonding, which become most evident at near-saturation coverages. Such coverage effects provide yet another demonstration of how dense monolayers allow facile turnovers for reactions that would proceed much more slowly, or not at all, at lower coverages, because crowded surfaces favor TS structures over those of the relevant precursors [57].

A concerted form of the two-step $\mathrm{H}_{2} \mathrm{O}$ elimination reaction (Steps 5-6, Scheme 5) of $\alpha$-hydroxy $\gamma$-carboxy alkoxide species (formed in the $\mathrm{C}$-C coupling step) to $\beta$-keto carboxylates becomes kinetically-accessible only at low acid coverages (1/3 $\mathrm{ML}$ AcO*, 
Scheme 12). This concerted route is mediated by a six-membered ring TS (Scheme 11f) and involves a direct shift of the carboxyl $\mathrm{H}$-atom to the leaving $\alpha-\mathrm{OH}$ group. This route exhibits a slightly lower free energy at the TS than for the $\mathrm{H}_{2} \mathrm{O}$ formation TS involved in the two-step route (Step 6, Scheme 5), but only at acid coverages much lower than those prevalent during practical ketonization catalysis (65 vs. $69 \mathrm{~kJ} \mathrm{~mol}^{-1}, 1 / 3 \mathrm{ML}$, Section S18, SI). The concerted route becomes favored at low coverages, which cannot provide the Hbonding interactions that favor the sequential two-step pathways. This concerted route, however, was not considered in previous studies [3,19], in which theoretical treatments were implemented on essentially bare surfaces.

5s. Intramolecular dehydration of $\alpha$-hydroxy $\gamma$-carboxy alkoxide to form $\beta$-keto carboxylate
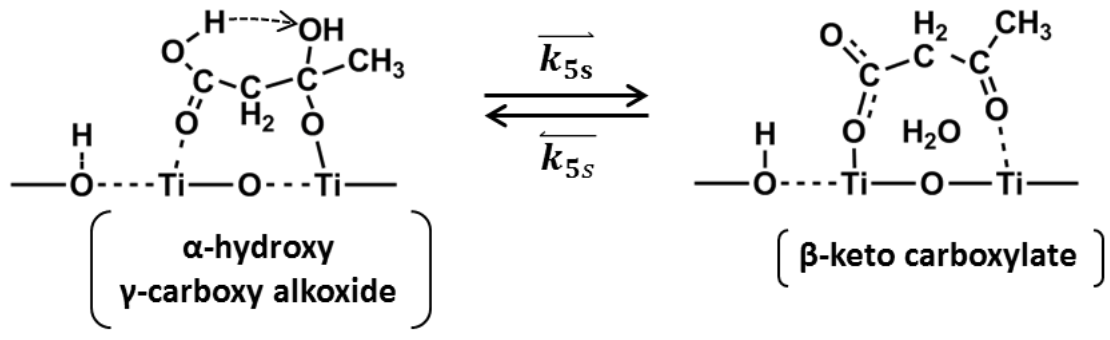

Scheme 12. Direct intramolecular dehydration of $\alpha$-hydroxy $\gamma$-carboxy alkoxide.

The ketonization elementary steps in Scheme 5 were also examined on coordinatively-unsaturated $\mathrm{Ti}_{5 \mathrm{c}}-\mathrm{O}_{2 \mathrm{c}}$ pairs at $\mathrm{TiO}_{2}(\mathrm{r})$ (110) surfaces. $\mathrm{AcOH}^{*}$ is the stable monodentate form of adsorbed ethanoic acid at $\mathrm{Ti}_{5 \mathrm{c}}-\mathrm{O}_{2 \mathrm{c}}$ pairs on $\mathrm{TiO}_{2}(\mathrm{r})$ surfaces (Scheme 9e), in contrast with the dissociated $\mathrm{AcO}^{*}$ species that prevail on $\mathrm{TiO}_{2}(\mathrm{a})(101)$ (Schemes 9b,c). These AcOH* species are much less stable, however, than bidentate carboxylates $\left(* \mathrm{AcO}^{*}\right)$ on $\mathrm{TiO}_{2}(\mathrm{r})(110)(\mathrm{Fig} .8) \cdot \mathrm{TiO}_{2}(\mathrm{r})$ surfaces thus prefer to saturate with $* \mathrm{AcO}^{*}$. The free energies for ${ }^{*} \mathrm{AcO}^{*}$ on $\mathrm{TiO}_{2}(\mathrm{r})(110)\left(-72 \mathrm{~kJ} \mathrm{~mol}^{-1}, 523 \mathrm{~K}, 1 \mathrm{bar}\right.$ ethanoic acid, with respect to gaseous ethanoic acid reactants and a $\mathrm{TiO}_{2}(\mathrm{r})$ surface henceforth) were more negative than those for other intermediates or transition states 
along the ketonization coordinate (Fig. 10; discussed in detail below), indicating that *AcO* is the MASI on $\mathrm{TiO}_{2}(\mathrm{r})(110)$ at ketonization conditions. These theoretical conclusions are consistent with the infrared spectra obtained from $\mathrm{TiO}_{2}(\mathrm{r})$ samples during ethanoic acid ketonization catalysis (Section 3.3).

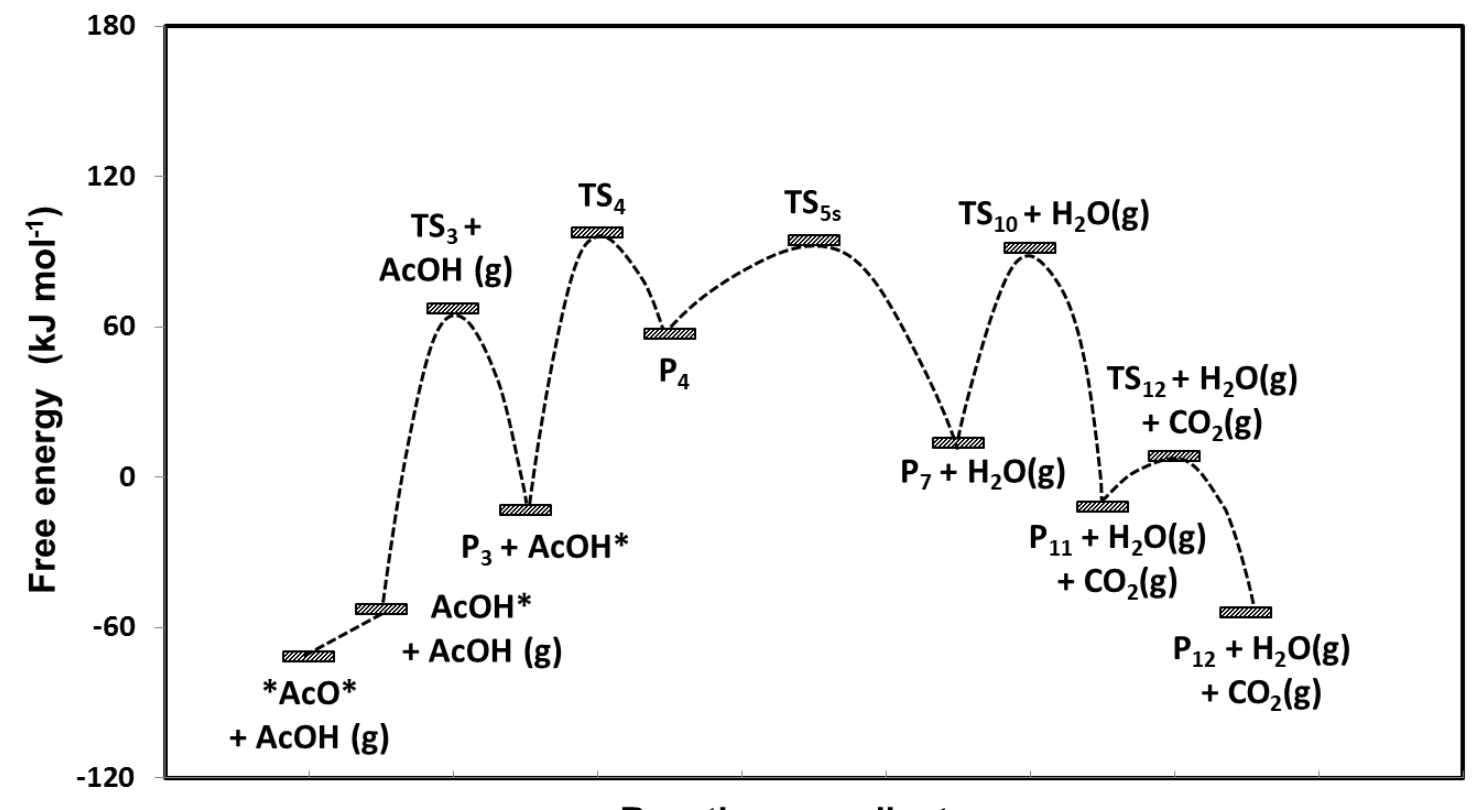

Reaction coordinate

Figure 10. DFT-derived free energy reaction coordinate diagram for ethanoic acid ketonization on $\mathrm{TiO}_{2}(\mathrm{r})$ (110) surfaces (PBE+D3BJ, PAW; $523 \mathrm{~K}, 1$ bar ethanoic acid, $1 / 2 \mathrm{ML} * \mathrm{AcO} *)$. All energy values are relative to two gaseous ethanoic acid reactants and a bare $\mathrm{TiO}_{2}$ surface, which defines the zero energy point in the ordinate. Only key surface intermediates and transition states are shown for clarity. $\mathrm{TS}_{x}$ and $\mathrm{P}_{x}$ represent the transition state and product of Step $x$ in Scheme 5, respectively, except $\mathrm{TS}_{5 \mathrm{~s}}$ that represents the transition state of Step 5s in Scheme 12.

The formations of 1-hydroxy enolates from monodentate and bidentate forms of adsorbed ethanoic acids on $\mathrm{TiO}_{2}(\mathrm{r})(110)\left(\mathrm{AcOH}^{*}\right.$ and $* \mathrm{AcO}^{*}$ in this case) were both examined. The enolization of $\mathrm{AcOH}^{*}$ at a $\mathrm{Ti}_{5 \mathrm{c}}-\mathrm{O}_{2 \mathrm{c}}$ pair on $\mathrm{TiO}_{2}(\mathrm{r})$ (110) involves $\mathrm{TS}$ structures (Scheme 13a) similar to those on $\mathrm{TiO}_{2}(\mathrm{a})$ (110) (Scheme 11a). The abstracted $\alpha$-H-atom at the TS on $\mathrm{TiO}_{2}(\mathrm{r})(110)$ is slightly closer to the $\mathrm{O}_{2 \mathrm{c}}$ site and farther from the $\alpha-\mathrm{C}$ atom than on $\mathrm{TiO}_{2}(\mathrm{a})$ (101) (0.109 vs. $0.113 \mathrm{~nm}, 0.162$ vs. $0.150 \mathrm{~nm}$, Schemes $11 \mathrm{a}$ 
and 13a). This later TS on $\mathrm{TiO}_{2}(\mathrm{r})(110)$ is consistent with the weaker basicity of $\mathrm{O}_{2 \mathrm{c}}$ sites on $\mathrm{TiO}_{2}(\mathrm{r})(110)$ than on $\mathrm{TiO}_{2}(\mathrm{a})(101)\left(E_{\mathrm{PA}}-1093\right.$ vs. $-1175 \mathrm{~kJ}$ mol${ }^{-1}$, Table 5). In contrast to $\mathrm{AcOH}^{*},{ }^{*} \mathrm{AcO} *$ binds to two neighboring $\mathrm{Ti}_{5 \mathrm{c}}$ centers via its two $\mathrm{O}$-atoms before its $\alpha$-H-atom is abstracted by a vicinal $\mathrm{O}_{2 c}$ site (Scheme 13b). The enolization TS of *AcO* has a more negative enthalpy than for $\mathrm{AcOH}^{*}\left(-45 \mathrm{vs} .-33 \mathrm{~kJ} \mathrm{~mol}^{-1}, 523 \mathrm{~K}, 1 / 2\right.$ ML AcO*, Section S19, SI), but also a larger entropy loss (-229 vs. $-192 \mathrm{~J} \mathrm{~mol}^{-1} \mathrm{~K}^{-1}$, Section S19, SI); these differences lead to a higher free energy for the enolization TS of *AcO* than that of $\mathrm{AcOH}^{*}$ (75 vs. $67 \mathrm{~kJ} \mathrm{~mol}^{-1}$ ), indicating the more strongly bound *AcO* species are less reactive than $\mathrm{AcOH}^{*}$ in the formation of 1-hydroxy enolates.

(a) Enolization of $\mathrm{AcOH}^{*}$

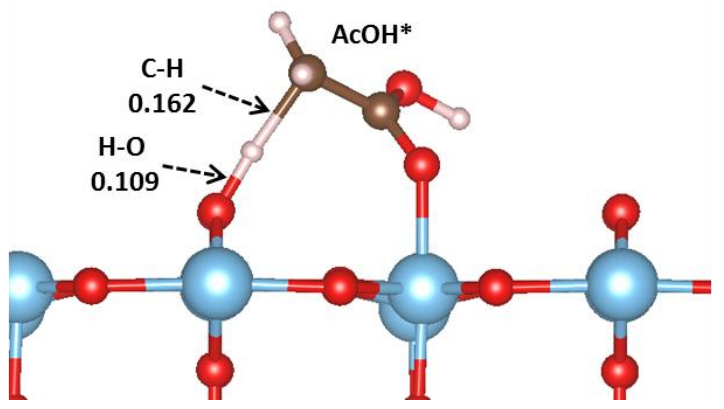

(c) C-C coupling with coadsorbed $\mathrm{AcOH}^{*}$

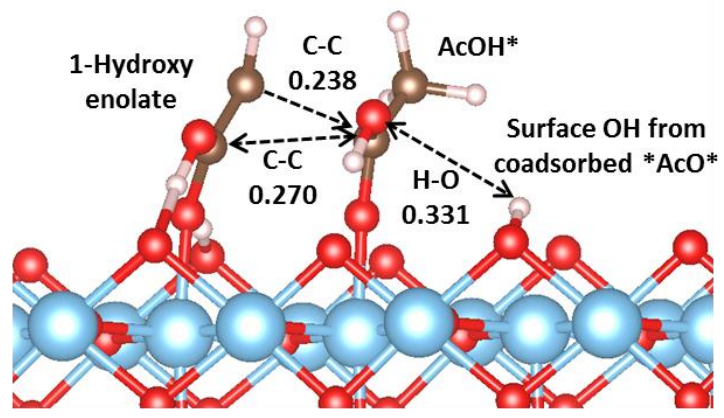

(b) Enolization of *AcO*

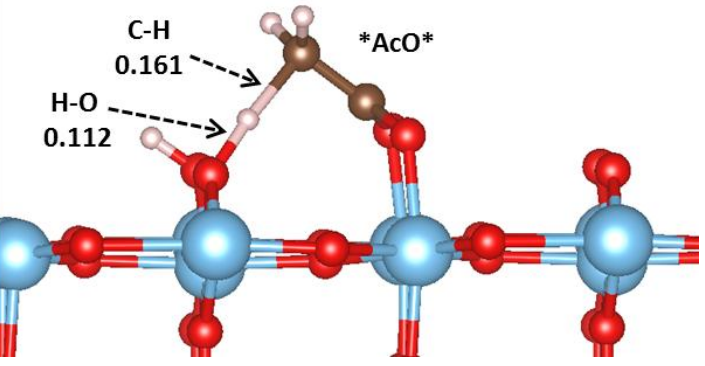

(d) Intramolecular dehydration

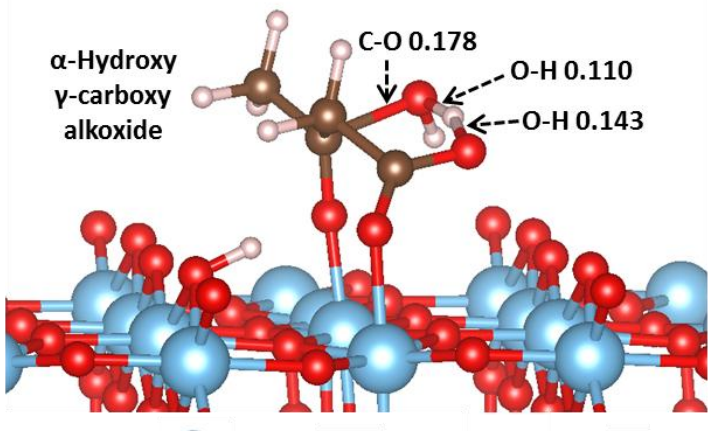

$\mathrm{Ti} ; \odot \mathrm{O} ; \odot \mathrm{C} ; \mathrm{O}$

Scheme 13. DFT-derived transition state structures involved in ethanoic acid ketonization on $\mathrm{TiO}_{2}(\mathrm{r})(110)$ surfaces $(\mathrm{PBE}+\mathrm{D} 3 \mathrm{BJ}, \mathrm{PAW}, 1 / 2 \mathrm{ML} * \mathrm{AcO} *)$. Spectator coadsorbed acids are not shown for clarity. 
The 1-hydroxy enolates nucleophilically attack another $\mathrm{AcOH}^{*}$ coadsorbed at a vicinal $\mathrm{Ti}_{5 \mathrm{c}}-\mathrm{O}_{2 c}$ pair to form a new C-C bond (Step 4, Scheme 5). The incipient $\mathrm{C}-\mathrm{C}$ bond at the C-C coupling TS on $\mathrm{TiO}_{2}(\mathrm{r})(110)$ has a distance of $0.238 \mathrm{~nm}$ (Scheme 12c), similar with that on $\mathrm{TiO}_{2}$ (a) (101) $(0.234 \mathrm{~nm}$, Scheme 10b). DFT-derived enthalpies for this TS, however, are much less negative on $\mathrm{TiO}_{2}(\mathrm{r})(110)$ than on $\mathrm{TiO}_{2}(\mathrm{a})(101)(-116 \mathrm{vs}$. $-152 \mathrm{~kJ} \mathrm{~mol}^{-1}, 523 \mathrm{~K}$, referenced to two gaseous $\mathrm{AcOH}$ reactants and a bare $\mathrm{TiO}_{2}(\mathrm{r}) / \mathrm{TiO}_{2}$ (a) surface, Sections $\mathrm{S} 16$ and $\left.\mathrm{S} 18, \mathrm{SI}\right)$; these less favorable enthalpies lead, in turn, to much higher TS free energies on $\mathrm{TiO}_{2}(\mathrm{r})(110)\left(97 \mathrm{~kJ} \mathrm{~mol}^{-1}\right.$, Fig. 10) than on $\mathrm{TiO}_{2}$ (a) (101) (61 kJ mol${ }^{-1}$, Fig. 9). The less stable C-C coupling TS structures on $\mathrm{TiO}_{2}(\mathrm{r})$ (110) reflect, in part, stronger repulsive interactions between the bound 1-hydroxy enolate and the coadsorbed $\mathrm{AcOH}^{*}$ reactants at the TS, because of the closer $\mathrm{Ti}_{5}-\mathrm{Ti}_{5}$ centers on $\mathrm{TiO}_{2}(\mathrm{r})$ (110); they also reflect the absence of H-bonding between the C-C coupling TS and surface $\mathrm{OH}$ species derived from $* \mathrm{AcO}^{*}$ bound at neighboring $\mathrm{Ti}_{5 \mathrm{c}}-\mathrm{O}_{2 \mathrm{c}}$ pairs, as a result of the longer $\mathrm{Ti}_{5 c}-\mathrm{O}_{2 c}$ distance on $\mathrm{TiO}_{2}(\mathrm{r})$ (110), which places surface $\mathrm{OH}$ species farther from the C-C coupling TS (Scheme 13c).

The subsequent dehydration of the C-C coupling products ( $\alpha$-hydroxy $\gamma$-carboxy alkoxide species) to $\beta$-keto carboxylates preferentially occurs via the concerted sixmembered ring TS route (Scheme 12) on $\mathrm{TiO}_{2}(\mathrm{r})$ (110) (Scheme 13d; free energy $94 \mathrm{~kJ}$ mol $^{-1}, 523 \mathrm{~K}, 1$ bar ethanoic acid, Fig. 10), as also found, but only at 1/3 ML coverages, on $\mathrm{TiO}_{2}$ (a) (101) (Scheme 11f). In contrast, the two-step intramolecular H-shift pathway (Steps 5-6, Scheme 5), mediated by $\mathrm{O}_{2 c}$ sites, is unfeasible on $\mathrm{TiO}_{2}(\mathrm{r})$ (110), as shown by the high TS free energies for the H-shift from the carboxyl group in alkoxides to a vicinal $\mathrm{O}_{2 \mathrm{c}}$ site (>150 kJ mol${ }^{-1}, 523 \mathrm{~K}, 1$ bar ethanoic acid; Step 5, Scheme 5). Such high free energies reflect the weakly basic $\mathrm{O}_{2 c}$ sites on $\mathrm{TiO}_{2}(\mathrm{r})(110)$, as well as the lack of $\mathrm{H}$ - 
bonding stabilization by neighboring surface $\mathrm{OH}$ species, which also leads to the high TS free energies for the $\mathrm{C}-\mathrm{C}$ coupling steps on $\mathrm{TiO}_{2}(\mathrm{r})$ as discussed above (Scheme 13c).

Decarboxylation and reprotonation of the $\beta$-keto carboxylate dehydration products form acetone and $\mathrm{CO}_{2}$ (Steps 10-14, Scheme 5), which complete the ketonization turnover on $\mathrm{TiO}_{2}(\mathrm{r})$ surfaces. DFT-derived structures of reactants, transition states, and products involved in these steps also resemble those on $\mathrm{TiO}_{2}(\mathrm{a})(101)$.

The C-C coupling TS (Step 4, Scheme 5) has the highest free energy along the ketonization pathway on $\mathrm{TiO}_{2}(\mathrm{r})(110)(523 \mathrm{~K}, 1$ bar ethanoic acid, with respect to two gaseous ethanoic acid reactants and a bare $\mathrm{TiO}_{2}(\mathrm{r})$ surface, Fig. 10), indicating that the ketonization rates on $\mathrm{TiO}_{2}(\mathrm{r})$ (110) are limited by the $\mathrm{C}-\mathrm{C}$ coupling step between 1hydoxy enolates and coadsorbed acids. Ketonization rates on saturated $\mathrm{TiO}_{2}(\mathrm{r})(110)$ surfaces, prevalent at ketonization conditions as evident from infrared spectra (Section 3.3), can thus be described as:

$$
\frac{r}{[L]}=\frac{k_{B} T}{2 h} \exp \left(-\Delta G_{\mathrm{CC}, \mathrm{r}}^{\ddagger} / R T\right) P_{\mathrm{acid}}
$$

where $[L]$ is the number of catalytically-relevant Ti-O pairs on $\mathrm{TiO}_{2}(\mathrm{r})(110) ; \Delta G_{\mathrm{CC}, \mathrm{r}}^{\ddagger}$ represents the free energy of the C-C coupling $\mathrm{TS}\left(G^{\ddagger} \mathrm{CC}\right)$ on $\mathrm{TiO}_{2}(\mathrm{r})(110)$ with respect to a bound $*$ AcO $*$ species $\left(G *{ }^{*} c^{*}\right)$ and a gaseous acid reactant $\left(G_{\text {acid }}\right)$ :

$$
\Delta G_{\mathrm{CC}, \mathrm{r}}^{\ddagger}=G_{\mathrm{CC}}^{\ddagger}-G_{* \mathrm{AcO} *}-G_{\text {acid }}
$$

DFT-derived $\Delta G^{\ddagger}$ CC,r value is $169 \mathrm{~kJ} \mathrm{~mol}^{-1}$ (523 K, 1 bar ethanoic acid, Fig. 10), leading to ketonization turnover rates that linearly increase from $7.3 \times 10^{-8}$ to $2.2 \times 10^{-6}$ (Ti-O) $)^{-1} \mathrm{~s}^{-1}$ as the pressure of ethanoic acid increases within $0.1-3.0 \mathrm{kPa}$ at $523 \mathrm{~K}$ (Eq. 21). Such a first-order kinetic dependence on ethanoic acid pressure is inconsistent with the functional form of Equation 7, which accurately describes the measured ketonization 
rates on $\mathrm{TiO}_{2}(\mathrm{r})$ within the same pressure range (Fig. 4); the respective ketonization turnover rates $\left(7.3 \times 10^{-8}-2.2 \times 10^{-6}(\mathrm{Ti}-\mathrm{O})^{-1} \mathrm{~s}^{-1}\right)$ estimated from the DFT treatments are also much lower than the experimentally-measured values $\left(4.3 \times 10^{-6}-3.0 \times 10^{-5}(\mathrm{Ti}-\mathrm{O})^{-1} \mathrm{~s}^{-1}\right)$, Fig. 4). These DFT calculations thus provide evidence that the majority $\mathrm{TiO}_{2}(\mathrm{r})$ surfaces are inactive for ketonization and that the minority sites or residual $\mathrm{TiO}_{2}$ (a) surfaces present in the $\mathrm{TiO}_{2}(\mathrm{r})$ powders account for the measured ketonization rates.

The above theoretical treatments and their accurate benchmarking with experiments shed light into the underpinning geometric factors that lead to marked reactivity differences between rutile and anatase $\mathrm{TiO}_{2}$ surfaces. Specifically, the identity and binding properties of the prevalent forms of dissociated acid reactants and their reactivity in ketonization depend on the local extended coordination of coordinatively-unsaturated $\mathrm{Ti}_{5 \mathrm{c}}-\mathrm{O}_{2 \mathrm{c}}$ pairs. The concerted stabilization of the relevant $\mathrm{C}-\mathrm{C}$ bond formation transition states leads to compensation effects that attenuate the differences in acid strength of the $\mathrm{Ti}_{5 c}$ centers and in basicity of the $\mathrm{O}_{2 c}$ centers between $\mathrm{Ti}_{5 c}-\mathrm{O}_{2 c}$ pairs on $\mathrm{TiO}_{2}(\mathrm{r})(110)$ and $\mathrm{TiO}_{2}$ (a) (101). Consequently, $\mathrm{Ti}_{5 \mathrm{c}}-\mathrm{O}_{2 \mathrm{c}}$ and $\mathrm{Ti}_{5 \mathrm{c}}-\mathrm{Ti}_{5 \mathrm{c}}$ distances are the most accurate descriptors of reactivity for ketonization of carboxylic acids on $\mathrm{TiO}_{2}$ and account for the very different reactivity of anatase and rutile surfaces.

\section{Conclusions}

$\mathrm{C}_{2}-\mathrm{C}_{4}$ carboxylic acids undergo selective ketonization to alkanones, $\mathrm{CO}_{2}$, and $\mathrm{H}_{2} \mathrm{O}$ on $\mathrm{TiO}_{2}$ and $\mathrm{ZrO}_{2}$ catalysts at $503-533 \mathrm{~K}$. Coordinatively unsaturated acid-base $\mathrm{M}-\mathrm{O}(\mathrm{M}=$ $\mathrm{Ti}, \mathrm{Zr}$ ) pairs on these oxides are catalytically relevant for ketonization reactions; the numbers of these pairs were titrated by carboxylic acids during aldol condensation reactions. Ketonization turnover rates are higher on monoclinic $\mathrm{ZrO}_{2}$ than on tetragonal 
$\mathrm{ZrO}_{2}$ and anatase $\mathrm{TiO}_{2}$ but are much lower on rutile $\mathrm{TiO}_{2}$. The more active oxides, however, show larger deactivation rate constants. Unreactive bidentate carboxylates, formed gradually from dissociation of carboxylic acids on $\mathrm{M}-\mathrm{O}$ pairs, account for the deactivation during steady-state catalysis. $\mathrm{Cu}$ co-catalysts and added $\mathrm{H}_{2}$ scavenge trace levels of gaseous ketene species, present in equilibrium with bidentate carboxylates, via hydrogenation of these ketene species to alkanals and 1-alkanols and thus inhibit deactivation significantly.

Infrared spectra and theoretical treatments show that dissociation of carboxylic acids on anatase $\mathrm{TiO}_{2}$ surfaces form monodentate carboxylates each bound on one Ti-O pair and bidentate carboxylates each bound on two vicinal Ti-O pairs. The stability of the monodentate carboxylates on anatase $\mathrm{TiO}_{2}$ surfaces is slightly influenced by the surface coverage, because of the absence of strong repulsive interactions between carboxylates bound to Ti-O pairs with large distances between nearest $\mathrm{Ti}$ centers. The bidentate carboxylates, in contrast, become less stable with increasing acid coverages, as a result of the mismatch between the distances of the Ti-Ti centers and of the $\mathrm{O}-\mathrm{O}$ atoms in the bidentate carboxylates. This difference in the stability dependence on the surface coverage for monodentate and bidentate carboxylates drives a strong preference to crowd anatase $\mathrm{TiO}_{2}$ surfaces with monodentate carboxylates, which are prevalent at ketonization conditions. In contrast with anatase $\mathrm{TiO}_{2}$, the closer $\mathrm{Ti}$ - $\mathrm{Ti}$ centers on rutile $\mathrm{TiO}_{2}$ lead to more efficient binding of the two $\mathrm{O}$-atoms in each bidentate carboxylate at these $\mathrm{Ti}$ centers and to stronger steric repulsion between monodentate adsorbed acids bound at vicinal Ti-O pairs. These effects combine to make bidentate carboxylates the predominant adsorbed species on rutile $\mathrm{TiO}_{2}$. 
The $\mathrm{C}-\mathrm{C}$ coupling of 1-hydroxy enolate species, formed from $\alpha-\mathrm{C}-\mathrm{H}$ cleavage of monodentate carboxylates or molecularly adsorbed acids, with coadsorbed acids acts as a common kinetically-relevant step for ketonization on anatase and rutile $\mathrm{TiO}_{2}$ surfaces. The C-C coupling transition state (TS) on anatase $\mathrm{TiO}_{2}$ becomes more stable relative to its monodentate carboxylate precursors as the coverage of the precursors increases, because of $\mathrm{H}$-bonding between this $\mathrm{C}-\mathrm{C}$ coupling $\mathrm{TS}$ and vicinal surface $\mathrm{OH}$ species derived from dissociation of coadsorbed carboxylic acids. Such stabilization via Hbonding also renders a surface-mediated two-step route favorable for the subsequent intramolecular dehydration of the C-C coupling products ( $\alpha$-hydroxy $\gamma$-carboxy alkoxides) at high acid coverages. In contrast, a concerted route through a six-membered ring TS prevails for this dehydration reaction at low acid coverages. These H-bonding interactions are absent on rutile $\mathrm{TiO}_{2}$ surfaces, because of the longer distance between $\mathrm{Ti}$ and $\mathrm{O}$ sites in $\mathrm{Ti}-\mathrm{O}$ pairs in rutile $\mathrm{TiO}_{2}$ than in anatase $\mathrm{TiO}_{2}$, making bound TS structures and surface $\mathrm{OH}$ species father apart from each other. The closer Ti-Ti centers on rutile $\mathrm{TiO}_{2}$ lead to steric hindrance between the coreactants at the $\mathrm{C}-\mathrm{C}$ coupling $\mathrm{TS}$, further rendering rutile $\mathrm{TiO}_{2}$ much less reactive than anatase $\mathrm{TiO}_{2}$ in ketonization catalysis. These differences in the stability of surface intermediates and transition states between anatase and rutile $\mathrm{TiO}_{2}$ surfaces unveil the necessity of moderate distances of acid-base and acid-acid centers for ketonization of carboxylic acids on metal oxides.

\section{Acknowledgments}

We acknowledge appreciatively the valuable technical insights and comments from Drs. Eric Doskocil, John Shabaker, Glenn Sunley, and all other members involved in the $\mathrm{BP} \mathrm{XC}^{2}$ program during this study. Drs. Stanley Herrmann, Prashant Deshlahra, and Elif 
Gurbuz at UC-Berkeley are also gratefully acknowledged for helpful discussions. The financial support of this research was provided by BP p.l.c. via the $\mathrm{XC}^{2}$ program at UCBerkeley. The computational resources were accessed through the Extreme Science and Engineering Discovery Environment (XSEDE), which is supported by National Science Foundation (grant number ACI-1053575).

\section{References}

[1] M. Renz, Eur. J. Org. Chem. 2005 (2005) 979-988.

[2] T.N. Pham, T. Sooknoi, S.P. Crossley, D.E. Resasco, ACS Catal. 3 (2013) 2456-2473.

[3] G. Pacchioni, ACS Catal. 4 (2014) 2874-2888.

[4] B. Peng, X. Yuan, C. Zhao, J.A. Lercher, J. Am. Chem. Soc. 134 (2012) 9400-9405.

[5] J. Sun, R.A.L. Baylon, C. Liu, D. Mei, K.J. Martin, P. Venkitasubramanian, Y. Wang, J. Am. Chem. Soc. 138 (2016) 507-517.

[6] C.A. Gaertner, J.C. Serrano-Ruiz, D.J. Braden, J.A. Dumesic, J. Catal. 266 (2009) 7178.

[7] A.J. Crisci, H. Dou, T. Prasomsri, Y. Román-Leshkov, ACS Catal. 4 (2014) 41964200.

[8] J.Q. Bond, A.A. Upadhye, H. Olcay, G.A. Tompsett, J. Jae, R. Xing, D.M. Alonso, D. Wang, T. Zhang, R. Kumar, A. Foster, S.M. Sen, C.T. Maravelias, R. Malina, S.R.H Barrett, R. Lobo, C.E. Wyman, J.A. Dumesic, G.W. Huber, Energy Environ. Sci. 7 (2014) 1500-1523.

[9] R. Martinez, M.C. Huff, M.A. Barteau, J. Catal. 222 (2004) 404-409.

[10] R. Pestman, A. van Duijne, J.A.Z. Pieterse, V. Ponec, J. Mol. Catal. A 103 (1995) $175-180$. 
[11] R. Pestman, R.M. Koster, A. van Duijne, J.A.Z. Pieterse, V. Ponec, J. Catal. 168 (1997) 265-272.

[12] K.M. Dooley, A.K. Bhat, C.P. Plaisance, A.D. Roy, Appl. Catal. A 320 (2007) 122133.

[13] R.W. Snell, B.H. Shanks, ACS Catal. 3 (2013) 783-789.

[14] F.C. Calaza, T.-L. Chen, D.R. Mullins, Y. Xu, S.H. Overbury, Catal. Today 253 (2015) 65-76.

[15] S.H. Hakim, B.H. Shanks, J.A. Dumesic, Appl. Catal. B 142-143 (2013) 368-376.

[16] T.N. Pham, D. Shi, D.E. Resasco, Top. Catal. 57 (2014) 706-714.

[17] T.N. Pham, D. Shi, D.E. Resasco, J. Catal. 314 (2014) 149-158.

[18] O. Nagashima, S. Sato, R. Takahashi, T. Sodesawa, J. Mol. Catal. A 227 (2005) $231-239$.

[19] A. Pulido, B. Oliver-Tomas, M. Renz, M. Boronat, A. Corma, ChemSusChem 6 (2013) 141-151.

[20] H. Bayahia, E.F. Kozhevnikova, I.V. Kozhevnikov, Appl. Catal. B 165 (2015) 253259.

[21] A.V. Ignatchenko, J.S. DeRaddo, V.J. Marino, A. Mercado, Appl. Catal. A 498 (2015) 10-24.

[22] M.A. Hasan, M.I. Zaki, L. Pasupulety, Appl. Catal. A 243 (2003) 81-92.

[23] M.J.L. Gines, E. Iglesia, J. Catal. 176 (1998) 155-172.

[24] S. Wang, K. Goulas, E. Iglesia, J. Catal. 340 (2016) 302-320.

[25] A.V. Ignatchenko, E.I. Kozliak, ACS Catal. 2 (2012) 1555-1562.

[26] W. Li, H. Huang, H. Li, W. Zhang, H. Liu, Langmuir 24 (2008) 8358-8366. 
[27] S. Xie, E. Iglesia, A.T. Bell, Chem. Mater. 12 (2000) 2442-2447.

[28] H. Zhang, J.F. Banfield, Chem. Rev. 114 (2014) 9613-9644.

[29] W. Piskorz, J. Gryboś, F. Zasada, S. Cristol, J.-F. Paul, A. Adamski, Z. Sojka, J. Phys. Chem. C 115 (2011) 24274-24286.

[30] W. Piskorz, J. Gryboś, F. Zasada, P. Zapała, S. Cristol, J.-F. Paul, Z. Sojka, J. Phys. Chem. C 116 (2012) 19307-19320.

[31] G. Kresse, J. Furthmuller, J. Comput. Mater. Sci. 6 (1996) 15-50.

[32] G. Kresse, J. Furthmuller, Phys. Rev. B 54 (1996) 11169-11186.

[33] G. Kresse, J. Hafner, Phys. Rev. B 47 (1993) 558-561.

[34] G. Kresse, J. Hafner, Phys. Rev. B 49 (1994) 14251-14269.

[35] J.P. Perdew, K. Burke, M. Ernzerhof, Phys. Rev. Lett. 77 (1996) 3865-3868.

[36] J.P. Perdew, K. Burke, M. Ernzerhof, Phys. Rev. Lett. 78 (1997) 1396-1396.

[37] P.E. Blochl, Phys. Rev. B 50 (1994) 17953-17979.

[38] G. Kresse, D. Joubert, Phys. Rev. B 59 (1999) 1758-1775.

[39] H.J. Monkhorst, J.D. Pack, Phys. Rev. B 13 (1976) 5188-5192.

[40] U. Diebold, Surf. Sci. Rep. 48 (2003) 53-229.

[41] F. Birch, Phys. Rev. 71 (1947) 809-824.

[42] G. Makov, M.C. Payne, Phys. Rev. B 51 (1995) 4014-4022.

[43] X. Wu, M.C. Vargas, S. Nayak, V. Lotrich, G. Scoles, J. Chem. Phys. 115 (2001) $8748-8757$.

[44] S. Grimme, S. Ehrlich, L. Goerigk, J. Comp. Chem. 32 (2011) 1456-1465.

[45] G. Henkelman, H.A. Jonsson, J. Chem. Phys. 113 (2000) 9978-9985.

[46] H.A. Jonsson, G. Mills, K.W. Jacobsen, Nudged Elastic Band Method for Finding Minimum Energy Paths of Transitions, World Scientific, 1998. 
[47] G. Henkelman, H.A. Jonsson, J. Chem. Phys. 111 (1999) 7010-7022.

[48] D.A. McQurrie, Statistical Mechanics, University Science Books: Sausalito, CA, 2000.

[49] P. Deshlahra, E. Iglesia, J. Phys. Chem. C 118 (2014) 26115-26129.

[50] E.J. Grootendorst, R. Pestman, R.M. Koster, V. Ponec, J. Catal. 148 (1994) 261-269.

[51] Y. Chiang, M. Hojatti, J.R. Keeffe, A.J. Kresge, N.P. Schepp, J. Wirzt, J. Am. Chem. Soc. 109 (1987) 4000-4009.

[52] A. Mattsson, L. Österlund, J. Phys. Chem. C 114 (2010) 14121-14132.

[53] L-F. Liao, C-F. Lien, J.-L. Lin, Phys. Chem. Chem. Phys. 3 (2001) 3831-3837.

[54] F.C. Meunier, D. Tibiletti, A. Goguet, D. Reid, R. Burch, Appl. Catal. A 289 (2005) $104-112$.

[55] C.M. Kalamaras, P. Panagiotopoulou, D.I. Kondarides, A.M. Efstathiou, J. Catal. 264 (2009) 117-129.

[56] J. Zhang, M. Li, Z. Feng, J. Chen, C. Li, J. Phys. Chem. B 110 (2006) 927-935.

[57] D. Hibbitts, E. Iglesia, Acc. Chem. Res. 48 (2015) 1254-1262. 


\section{*Graphicālấbstract (for review)}

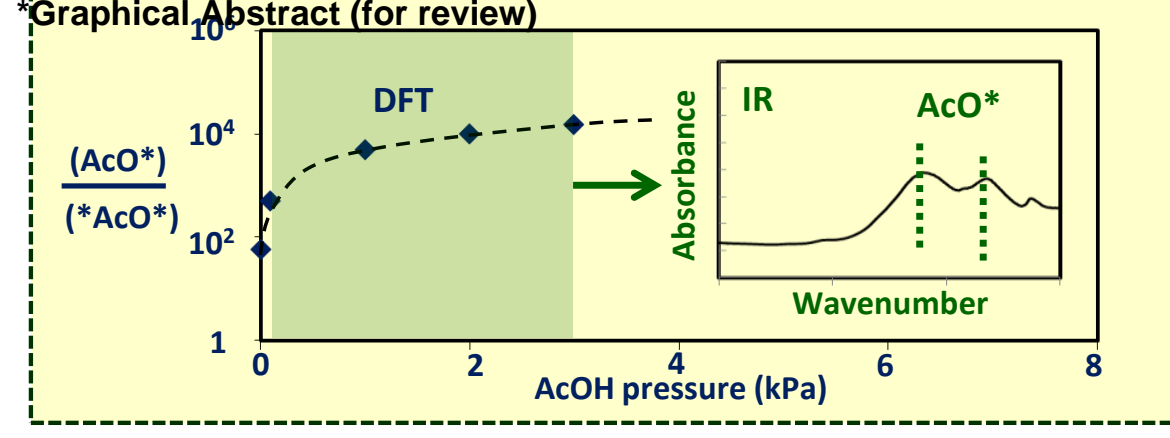

$\int_{-} \mathrm{H}_{2} \mathrm{O}(\mathrm{g})$

Ketene (g)

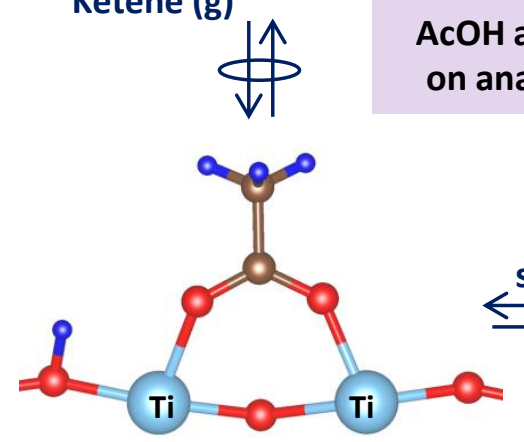

Bidentate *AcO* (unreactive)

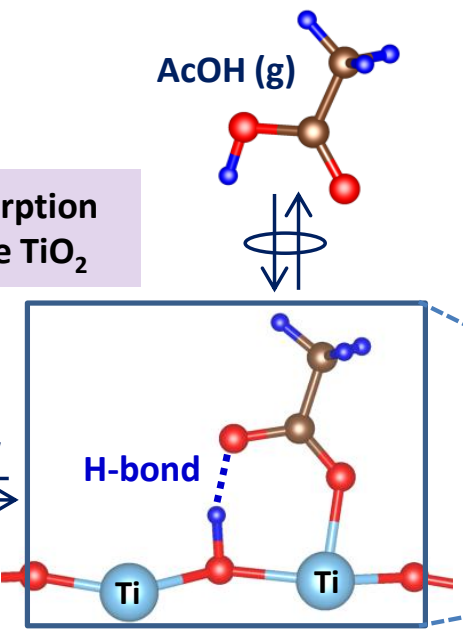

Monodentate AcO*

(reactive)

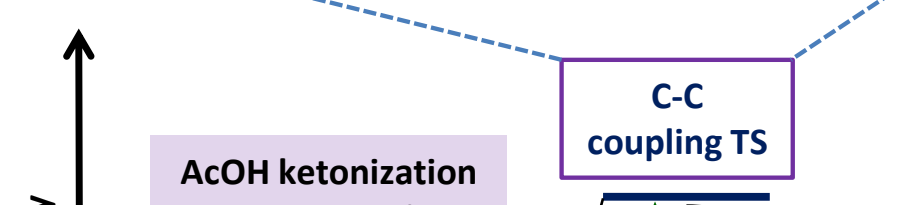

AcO* $\quad \Delta G^{\ddagger}{ }_{c c}$ coverage (ML) ( $\left(\mathrm{KJ} \mathrm{mol}^{-1}\right)$

$2 \mathrm{AcOH}$ (g)

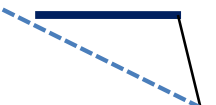

$2 \mathrm{AcO}^{*}$

Reaction coordinate

- General to $\mathrm{C}_{2}-\mathrm{C}_{4}$ carboxylic acids and to $\mathrm{TiO}_{2}$ and $\mathrm{ZrO}_{2}$
H-bonding stabilization at saturation coverages 166 (Exp.)

523 K, 1 bar

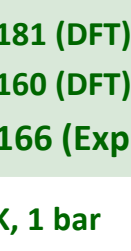

